\title{
The fascination of knowledge creation : studies on knowledge interfaces in high-tech services
}

Citation for published version (APA):

Blazevic, V. (2005). The fascination of knowledge creation : studies on knowledge interfaces in high-tech services. [Doctoral Thesis, Maastricht University]. Universiteit Maastricht. https://doi.org/10.26481/dis.20050218vb

Document status and date:

Published: 01/01/2005

DOI:

10.26481/dis.20050218vb

Document Version:

Publisher's PDF, also known as Version of record

\section{Please check the document version of this publication:}

- A submitted manuscript is the version of the article upon submission and before peer-review. There can be important differences between the submitted version and the official published version of record.

People interested in the research are advised to contact the author for the final version of the publication, or visit the DOI to the publisher's website.

- The final author version and the galley proof are versions of the publication after peer review.

- The final published version features the final layout of the paper including the volume, issue and page numbers.

Link to publication

\footnotetext{
General rights rights.

- You may freely distribute the URL identifying the publication in the public portal. please follow below link for the End User Agreement:

www.umlib.nl/taverne-license

Take down policy

If you believe that this document breaches copyright please contact us at:

repository@maastrichtuniversity.nl

providing details and we will investigate your claim.
}

Copyright and moral rights for the publications made accessible in the public portal are retained by the authors and/or other copyright owners and it is a condition of accessing publications that users recognise and abide by the legal requirements associated with these

- Users may download and print one copy of any publication from the public portal for the purpose of private study or research.

- You may not further distribute the material or use it for any profit-making activity or commercial gain

If the publication is distributed under the terms of Article $25 \mathrm{fa}$ of the Dutch Copyright Act, indicated by the "Taverne" license above, 


\section{The fascination of KnOWLedge Creation}

Studies on Knowledge Interfaces

in High-Tech Services 
(c) 2004, Vera Blažević, Maastricht.

All rights reserved. No part of this publication may be reprinted or utilized in any form or by any electronic, mecharilical or other means, now known, or hereafter invented, including photocopying and recording, or in any information storage or retrieval system, without written permission from the copyright owner.

Cover Design: Andrea Josipović

ISBN : 90-9018912-2

Printed by: $B+W$ Computerformulare 


\section{The fascination of Knowledge Creation}

\section{Studies on Knowledge Interfaces in High-Tech Services}

\section{PROEFSCHRIFT}

Ter verkrijging van de graad van doctor aan de Universiteit Maastricht, op gezag van de Rector Magnificus, Prof. Mr. G.P.M.F. Mols, volgens het besluit van het College van Decanen, in het openbaar te verdedigen op vrijdag 18 februari 2005 om 14.00 uur

door

Vera Blažević 


\section{Promotoren:}

Prof. Dr. J.G.A.M. Lemmink

Prof. Dr. J.C. de Ruyter

\section{Copromotor:}

Dr. A. Llevens

\section{Beoordelingscomissie:}

Prof. Dr. Ir. B.G.C. Dellaert

Prof. Dr. J.F. den Hertog

Prof. Dr. R.K. Moenaert 
Fùr Saša

und

Mama und Papa 



\section{ACKNOWLEDGEMENTS}

My dissertation deals with "The Fascination of Knowledge Creation" and at the same time, this has been my strongest motivation to do this PhD. When 1 was offered the position as $a \mathrm{PhD}$ in 2000, I also had an offer from a company for an interesting position - and with a much higher salary. I still decided for the PhD position, mainly because I had the feeling that I didn't have enough knowledge yet. I wanted to learn more and the PhD period has taught me a lot, not only about how to conduct research, how to use statistical methods, and how to teach. It has also taught me a lot about my own capabilities, about the fun of thinking about practical problems in an analyticall way and about the enjoyable life of academia.

Each project has been like a big mountain in the beginning. You did not really know where to start climbing it, running around it to find the best anchor, at a certain point in time, there was no way back, but once you were on top you had a wonderful view and a great feeling of success. The view, however, could not be enjoyed and would definitely not have been possible without many people that crossed my path or walked along (the entire way).

I would like to express my sincerest gratitude to my supervisor, Annouk Llevens. She has always given me inspiration, guidance, motivation, feedback and faith in my own capabilities to an extent that is absolutely extraordinary. At all times, she has been responsive to my questions, doubts and problems. She has read my papers for many times and provided extensive feedback, she has even checked my final version of the dissertation for spelling mistakes. One of my fellow PhD students even asked whether I could lend Annouk to her. She thas shared her knowledge and experience with me and I have not only learnt about research design, etc. but also that one should stay flirst and foremost a social human being, that one should have fun while working, and that sometimes a glass of wine during lunch can help research inspiration. Annouk, you are the best supervisor on the planet! You truly are my" "Doktormutter"! Thank you so much for everything!

I would also like to thank my promoters, Jos and Ko, for their dedicated support and faith. Jos, I have been fascinated with your knowledge of how to stay calm, when everyone else is already panic-stricken. I have learnt from you that it is sometimes better to only worry about the problem, once the problem is there. You brought Nike's 
commercial into practice: "Just do it": From Ko, I have learnt to find the right balance between creativity and focus. It is amazing how creative you are and how you can manage to have two strings to your bow. Furthermore, you have provided me with many valuable rules, such as 1 ) there is always room for improvement, 2) three apples a day keep the doctor away, 3) never close your eyes to what is going on around you, and 4) it is always good to have a chapter in a book. Thanks to both of you?

Very special thanks go to Caroline, Lisa and Jil, my friends and roommates! Caroline, it has been such a pleasure to walk this PhD mountain simultaneously. We have managed lang train hours to Groningen and turned them into fun, we went together to Bergen, London, Braga, and Murcia and always shared a room, and we had wonderful discussions about our respective research and of course all private matters. I have learnt from you to deeply think about all possible problems in a paper, that a Wednesday is just not a good day to play plano, and the loyalty of a true friend. Lisa, you have always helped me with any rocks that seemed too heavy for me alone, and of course you were my wonderful partiner for bridging the post-lunch dip with Cola light. I have learnt from you that: sometimes we cannot wait for the inspiration to come, but rather need to force ourselves to find the inspiration, that "one should not take any work home, unless one wants to work at home", and that a dragon is an animal that is white and makes uhuh! I wish everyone a friend like you! Jill, you have entered our German Trio a little later and introduced us to Chinese culture and traditions. Your feedback on papers is always very valuable, and you are one of the funniest persons I know (especially after one or two glasses of wine). We had so much nice laughter together for example about the stick and the difficulties of not moving your head when trying to speak Chinese and I have learnt from you to enjoy the moment, as indeed it "would be nice to work half a year and then have half a year off".

Furthermore, I would like to express my gratitude to my dissertation committee, Prof. Dr. Ir. Benedict Dellaert, Prof. Dr. Rudy Moenaert, and Prof. Dr. Friso den Hertog, for the time and effort they invested into reading my manuscript. Their valuable comments and suggestions have provided the last fine-tuning. I would also like to thank Steve Muylle for his cooperation on one of the projects; his constructive feedback and his congenial personality made it a pleasure to work with him. I also really appreciate the help of Rajesh Chandy, Charla Mathwick, Matthew Meuter, Corine Noordhoff, and Piet Pauwels for providing feedback on parts of the dissertation. In addition, I would like to express 
my appreciation to Martin Wetzels and Sandra Streukens for sharing their impresslve knowledge on statistical concepts and software with me. Thanks also to my previous roommate Mark for knowing everything about $\mathrm{PC}$, servers, software and geography, I know now where Bahrain is situated. It was an honor to be your assistant! Moreover, I am indebted to Simone van Schaik and especially Claudia Ullitch for being my connection to the "real" world. Claudia, you have been such a dedicated support to me and my research. Thanks also to Deniz and Peter for their imperturbable belief in my capabilities and for always taking care that I had a vehicle to get to work, and to Eva and Dirk for medical and coffee supplies.

Furthermore, I would like to thank my family. My sisters, Andrea und Yvonne, are wonderful siblings; caring, funny and always there for me. Thanks to Andrea, I have this wonderful and very original cover design. It symbolizes one of the main messages in this dissertation: No matter what perspective you take, when two (or more) persons come together (e.g. a marketing and a R\&D employee, or a company and a customer), you can create knowledge together as represented by the golden circle. This knowledge creation process has no ending as long as you are united by some common goal. Thanks to Ywonne, I have not lost connection to "the youth" and she reminds me to stay down at: the earth. My parents have at all times supported and encouraged me, they have taught me to help each other, show respect to each other, and that the magic in life is often in the small things. Whenever I had a problem and did not know where to start searching for a solution, my mother would immediately mobilize an entire Armada to help me. My father has taught me to be interested in all areas and facets of life. Thank you for your enduring faith in me!

Most importantly, Saša deserves my deepest gratitude. From the start, he has encouraged me to do this PhD project, he has tolerated my mood swings, he has given me confidence whenever I needled it, and he has reminded me that there are many important things in life. Together, we know that we will stay happy as long as we have love, trust, honesty, communication and a good sense of humor, and together, we can master everything! Saša, puno hvala! 


\section{TABLE OF CONTENTS}

1. 1. Research Problem 2

1.2 KNOWLEDGE CREATION 4

1.3 HIGH-TECH SERVICES

1.4 KNOWLEDGE INTERFACES ___ 8

1.5 INTEGRATIVE FRAMEWORK _— 10

1.6 OBJECTIVES___ 10

1.6.1 OBJECTIVES CHAPTER $2 \ldots 11$

1.6.2 OBJECTIVES CHAPTER $3 \ldots 11$

1.6.3 OBJECTIVES CHAPTER $4 \ldots 12$

1.6.4 OBJECTIVES ChAPTER $5 \ldots 12$

1.7 OUTLINE OF THIS DISSERTATION __ 12

\section{ANTECEDENTS OF PROJECT LEARNING AND TIME-TO-MARKET DURING NEW MOBILE SERVICE DEVELOPMENT}

2.1 INTRODUCTION

2.2 The New Information Economiy: Opportunities for Mobile Services:

2.3 Case Study Research Design

2.4 CASE Study Research Frndings

2.4.1 ANTECEDENTS OF PROJECT LEARNING

2.4.1.1 Decision Architecture

2.4.1.2 Project Team Memory

2.4.1.3 Information Awareness

2.4.1.4 Information processing requirements and capabilities

2.4.1.5 Nature of Communication

2.4.2 ANTECEDENTS OF TIME-TO-MARKET

2.4.2.1 Project Complexity

2.4.2.2 Top management support

2.4.2.3 Information power of the supplier ______ 31

2.4.2.4 Technological synergy______________ 32

2.4.3 PROJECT LEARNING AND TIME-TO-MARKET ___ 32

2.4.4 A PROPOSITIONAL FRAMEWORK

2.5 CONCLUSION AND IMPLICATIONS 
THE MEDIATING ROLE OF COMMUNICATION BETWEEN PROJECT TEAM MEMORY

3.1 INTRODUCTION 42

3.2 CONCEPTUAL FRAMEWORK 43

3.2.1 PROJECT OUTCOMES

3.2.1.1 The impact of project learning on new service performance ___ 44

3.2.1.2 The impact of time-to-market on new service performance____ 45

3.2.2 THE TYPE OF COMMUNICATION__ 45

3.2.3 MEMORY DIMENSIONS ______________ 49

3.2.4 PROJECT COMPLEXITY AND GENERATIONAL MEMORY _________________ 51

3.4 METHOdOLOGY

3.4.1 SAMPLE AND PROCEDURE ___ 52

3.4.2 MEASUREMENT _____________ 53

3.4.3 DATA ANALYSIS _ 53

3.5 RESULTS_ $\mathbf{5 5}$

3.5.1 DIRECT EFFECTS MODEL ________ 55

3.5.2 MODERATING EFFECTS MODEL _ 56

3.6 DISCUSSION AND IMPLICATIONS _

3.7 LIMITATIONS _ _ _ _ _ _ 60

3.8 FUTURE RESEARCH GUIDELINES __ 61

3.9 CONCLUSION ___ 61

THE ROLES OF CUSTOMERS DURING KNOWLEDGE CO-CREATION IN ELECTRONIC SERVICES: AN EXPLORATORY STUDY

4.1 INTRODUCTION 64

4.2 THEORETICAL BACKGROUND ___ 65

4.3 Case Study Research Design___ 66

4.4 FINDINGS _ 71

4.4.1 DEFINITION OF KNOWLEDGE CO-CREATION 71

4.4.2 CUSTOMER ROLES IN KNOWLEDGE CO-CREATION ___

4.4.2.1 Customers as users _ _ _ _ _ _ _

4.4 .2 .2 Customers as informers 74

4.4.2.3 Customer as creator ________ 76

4.4.3 ORGANIZATIONAL KNOWLEDGE: OBJECTIVE VS. SUBJECTIVE KNOWLEDGE _._._. 79

4.4.3.1 Objective knowledge ___ _ _ _ _ _ _ 79

4.4.3.2 Subjective knowledge ___ 81

4.4.4 OUTCOMES: PERCEIVED SERVICE QUALITY AND INPUT FOR INNONATION

4.4.4.1 The impact of organizational knowledge on perceived service quality _ 83

4.4.4.2 The impact of organizational knowledge on the information input for the upfront innovation activities__ 84

4.5 CONCLUSIONS AND IMPLICATIONS ___ 85

4.6 SUGGESTIONS FOR FUTURE RESEARCH 
w Table of Contents

SERVICE CO-CREATION BY CUSTOMERS IN AN ELECTRONIC SERVICE SUPPORT SETIING

5.1 INTRODUCTION 90

5.2 THEORETICAL BACKGROUND ______ 91

5.2.1 SERVTCE CO-CREATION BY CUSTOMERS ___ 91

5.2 .2 BENEFITS TO COMPANIES ________ 93

5.2 .3 BENEFTS TO CUSTOMERS___ 93

5.3 HYPOTHESES — 93

5.3.1 THE MMPACT OF SERVICE CO-CREATION ON PERCEIVED SERVICE QUALITY____ 94

5.3.2 THE IMPACT OF SOCIAL INTERACTION ON PERCEIVED SERVICE QUALITY __ 94

5.3.3 MOTIVATIONAL ANTECEDENTS ___ _ _ 95

5.3.3.1 The antecedent impact of fun _____ 95

5.3.3.2 The antecedent impact of relational embeddedness___ 96

5.3.4 THE IMPACT OF DIFFERENT STATES OF MIND: FLOW THEORY___ 97

5.4 METHOdOLOGY___ 99

5.4 .2 MEASUREMENT__ 100

5.4.3 DATA ANALYSIS 101

5.5 RESULTS 102

5.5.1 PARTIAL LEAST SQUARES ANALYSIS: FULL SAMPLE___ 102

5.5 .2 CLUSTER ANALYSIS _________ 103

5.5.3 ANOVA ANALYSIS ________________ 103

5.5.4 PARTIAL LEAST SQUIARES ANALYSIS: SUBSAMPLES

5.5.4.1 Results for flow __ 106

5.5.4.2 Results for apathy_____________ 106

5.5 .4 .3 Results for anxiety _ 107

5.5.4.4 Results for boredom 107

5.6 DISCUSSION AND IMPLICATIONS 107

5.7 LIMITATIONS AND FUTURE RESEARCH GUIDELINES 109

5.8 MANAGERIAL IMPLICATIONS

5.9 ConCluston ___

CONCLUSION 113

6.1 SYNOPSIS _ 114

6.2 ORganizational fascination OF KNOWLEDGe CREATION ___ 115

6.3 KNOWLEDGE INTERFACES WITHIN THE ORGANIZATION __ 115

6.4 KNOWLEDGE INTERFACES WITH CUSTOMERS __ 117

6.5 A PERSPECTIVE ON FUTURE RESEARCH _

\begin{tabular}{lr} 
REFERENCES & 121 \\
\hline
\end{tabular}

APPENDIX A: SCALE ITEMS CHAPTER 3

APPENDIX B: SCALE ITEMS OF CHAPTER 5 141 
Chapter 1

INTRODUCTION 


\section{All men by nature desire knowledge}

\section{Aristotle (384-322 B.C.), Metaphysics, book 1, chapter 1}

Already in the $4^{\text {th }}$ century B.C., Aristotle observed that humankind is fascinated with knowledge. Throughout the centuries, scientists from various kinds of disciplines, such as philosophy, economics, sociology, psychology, organizational theory, information systems, and marketing have investigated facets of knowledge. They have been intrigued by questions, such as how knowledge is created, how it is transferred, how it is retained for further usage, and what effect it has on all kinds of (performance) outcomes. Knowledge has been identified as a fundamental basis of competitive advantage, economic growth and a key source of wealth (e.g. Vargo and Lusch 2004). The industrialized world has evolved from a labor and capital-intensive to a knowledgebased economy (Achrol and Kotler 1999; Capon and Glazer 1987). This evolution has resulted in knowledge becoming a primary resource within markets and a key asset for most arganizations. However, knowledge as a resource is different from other resources (e.g. labor, capital, energy), because it grows through use rather then depletes.

\subsection{Research Problem}

Managing knowledge is critical for organizations to create a competitive advantage and have $a$ superior business performance. In the marketing literature, there is a growing attention that knowledge creation is fundamental for business success (e.g. Achrol and Kotler 1999; Vargo and Lusch 2004). Despite an extensive body of literature on organizational learning (Cohen 1991; Daft and Lengel 1986; Daft and Weick 1984; Huber 1991; Walsh and Ungson 1991), market information use (Deshpande and Zaltman 1982; Moorman, Deshpande, and Zaltman 1992; Sinkula 1994), and market orientation (Baker and Sinkula 1999; Jaworskl and Kohli 1993; Slater and Narver 1995), only llttle is known about the rolle and impact of knowledge interfaces on knowledge creation. Literature suggests that knowledge is often created through employee interactions within the flirm (e.g. Mahajan, Vakharia, Paul, and Chase 1994; Moenaert, Caeldries, Lievens, and Wauters 2000), as well as interactions of the organization with the customer (Gupta and Vajic 2000). It is imperative to study how these various interactions provide opportunities and challenges for the creation and management of knowledge. Marketing is concerned with the management of knowledge flows for these interactions (Moorman and Rust 1999). Employees from the marketing function should ensure that information about customers as well as intraorganizational knowledge is disseminated within the organization. Therefore, interfaces with marketing as a function are perceived as knowledge interfaces. Marketing interacts with other functions from the same 
organization, as well as with all kinds of companies from an organization's business network. These companies can be, for example, suppliers, alliance partners, institutional investors or customers. In this dissertation, we focused on two types of knowledge interfaces: 1) within organizations, and 2) between organizations and customers. Due to our high-tech service context, service innovation is an important mean to create and sustain a competitive advantage. Furthermore, during innovation activities knowledge is created in intraorganizational interfaces. Therefore, we decided to concentrate on the interfaces within organizations. Moreover, services are characterized by a simultaneous production and consumption of the respective service. Hence, customers become involved in the service delivery (i.e. during the service encounter). The recent technological developments have further enhanced opportunities to create knowiedge in the company-customer interface. Thus, we also studied the knowledge interface between organizations and customers. The overall aim of this dissertation is to uncover the role of knowledge interfaces during knowledge creation in high-tech services.

Knowledge creation through knowledge interfaces within the organization is especially relevant in an innovation setting. Innovations are mainly developed in crossfunctional teams (e.g. Sarin and Mahajan 2001). Hence, employees with different functional backgrounds exchange knowledge to create a new service, thereby, engaging in organizational learning. Research contributions in the field of services innovation have evolved only gradually and are still largely fragmented (Lievens and Moenaert 2000a; Menor, Tatikonda, and Sampson 2002). Also within the service marketing and management literature, the role of effective interfaces between marketing and other departments has repeatedly been emphasized on a theoretical/conceptual level (e.g. Mahajan et al. 1994; Ruekert and Walker 1987). Despite the importance of innovation for service-based companies, very little empirical research attention has actually been given to the nature of these interfaces during service innovation. Therefore, research should consider how organizations learn during new service development. What are critical antecedents? How can organizations design their teams and processes to improve learning, other innovation project outcomes and subsequently new service performance?

Also the organization-customer interface represents opportunities and challenges in terms of knowledge creation. The pervasiveness of information technology and the Internet offer companies new opportunities to collaborate with customers. Prahalad and Ramaswamy (2000) agree that nowadays corporations need to see customers as a new source of competence. Companies should encourage a dlalogue with their customers, create customer communities and co-create personalized experiences. Customers embody a wide base of skills, sophistication and interest (Prahalad and Ramaswamy 2004; Vargo and Lusch 2004), and present an often untapped resource of knowledge. Therefore, companies that draw on the knowledge of their customer base can co-create 
knowledge together with them. Furthermore, research on lead users (e.g. Lillien, Morrison, Searls, Sonnack, and von Hippel 2002; Nambisan 2002), customer toolkits (Thomke and von Hippel 2002; von Hippel and Katz 2002), and listening in to ongoing dialogues between customers (Dahan and Hauser 2002; Urban and Hauser 2004) shows that customer involvement in the innovation process can offer many advantages. However, all this evolving research on the general premise of customer collaboration has not yet considered the dimensions and impact of knowledge co-creation by customers. Knowledge co-creation by customers is more than providing customers access to an organization's knowledge base or seeking their involvement in innovation (Sawhney and Prandelli 2000). Knowledge co-creation encompasses several unexplored dimensions, such as the roles customers play during knowledge co-creation.

Furthermore, customers do not only co-create knowledge, but they can also coproduce the service itself. The notion of customer participation in service delivery is not new. Already in 1979, Lovelock and Young stress the importance of customers' particlpative behavior to increase productivity. Other research in marketing has examined customers as partial employees (Mills and Morris 1986), the role of customers in service encounters (Kelley, Donnelly Jr., and Skinner 1990), the effects of customers' attitudes and behaviors on customer participation (Risch Rodie and Schultz Kleine 2000), customer woluntary performance (Bettencourt 1997) and the psychological implications of customer participation (Bendapudi and Leone 2003). Customer participation in service delivery clearly impacts service quality perceptions. All these studies considered customer participation as a joint production between the customer and the firm. The recent technological developments and especially the rise of the Internet have made it possible to move from joint production to service co-creation by customers. In joint production, the service is produced as cooperation between the company and the customer, whereas in service co-creation customers produce the service for other customers by exchanging their knowledge. This kind of service co-creation requires the customer to provide either information and/or effort to the company. However, so far no research has investigated the phenomenon of service co-creation. Furthermore, research attention should be granted to the motivation of customers to provide information to other customers. Finally, we need to investigate how customers evaluate a service that has been co-created by other customers.

\subsection{Knowledge creation}

As knowledge is a primary resource, organizations need to spend considerable time and effort on the creation of knowledge. In line with the information processing view of organizations, organizations are information systems (e.g. Daft and Weick 1984; Moorman 1995; Souder and Moenaert 1992) and devellop organizational knowledge 
(Duncan and Weiss 1979). Organizations need to learn continuously to keep up with the latest technological, competitive and customer trends. Knowledge creation is the formation of a dynamic stock of knowledge. Organizational leaming has been described as "the process within an organization by which knowledge about action-outcome relationships and the effect of the environment on these relationships is developed" (Duncan and Weiss 1979, p. 84). The knowledge that is created is a result of a process involving the acquisition, dissemination and interpretation of knowledge (e.g. Blazevic and Lievens 2004; Huber 1991; Moorman 1995; Sinkula 1994; Slater and Naver 1995). Acquisition of information relates to the process by which information is obtained and may originate in the direct experiences, experiences of others and the existing knowledge base of the organization (Kogut and Zander 1992; Sinkula 1994; Slater and Narver 1995). Dissemination of information refers to the process of information transfer between different information sources (Daft and Weick 1984: Huber 1991). Interpretation of information occurs when information becomes meaningful by sharing perceptions and building cognitive maps (Hurley and Hult 1998; Levitt and March 1988; Moorman 1995).

Research on organizational learning has been extensive (e.g., Cohen 1991; Cyert and March 1963; Daft and Weick 1984; Duncan and Weiss 1979; Huber 1991), although less in a marketing context. Furthermore, the largest portion of research on knowledge and learning has not related it to performance outcomes, but has rather explored the conditions for learning and the nature of learning. However, some researchers have claimed that knowledge is the fundamental source of competitive advantage (Day 1994; Vargo and Lusch 2004). Others have related knowledge to a firm's capabilities or competences (Johnson, Sohi, and Grewal 2004; Leonard-Barton 1992) and subsequently to superior performance (Eisenhardt and Martin 2000; Teece, Pisano, and Shuen 1997). Some research attention has also been given to the role of knowledge in new product development ( $\mathrm{L}$ and Calantone 1998; Madhavan and Grover 1998; Moorman and Miner 1997). Nevertheless, systematic research on the performance consequences of knowledge creation still remains underdeveloped.

Despite the importance of investigating performance consequences of knowledge creation, the antecedent drivers of knowledge creation also need considerable attention. Several studies have investigated the link between organizational design variables and new service development (e.g. Moenaert, Deschoolmeester, De Meyer, and Souder 1992; Van de Ven 1986) whereas only a few studies relate organizational design and learning (Sinkula, Baker, and Noordewier 1997; Slater and Narver 1995). Therefore, it is critical to examine organizational design antecedents of knowledge creation in new service devellopment. Furthermore, communication is an essential means to achieve knowledge creation within organizations. Several studies have shown the importance of 
communication in new service development (de Brentani 1989; Easingwood and Storey 1991; Leveris and Moenaert 2000a; Lievens, Moenaert, and Sijegers 1999b) whereas little research has been published that investigates communication and learning.

Knowledge is not only created through communication within organizations, but also through customers participating in electronic service delivery. Companies can collect data about the electronic behavior of their customers as well as communicate with customers via electronic means. In these interactions, customers can provide their knowledge to the company and hence co-create knowledge. Research on customer participation in services has not yet considered the phenomenon of knowledge cocreation by customers and its impact on knowledge creation within organizations. Furthermore, research attention should be granted to the motivations of customers to actively co-create knowledge.

\subsection{High-tech services}

The academic and business importance of the service sector is increasing, as services dominate most economies (Froehle, Roth, Chase, and Voss 2000). Furthermore, even product-based industries compete on the basis of customer service and service offerings nowadays (Oliver, Rust, and Varki 1997; Rust 1998). For example, IBM has revenues of over $\$ 30$ billion and considerable growth from their service offerings (Bitner, Brown, and Meuter 2000). The environment of high-tech services is often characterized as being uncertain and highly dynamic. Uncertain settings mean markets in which future evolutions and technologies are difficult to envisage. Dynamic environments are those in which these evolutions arise rapidly (MacCormack, Verganti, and Iansiti 2001). In uncertain and dynamic environments, organizational knowledge and skills are increasingly important to deliver value-adding services to customers. Based on Vargo and Lusch $(2004$, p. 2), high-tech services are defined as the application of specialized competences (knowledge and skills) through deeds, processes, and performances supported by state-of-the-art technology for the benefit of another entity or the entity itself.

A major factor in high-tech services is the exploitation (and exploration) of information technology. The increasing pervasiveness of information technology has made it possible to codify, store and disseminate certain types of knowledge more easily and less costly than ever before (Hansen, Nohria, and Tierney 1999). It has also led to an increase in the speed with which information can be disseminated and in the amount of information that can be stored and processed (Glazer 1991). Furthermore, information technology coupled with the popularity of the Internet has eliminated the trade-off between richness (i.e. bandwidth, customization, and interactivity of information flow) and reach (1.e. the number of peaple exchanging information) (Evans and Wurster 1997). 
Consequently, companies can reap potential benefits for their customers and their own business. Companies can now communicate with many customers at the same time, exchange rich information and further personalize services. They can offer customers essential advantages of convenience, speed and lower costs. These lower costs for customers arise from substantial cost reductions of the business itself, as labor-intensive services are replaced by information technology-based services. However, the opportunities emerging through information technology and the Internet also infer challenges for companies operating in high-tech services. Customers have become more demanding, as it is easier to compare prices and service specifications. Similarly, competition has intensified due to shrinking product and service life cycles. consequently, organizations need to continuously improve existing services and effectively innovate new services.

The dynamic technological progress and relative simplicity to copy services force companies to focus an time-to-market as an essential success factor for innovation. Several researches within the new product development literature have demonstrated a positive link between time-to-market and innovation performance, using a wide variety of performance undicators, such as revenue, profitability, corporate and brand image (such as Menon, Chowdhury, and Lukas 2002), return on assets, return on sales, sales growth (Ittner and Larcker 1997), and general commercial success measures (Griffin 2002; Lynn, Skov, and Abel 1999). When time-to-market is not managed, companies have to struggle with false starts, delays, and missed opportunities (Srivastava, Shervani, and Fahey 1998). These can be extremely costly with regard to both time and money. However, the pure strive for reducing time-to-market is not always desired and favorable as minimizing time-to-market often has negative effects on new service quality and hence good business performance (Millson, Raj, and Wilemon 1992). Companies that want to achieve high new service quality need to create knowledge by processing and communicating market and technological information. It is critical that they transform technological and market information into market-demanded outcomes (Lievens, de Ruyter, and Lemmink 1999a; Sinkula 1994). Innovation activities are often highly complex, need creative efforts, and involve major resource allocations (Elsenhardt and Tabrizi 1995). Furthermore, newly developed services should take advantage or at least be aligned with environmental conditions. Learning is required to reduce the probability of "blind-spots" and, consequently, inappropriate responses to critical environmental situations. However, the relationship between time-to-market and learning comprises different patterns. On the one hand, information processing absorbs time and resources taken away from realizing fast time-to-market. On the other hand, project learning supports time-to-market by minimizing time-consuming errors and rework (Millson et al. 1992). Thus, considering the growing knowledge content that can be processed with the 
support of IT, innovation performance will largely depend upon the organization's ability to challenge this intersection of organizational speed and knowledge.

Knowledge is also created through activities and interactions with the customer (Gupta and Vajic 2000). In electronic service settings, customers have become more knowledgeable, have more access to a wide variety of information, and have become more connected with each other (Prahalad and Ramaswamy 2003). The Internet has facilitated the interaction between customers and organizations and among customers. IT provides cost effective mechanisms to globally communicate with customers. This communication process is increasingly characterized by a continuous dialogue between companies and their customers (Vargo and Lusch 2004). Furthermore, customers increasingly demand memorable experiences (Pine and Gilmore 1998).The growing degree of customer participation facilltates the global access of knowledge, while at the same time it provides companies with opportunities to create memorable experiences. Experience has been defined as "any sensation or knowledge acquisition resulting from a person's participation in daily activities" (Gupta and Vajic 2000, p. 35). The perception of a service consumption experience is based upon interactions that offer extrinsic and intrinsic benefits (Mathwick, Malhotra, and Rigdon 2001). Thus, the interaction with customers not only needs to serve its utilitarian purpose, but should also be enjoyable in itself.

\subsection{Knowledge interfaces}

Particularly in service firms, the crucial importance of managing knowledge interfaces originates from the simultaneous nature of production and consumption of services. In this dissertation, we adopt an open socilal system view (e.g. Weilck 1979) to study knowledge interfaces from a marketing perspective. According to this view, service organizations/Innovation project teams may be wiewed as information processing organisms operating in a compllex and dynamic context. Knowledge interfaces can exist between different functions in organizations (e.g. marketing, R\&D, accounting, etc.), as well as between the organization and the customer.

Within organizations, functional departments are linked to specific information domains (Lawrence and Lorsch 1967; Llevens and Moenaert 2000b; Rogers and Kincaid 1981). The specific information inherent in each function needs to be communicated to exchange skills and knowledge essential for organizational learning. Extant research has pointed to the critical importance of communication and cooperation between the different functional departments (Ruekert and Walker 1987). Hence, communication is an essential means through which information is acquired, disseminated and processed within organizations (e.g. Duncan and Weiss 1979; Ebadi and Utterback 1984; Tushman and Katz 1980). Through communication, team members better identify, access, and 
exploit emergent opportunities as they arise. We adopt the definition of communication provided by Duncan and Moriarty $(1998$, p. 2): "Communication is the human activity that links people together and creates relationships. It is at the heart of meaning-making activities. [...] It serves as a way to develop, organize, and disseminate knowledge." Communication provides a vehicle for otherwise isolated employees to congregate and share their unique knowledge and apply it for example, to the innovation task.

In addition to knowledge interfaces within companies, knowledge can also be created in the organizational interface with the customer. The customer is often a primary informational source for the organization (Siehl and Bowen 1992). Marketing is moving towards a service-centered view where the collaboration and the learning from customers is at the center of marketing activities (Vargo and Lusch 2004). Furthermore, customer collaboration is a necessary prerequisite for an enjoyable exchange experience (Deighton and Grayson 1995). In this enjoyable collaboration experience, companies cain stimulate theirr customers to transfer knowledge. Consequently, the knowledge interface with the customer, coupled with the discussed possibilities of information technology, enables companies to incorporate customer knowledge in their own knowledge base. Furthermore, companies can benefit from cost reduction, when customers start to deliver part of the services to themselves (i.e. through self-service technologies) (Meuter", Ostrom, Roundtree, and Bitner 2000). The participation of customers in service delivery is even extended when customers provide information to other customers in, for example, virtual customer communities. Customers generate relevant content, which can be used as a knowledge base and results in organizational learning (Constant, Kiesler, and Sproull 1994). Moreover, in these communities companies receive valuable feedback about their products and services. This feedback is often an important stimulus for innovation (such as Mclure Wasko and Faraj 2000). Furthermore, the interaction with customers helps developing intimate and sustained relationships that enhance the collective and cooperative determination of new customer functionalities (Srivastava et. al. 1998). In the knowledge interface with customers, marketing can also provide information about services to the customer. Hence, marketing as a function adds value to a firm's financial performance in the degree to which it develops knowledge and skills in connecting customers to a firm's products and services (Moorman and Rust 1999).

Taken together, the knowledge interfaces offer marketing many opportunities for the creation of new knowledge by interacting with other functions as well as with customers. Each individual has his own repertoire of knowledge and skills, which must be exchanged with other individuals for new knowledge creation (Machavan and Grower 1998). 


\subsection{Integrative framework}

In figure 1.1, an integrative framework is shown. This framework summarizes the main areas of this dissertation. The context of high-tech services is characterized by a turbulent market environment. This environment demands from organizations a fast time-to-market in their innovation efforts. At the same time, it offers opportunities to cocreate knowledge and services with customers. Knowledge is created in marketing interfaces within organizations and between customers and organizations with the help of innovation and communication. ICT, online and offline communication means, and intracompany platforms support the knowledge creation in the respective contexts.

Figure 1.1: Integrative framework

\section{High-tech services}

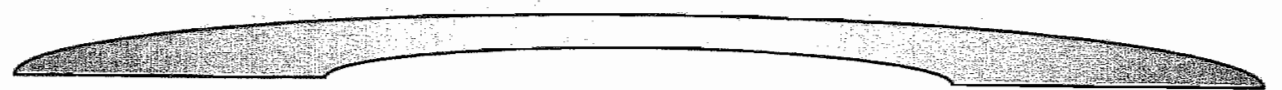

Turbulent market environment

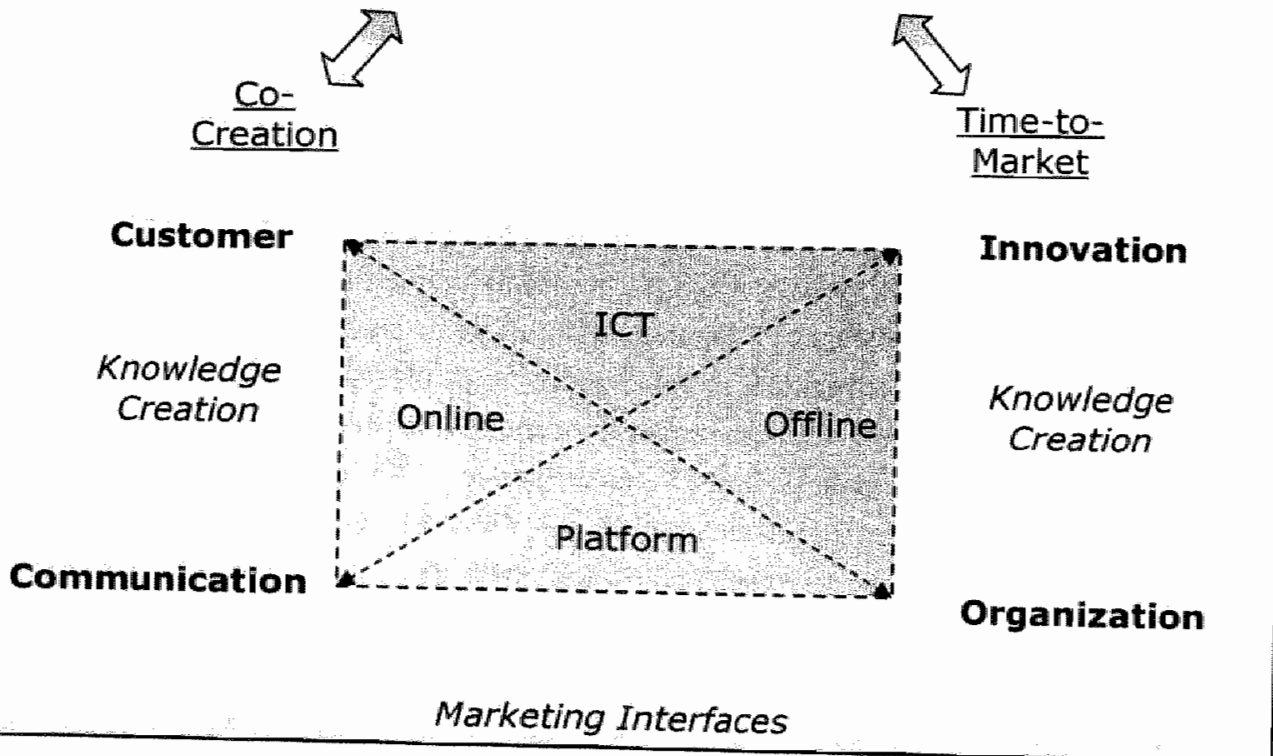

\section{6 objectives}

In this dissertation, we focus on knowledge interfaces in high-tech services. We differentiate between knowledge interfaces within organizations as well as knowledge interfaces between organizations and customers. The central research problem of this dissertation is as follows: 


\section{What is the rolle of knowledge interfaces during knowledige creation in high-tech services?}

The central research problem will be adidressed in four inter-related studies. In each study, a different facet of the research problem is investigated. The first two studies examine intraorganizational knowledge interfaces in the context of high-tech new service development. Thereafter, we turn beyond the boundaries of the firm and study how knowledge can be created in the interface with the customer. In the next section, each study and their respective objectives will be explained.

\subsubsection{Objectives chapter 2}

In chapter 2, the mobille telecommunication industry was selected to explore the antecedents of knowledge (i.e. project learning) and speed (i.e. time-to-market) during new service development. The mobile telecommunications market is shifting towards saturation, so, the need for innovating new revenue-generating services is very high. A case study research was conducted in order to develop relevant constructs and propose relationships between these constructs. Desk research as well as in-depth interviews with senior managers and project leaders of four new mobile service projects served as a platform for theory development. Based on the case study findings and an extensive literature review, the specific objectives of this chapter are: (1) to investigate the critical antecedents of project learning during mobile service development, (2) to explore the critical antecedents of time-to-market during mobile service development, and (3) to examine how project learning and time-to-market relate to each other.

\subsubsection{Objectives chapter 3}

In chapter 3, project learning and time-to-market are once again considered as crucial innovation project outcomes. Within the innovation literature, there is a growing attention that the memory (l.e. existing knowledge stock) of the project teams positively impacts innovation project outcomes (e.g. Faraj and Sproull 2000; Moorman and Miner 1997). However, we propose that communication is an important mediator of the relationship between memory and the innovation project outcomes. Memory can only impact project learning and time-to-market, when innovation project team members exchange their knowledge, hence, communicate. Consequently, the specific objectives of the chapter are to: (1) conceptualize and empirically test the mediating impact of communication between memory and innovation project outcomes, (2) expand the existing literature by proposing two different types of communication, (3) empirically investigate the influence of project learning and time-to-market on innovation performance, and (4) test for the moderating role of project complexity in our model. 


\section{$1,6.3$ Objectives chapter 4}

In chapter 4 , we focus on the knowledge interface with customers. Customers are increasingly knowledgeable, connected to companies and other customers, and present an often untapped resource of knowledge (Prahalad and Ramaswamy 2004). Based on a qualitative case study design, we propose a framework on the impact of knowledge co. creation by customers on organizational knowledge increase. The organizationa knowledge increase positively influences perceived service quality and delivers information input for upfront innovation activities. Desk research as well as in-depth interviews with managers, engineers and customers of a global, leading computer services company builds the basis for theory development. The objectives of this chapter are: (1) to identify and examine the roles customers play during knowledge co-creation, (2) to explore the dimensions of arganizational knowledge increase resulting from the knowledge co-creation, and (3) to conceptualize the impact on performance of the organization.

\subsubsection{Objectives chapter 5}

In chapter 5, we continue to study the knowledge interface with the customer. We again consider the active participation of customers in an organization's service delivery. In this chapter, the focus will shift from the impact of knowledge co-creation on the organization to the motivation of customers to co-create a service. In chapter 4 , the highly participatory service of a virtual community has been described. In this chapter, we have used an online technical support community as context for our empirical investigation. In this virtual community, customers co-produce knowiedge and interact socially, thereby co-creating the service. As this service is delivered to customers by other customers, it is also interesting to study the evaluation of such a service. The objectives of this chapter are to: (1) investigate the motivational antecedents of service co-creation by customers and social interaction, (2) examine the impact of a customer co-created service on the evaluation of this service, and (3) empirically test the proposed model while taking contingencies into account.

\subsection{Outline of this dissertation}

The structure of the dissertation is illustrated in table 1.1. Chapter 2 and 3 focus on how knowledge is created in the intraorganizational interfaces in the context of hightech service innovation. While the study described in chapter 2 uses a qualitative case study design, the investigation discussed in chapter 3 has been conducted using a quantitative survey design. Chapter 2 deals with the critical antecedents of project learning and time-to-market during new mobile service development. Chapter 3 
discusses how communication mediates the impact of memory on project learning and time-to-market in high-tech service development. Chapter 4 and 5 focus on how knowledge is created in the interface with the customer during high-tech services. Again, the study described in chapter 4 uses a qualitative case study design, while the inquiry discussed in chapter 5 has been conducted using a quantitative survey design. Chapter 4 is devoted to the roles of customers during knowledge co-creation and the respective impact on organizational knowledge increase. Chapter 5 deals with the motivations of customers to co-create a service and the evaluation of customer co-created services. Finally, chapter 6 concludes this dissertation with a summary of the results, the theoretical and managerial implications, as well as suggestions for future reseanch.

Table 1.1 Overview of the dissertation

\begin{tabular}{|c|c|c|}
\hline Chapter & Research question & Methodology \\
\hline 1 & (Intraduction) & \\
\hline 2 & $\begin{array}{l}\text { What are the critical antecedents of project } \\
\text { learning (i.e. knowledge) and time-to-market } \\
\text { (i.e. speed) during mobile service development? }\end{array}$ & $\begin{array}{l}\text { Qualitative case study } \\
\text { design }\end{array}$ \\
\hline 3 & $\begin{array}{l}\text { How does communication mediate memory's } \\
\text { influence on project learning and time-to-market } \\
\text { during new service development? }\end{array}$ & Quantitative surver design \\
\hline 4 & $\begin{array}{l}\text { What are the dimensions of knowledge co- } \\
\text { creation by customers and their impact on } \\
\text { organizational knowledge and subsequently on } \\
\text { performance outcomes? }\end{array}$ & $\begin{array}{l}\text { Qualitative case study } \\
\text { design }\end{array}$ \\
\hline 5 & $\begin{array}{l}\text { What motivates customers to co-create a service } \\
\text { for other customers? How do customers evaluate } \\
\text { a service co-created by themselves and other } \\
\text { customers? }\end{array}$ & Quantitative survey design \\
\hline 6 & (Condusion) & \\
\hline
\end{tabular}





\title{
Chapter 2
}

\section{ANTECEDENTS OF PROJECT LEARNING AND TIME-TO-MARKET DURING NEW MOBILE SERYICE DEVELOPMENT ${ }^{1}$}

\begin{abstract}
Mobile service innovations are crucial for the long-term success of companies operating in turbulent and uncertain environments. These innovations need to be introduced at a rapid pace while at the same time companies have to absorb market information during the new mobile service development. Hence, the purpose of this chapter is to construct a conceptual framework on the critical antecedents of project learning and time-to-market during new mobile service development. An extensive case study research involving four innowation projects. was performed in a leading Dutch telecommunications company. With respect to project learning, our research findings indicate the crucial influence of a flexible decision architecture, project team memory, high information awareness and a good fit between information requirements and capabilities. Both innovative and coordinative communication is required throughout the service innovation process. With regard to time-to-market, our research results point to the essential impact of project complexity, top management support, information power of suppllers and technological synergy. Finally, a medium level of project learning is the ideal condition for a fast time-to-market during mobile service innovation.
\end{abstract}

\footnotetext{
"This chapter has been published as: Blazevic, Vera, Lievens, Annouk and Evelien Klein (2003), "Antecedents of project learning and time-to-market during new mobile service development," International Joumal of Service Industry Management, 14 (1), 120-47.
} 
Knowledge is and will be produced in order to be sold, it is and will be consumed in order to be valorized in a new production: in both cases, the goal is exchange. Knowledge ceases to be an end in itself, it lases its Use-value.

\section{Jean Francois Lyotard (1924-)}

\subsection{Introduction}

As the mobile telecommunications market is shifting toward saturation, telecommunications companies in Europe need the introduction of UMTS to supply additional capacity and offer new revenue-generating services (Durlacher 2001). Increasingly, moblie operators will derive revenues from mobile service innovations competing to develop value-adding user experiences (Durlacher 2000). Mobile service innovations are defined as any new services that are delivered with the support of wireless devices. Within the telecommunications market, the mobile services market is one of the most dynamic and fastest growing segments (IDC-Research 2000). So far, moblle commerce applications have not been very successful, as many consumers did not adapt these services in combination with the GSM ${ }^{2}$ standard. However, telecommunications companies believe that especially the UMTS ${ }^{3}$ introduction will lead to a widespread adoption of moble services in combination with mobile commerce applications.

The mobile telecommunications industry comprises a highly competitive, dynamic and uncertain environment (Lal, Pitt, and Beloucif 2001), hence high velocity of innovation introductions in the market is a key success factor for offering new valueadded services in the mobile industry . Extant literature has shown that a fast time-tomarket of an innovation creates a sustainable competitive advantage (Bayus 1997; Griffin 1997; Karagozogiu and Brown 1993; Kessler and Chakrabarti 1996; Kessler and Chakrabartl 1999; Lynn et al. 1999; Meyer and Purser 1993; Sherman, Souder, and Jenssen 2000). Mobile businesses can achieve a ploneering advantage by the fast intraduction of new services. Research has revealed that pioneers benefit from higher brand recognition and a likely increase in customer loyalty due to customer's reluctance to change to competitors' services because of high information and switching costs. Moreover, innovation speed increases resource efficiency as long development times take

\footnotetext{
"GSM is the abbreviation for "Global system for mobile communication", It is a globally accepted standard for digital cellutar communlcation originating from a European initiative to create a common European mabile telephone operating at $900 \mathrm{MHz}$. Taday, GSM has over 120 million users worldwide and is available in 120 countries (Whatis.com, 2002).

"UMTS is the abbrewlation for "universal Mobile Telecommunications Service" and is supposed to become the standard for mobille users in the near future. The advantage of UMTS is the fast, broadband transmission of text, wolce, wideo and multimedia data at a rate of up to 2 megabits per second. Sometimes it is also called the "third generation" (3C) mobile service (Techtarget, 2002).

- Following MacCormack et al. (2001), uncertain settings mean markets in which future ewolutions and technologies are difficult to envisage. Dymamic environments are those in which these evolutions arise rapidly.
} 
away resources from other prospective projects (Eisenhardt and Tabrizi 1995) and reduces the risk of launching an obsolete service in the market. However, some research has questioned whether it is always appropriate to aim for a quicker time-to-market (Bayus, Jain, and Rao 1997; Gupta, Brockhoff, and Weisenfeld 1992; Millson et al. 1992). For example, Bayus (1997) found that project teams have to balance high quality and low costs with fast time-to-market of an innovation as only two of the latter three goals can be emphasized for a specific innovation project. Nevertheless, time-to-market remains an important performance measure where additional research is required as to the interaction with other organizational determinants, such as learning.

The velacity of an innovation project depends on project learning, l.e. the effective processing of market and technological information into successful mobile services by project team members. The latter clearly implies that project teams build kinowledge, hence learn throughout the innovation process. Effective information processing provides the project team with a more complete set of alternatives, which reduces the probability that unanticipated problems may impede the development of a new service. Information processing activities consist of the acquisition, the dissemination and the interpretation of information within the project team (Huber 1991; Moorman 1995; Sinkula 1994; Slater and Narver 1995). Therefore, project innovation teams are seen as information systems that explore and exploit organizational knowledge. However, especially in uncertain and dynamic markets, information overload may increase the time-to-market of an innovation due to the limitation of project team members' cognitive capacities (Zirger and Hartley 1994).

Despite the widely recognized importance of service innovation, hitherto little research attention has been granted to the critical factors of speed and knowledge during mobile service innovations. We believe that speed and knowledge are the major business components to achieve sustainable competitive advantage of new mobille services. Therefore, the purpose of this study is to construct a conceptual framework on the critlcal antecedents of project learning and time-to-market during new mobile service development. Considering the exploratory nature of our research question, we felt it was necessary to design and conduct a case study research in order to develop the relevant constructs $^{5}$ and develop hypotheses between these constructs. Following a literature review, an exploratory case study approach has been used within a leading Dutch telecom company. Desk research and in-depth interviews with senior managers and project leaders of four new mobile service projects served as a platform for theory development.

\footnotetext{
According to Peter (1981, p. 134) we can describe a construct as "a term specifically designed for a special scientific purpose, generally to orgavize knowledge and direct research in an attempt to describe or explain some aspect of nature ${ }^{x /}$.
} 
This chapter is structured as follows. We start by providing a description of the current situation for mobile operating companies using the concept of richness and reach (Evarns and Wurster 1997). The second section deals with the case study research design that was developed within a Dutch telecommunication company. Following the case study research findings, a propositional framework is formulated regarding the critical antecedents of speed and knowledge and their relationship with time-to-market and learning. Finally, we discuss the managerial and research implications of this study.

\subsection{The New Information Economy: Opportunities for Mobile Services}

The diffusion of mobile commerce services, where consumers conduct commercial transactions via their wireless device, has been very poor so far due to high cost, slow transmission rates, high power consumption of devices and inadequate mobile interfaces (Barnes 2002). Current mobile networks are mainly based on second-generation (2G) technology, e.g. GSM and PCS. Although the adoption of mobile commerce applications has not been successful yet, mobile phone penetration has been growing tremendously. At the end of 2001, there were one billion mobile phone users. Moreover, over $90 \%$ of countries had bulit a mobile phone network, almost every sixth of the worlds' inhabitants possessed a mobile phone and approximately 100 countries in the world had more mobile than fixed telephone subscribers (International-Telecommunication-Union 2002). Barwise (2001) estimates that by 2010 , in most developed countries $80-95 \%$ of consumers are expected to have at least one wireless device. Furthermore, mobile phome operators are investing massively in third generation (3G) wireless technologies that possess resilient data capabilities, e.g. UMTS (Network-World 2001). These $3 G$ networks are expected to overcome especially the low data transmission rates.

Considering the richness and reach benefits, we define mobile business as the necessary application infrastructure in order to preserve business relationships and sell information, services, and commodities via mobile devices (Kalakota and Robinson 2002). Before the Internet was used as an additional information channel, a very strict trade-off exlsted between richness and reach (Evans and Wurster 1999; Evans and Wurster 1997). In these days, information mainly followed the linear flow of the physical value chain. Thus, it was almost impossible for a company to deliver personalized information to many customers. Either the company could provide imany customers with the same information or could supply a limited number of people with personalized information. The latter implies a trade-off between richness and reach (Evans and Wurster 1999; Evans and Wurster 1997). Richness means the profundity of information that a business can offer to the customer, as well as the information profundity that it gathers aboutt the customer. Reach is about access and connection, i.e. the number of customers a company has access to and connects with each other. 
The Internet world has made this trade-off obsolete because as soon as all players within the value chain are connected electronically, information can flow in all directions. Moreover, companies are now able to have rich communication with many people at the same time, thus leveraging the informational value. However, when we compare the electronic world to the mobile world, mobile businesses might contain even more advantages.

In terms of richness, mobile businesses can gain more detailled information about the customer, as the mobile phone is a very personal device that is often not shared by different customers (Barnett, Hodges, and Wilshire 2000; Kehoe 2000). Thus, mobile behavior can be clearly linked to one person. If the customer has a postpaid contract, the mobile operator normally has access to detailed personal information that is necessary to get a phone subscription. Moreover, the users' locations are known when they consume specific services (Barnett et al. 2000; Kehoe 2000). This additional information provides the opportunity to personalize existing and new services. Therefore, the company can obtain specific customer information by tracking customer behavior, which offers unique opportunities to develop new services.

In terms of reach, mobile services comprise time and space advantages in comparison to Internet services. Mobile services contain a time advantage because companies can deliver service offerings more frequently to the customer, as mobile phones are constantly switched on (Barnett et al. 2000). Furthermore, they include a space advantage as in mobile service delivery, the customer is reachable at all places, e.g. While sitting in a train or car or whille waiting in a café. When using the Internet, users are bound to their computers to access specific service offerings.

\subsection{Case Study Research Desilgn}

We have developed a case study design at a leading Dutch telecommunications company. The company has a reputation for telecom innovations, and is considered to be a technological pioneer in that industry. A case study can be defined as "... an empirical inquiry that investigates a contemporary phenomenon within its realilife context; when the boundaries between phenomenon and context are not clearly evident; and in which multiple sources of evidence are used" (Yin 1994, p. 13). An inductive manner is being used, as we move from observation to the development of hypotheses (Judd, Smith, and Kidder 1991). Stated otherwise, the major function of our case study research efforts is "discovery" in which we focus on the heuristic view in science. "The heuristic view in science emphasizes theory and interconnected conceptual schemata that are fruitful for further research. A heuristic emphasis is a discovery emphasis." (Kerlinger 1986, p.8). Thus, a case study research and a literature review were used as a platform for theory development. Reflective reasoning (Kerlinger 1986) entered the research process during 
the literature analysis and has led to the design of a research setup to falsify the constructed research hypotheses. The case study data are being used for theory development following the process proposed by Eisenhardt $(1989$, p.533) and Lievens, Moenalert, and $\mathrm{S}^{\prime \prime}$ Jegers $(1999 \mathrm{~b}, \mathrm{p}, 25)$ :

1. Formulation of research question containing preliminary constructs: project team learning, organization and communication antecedents, innovation project characteristics and time-to-market.

2. Theoretically useful cases are being selected. Four different projects/tellecom service innovations are selected on the basis of two dimensions. As already mentioned, the immediacy of mobile markets makes knowledge and speed two crucial factors for innovation performance. Therefore, the first dimension concerns the outcome of the service innovation, i.e., fast wersus slow time-to-market. In selecting the projects, time-to-market was based on a broad base of innovation speed measures (Kessler and Chakrabarti 1996). The description of the dimension included a time-related definition: "the time between the conception of an innowation and its introduction into the commercial market." (Gee cited in Kessler and Chakrabarti, 1996, p. 1151) and a goal-oriented definition: "the degree to which a product stayed on schedule, and the degree to which the work was done relative to how fast it could have been done" (Cooper and Kleinschmidt cited in Kessler and Chakrabarti, 1996, p. 1151). The second dimension relates to the level of information processing, l.e. the amount and intensity of information processing activities. Recent research within e-businesses points to the cruciall importance of handling the necessary information flows efficiently and effectively to be able to challenge knowledge and speed (Tapscott, Lowy, and Ticoll 1998).

A general innovation manager was chosen as focal contact and was verbally informed about the project selection criteria. The term "project" was subsequently used to indlicate the task or process of transforming a service idea into a new service introduced in the market. In order to maximize research validity, we have asked the contact manager to select projects that fulfilled the following criteria:

(1) These four projects had been completed recently: market launch happened a maximum of 6 months ago.

(2) The projects are internal projects (or at least partly internal, i.e., not fully outsourced): personnel from different departments within the company were involved in the development of the project. 
Finally, following these requirements, four mobile service innovation projects were selected based on the aforementioned dimensions (speed, level of information processing). In-depth interviews took place with involved project members.

Figure 2.1

\begin{tabular}{l|c|c|}
\multicolumn{2}{c}{ Silow } & \multicolumn{2}{c}{ Fast } \\
\cline { 2 - 3 } $\begin{array}{c}\text { Level of } \\
\text { Information- } \\
\text { processing } \\
\text { activities }\end{array}$ & $\begin{array}{c}\text { Service } \\
\text { Innovation } \\
\text { Project I }\end{array}$ & $\begin{array}{c}\text { Service } \\
\text { Innovation } \\
\text { Project II }\end{array}$ \\
\cline { 2 - 3 } & $\begin{array}{c}\text { Service } \\
\text { Innovation } \\
\text { Project III }\end{array}$ & $\begin{array}{c}\text { Service } \\
\text { Innovation } \\
\text { Project IV }\end{array}$ \\
\hline
\end{tabular}

Unit of Analysis: Project

An embedded case study design is being used (Yin, 1994), because multiple units of analysis are defined (project level, type of innovations, decision makers). The first project (low level of information processing and slow time-to-market) dealt with developing a key service for a mobile telecommunication company: the delivery of voice and fax mail services. The second project (low level of information processing and fast time-to-market) was developed to ensure that content provided via SMS to the customer is up-to-date and adaptable to customer requirements. The third project (high level of information processing and slow time-to-market) aimed at designing a virtual private network where members can call each other on one personal short number at their office phone or their personal phone. The fourth project (high level of information processing and fast time-to-market) consisted of the development of information and entertainment services provided via the mobile phone. An extensive description of the four different projects can be found in table 2.1. 
Table 2.1: Description of the Various Service Innovation Projects

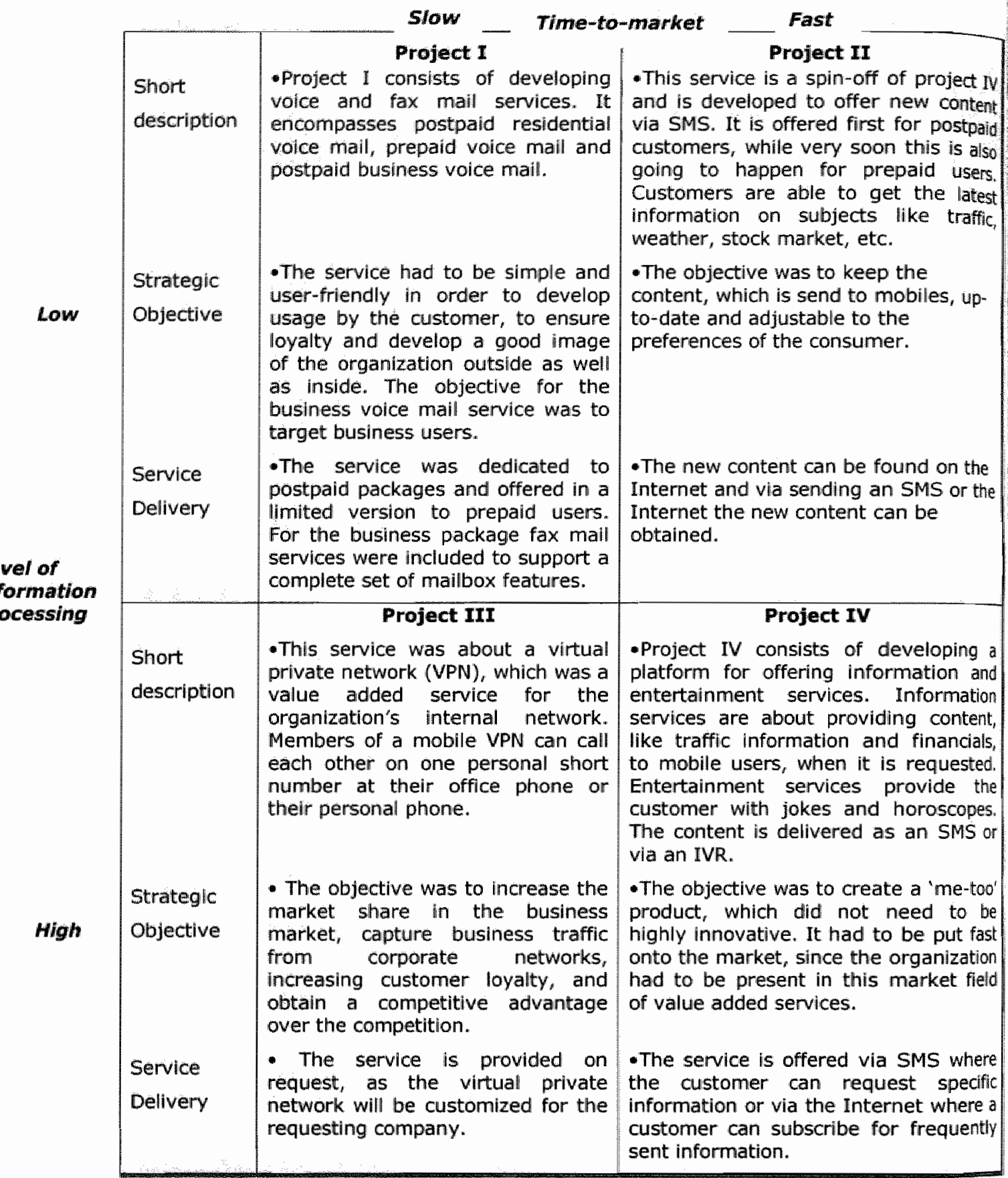


3. The data collection methods of our case study research include both desk research and field research. Firstly, desk research is based on internal company documents to obtain a good understanding of the marketing and the technological strategy of the company. Secondly, field research has been performed through in-depth interviews. with key informants for each project (e.g., project leader, product manager, marketing manager, project team members). The selection dimensions have not been communicated to the interviewed project members, thereby avolding bias.

An averagie of five in-depth interviews was conducted per project. The interview guide was build on the basis of the conceptual frameworks developed by Kessler and Chakrabarti (1996), Karagozoglu and Brown (1993), Sinkula (1994), Garvin (1993), Huber (1991) and Edimondson (1999). The questionnaire consisted of open-ended questions as this research is exploratory in nature. The interviews lasted between one and a half and two hours. The check-list contained open-ended questions that involved the following subjects: (i) the actual innovation process and related information processing activities (acquisition, dissemination and sharing), (ii) project team diversity and existing knowledge (i.e., memory) as well as the nature of communication (i.e., innovative versus coordinative communication and inside project team versus outside project team communication), (iii) the impact of project complexity, technological and marketing synergy as well as network effects on timeto-market.

4. The transcripts of the interviews were used to perform a thematic content analysis. The preliminary conceptual model guiding our case study anaiysis is represented in figure 2.2. The case study research process comprises an inductive process (Kerlinger 1986) as we move from observation to the development of hypotheses. Thus, the case study data were screened for content themes relating to project learning and time-to-market:

5. A model has been constructed through an iterative process involving (i) a comparison with the relevant literature and (ii) a confrontation during a feedback workshop with the interviewed telecom personnel. During the course of the case study research, several feedback sessions were organized with the marketing manager of the participating telecom company. This person provided us with the necessary context variables we needed to acquire a more fine-grained insight in the processes and some of the findings. Moreover, the feedback sessions enabled us to steer and change our data collection procedures if necessary in order to enable the assessment of the plausibility of the data interpretation as well as the search for new cues. A final feedback session was organized within the telecom company inviting all participants of 
the case study research. Furthermore, one person of this study spent an entire month at the company. This approach offered excellent access to key informants and company documents as well as continuous feedback for hypothesis formulation and validation of the results across the four case study projects.

\subsection{Case Study Research Findings}

\subsubsection{Antecedents of Project Learning}

In a first stage of our case study research analysis, we identified the conditions preceding the building of a knowledge base. The following antecedents emerged from our analysis: decision architecture, information awareness, project team memory, the fit between information capabilities and information requirements and the nature of communication.

\subsubsection{Decision Architecture}

The studied innovation projects indicated that the decision architecture of the organization strongly influences project learning during the innovation process. Although the company had a very flexible organizational structure that supported fast and information rich projects, the organizational culture was characterized by a very hierarchical decision authority. For instance, in the virtual private network project (III) top management decided about the hardware basis for developing the service. The bought hardware was too complicated to design the new service and did not correspond to project team members' preferences. Without the regular approval of top management, the project members could not proceed with the development and launch of the virtual private network (III). The pressure on project teams caused by this system led to less effective project learning. Moreover, during the information and entertainment services project (IV) the technical department had to choose a supplier. Due to high pressures of the stage gate development process, the project team lacked sufficient time to select an appropriate supplier carefully. Two weeks after the decision for a certain supplier was taken, a more suitable candidate became available. This company could have contributed much better to efficient information processing activities. Moreover, learning was inhiblted when the top manager was absent and could not take decisions that were necessary for the progress of a project. During the voice and fax mail services project (II), information processes were interrupted only because the manager who possessed decision authority was not reachable. Whenever the project teams had to wait for top management to take a decision, the whole project was stuck and learning was inexistent during these periods.

Decision-making is a key element of the information and interpretation processes in a company (Daft and Weick 1984; Mendelson and Pillai 1999; Simon 1979). Flexible 
decision architecture is constituted by the co-location of decision rights, where the most knowledgeable people are responsible to take decisions. Organizations in the traditional world mainly employed hierarchical structures and top-down processes (Johnson and Frohman 1989; Mendelson 2000). According to contingency theory, bureaucratic structures with top-down decision authority improve performance in stable environments whereas organic structures with decentralized decision-making authority enhance performance in turbullent environments (Lawrence and Lorsch 1967; Moorman and Miner 1997). Moreover, information quality vanishes when it has to go through many hierarchical layers. Considering the turbulent nature of the telecommunications industry and our case study findings, a flexible and decentralized decision architecture supports a fast and information rich service innovation process in the telecommunications industry (MacCormack et al. 2001; Mendelson and Pillai 1999). Thus, we suggest that decisionmaking authority should be co-located where the specific knowledge is avalable. Hence, we postulate the following proposition:

P1: The level of project learning is positively related to a high level of co-location of decision rights.

\subsubsection{Project Team Memory}

The four innovation projects designated that project team memory contributes to project llearning. The interviewees described project team memory as the past knowledge from previous projects that could be used and applied to the respective service innovation project. The voice and fax mail services project (I) and the entertainment and information services project (IV) were initiated when the company was just founded. Formalized procedures and processes were not developed at that time resulting in uncertainty about how to approach the design of the new services. Although both projects were set up to construct a relatively simple 'me-too' service, the team members were rather inexperienced. Especially in the volce and fax mall services project (I), the involved marketing department dild not have enough market information and hence had difficulties in fitting the service to the Dutch market. Contrary, the new content on SMS project (II), which was a follow-up of the information and entertainment services project (IV), could easily use the established procedures and processes and the already acquired knowledge. For instance, some team members were already familiar with the service platform and the targeted market.

Although the virtual private network project (III) was also started when formal rules were already established, this project suffered due to another major problem: the turnover of team members during the project life cycle. The project team manager changed three times during the development. In general, the interviewees reported a high turnover of middle management within the telecommunications industry. 
Consequently, time and knowledge were lost. Time was lost as the new project leader had to become acquainted with the existing project issues inhibiting efficient and smooth information processing. Additionally, knowledge was lost due to the extraction of information by the former project leader during the project life cycle. Therefore, the lockin of knowledge is very important and showed to be one of the major priorities within telecommunication companies. Locking in the existing knowledge avoids the extraction of knowledge every time a project leader/member leaves and facilitates the access to appropriate information for new employees (Nevis, DiBella, and Gould 1995). Consequently, project team memory is a determining driver of project learning. It can be defined as the collective knowledge embedded within the service innovation project team. It Includes shared Ideas, information databases, formalized procedures and routines and the formal cultural codes of acting within the company (Sinkula et all. 1997). This collective, already existing knowledge influences all information processes, i.e. the creation, the dissemination and the sharing of new knowledge. Thus, the already acquired knowledge is an important capability that the project team can build on (Kogut and Zander 1992). In the turbulent mobile markets a company has to create absorptive capacity (Cohen and Levinthal 1990) institutionalizing the right mechanisms to process new information. Absorptive capacity supports the recognition, processing and assimilation of new valuable information. Therefore, project teams need to build up an experience memory in order to cope with the generation of new information. Experience smoothes the progress of knowing how to learn, how to incorporate new information, to spread and use it (MacCormack et al. 2001). Consequently, we hypothesize the following proposition:

P2: The level of project learning will be positively related to the memory of service innovation project teams.

\subsubsection{Information Awareness}

Information awareness, li.e. new information spread by different communication channels, is an essential mechanism to stimulate project learning. Within the studied projects, new valuable information about the market was mainly acquired via the Internet, brainstorm sessions and focus groups. Project team members were stimulated to share new information with other team members during project team meetings, by means of spreading minutes via e-mails and by sending electronic briefings via the Intranet.

Moreover, team members could disseminate and exchange information by using speclal project drives operating via the network system of the company. However, storing information electronically was not at all popular during most of the projects. Only in the entertainment and information services project, the drive was used to amass 
project related information, planning processes, and contracts due to a heavy promotion by the project manager. As a result, information was spread much more frequently and project team members performed a high level of information processing activities. Moreover, project team members felt that they had up-to-date information, which was a necessary requirement to develop this service. Especially in dynamic industries such as the telecommunications industry, firms have to generate new information about the latest technology trends, about actions of competitors and about changing consumer tastes and lifestyles in order to be able to develop services that suit the market. We define information awareness as the "promation of widespread awareness of new information from the organization's external environment, including information about markets, new technologies, and changes in customer tastes" (Mendelson 2000, p. 515). Project teams need to acquire new external information continuously in order to incorporate emerging changes into the service innovation (MacCormack et al. 2001). Moreover, the short life span of information in highly dynamic industries increases the need for information awareness (Bhattacharya, Krishnan, and Mahajan 1998; Moorman and Miner 1997). However, external information acquisition is not enough. The obtained information must be shared within the project team, so that it can disseminate throughout the organization. Hence, we deduce the following proposition:

P3: The level of project learning will be positively related to the level of information awareness.

\subsubsection{Information processing requirements and capabilities}

Our case studies lllustrated the importance of a clear fit between the information processing requirements and the information processing capabilities. We saw that all projects had the technical opportunity to share information via Intranet. However, only the information and entertainment services project (IV) used the Intranet because the project leader stimulated the other members. Research has shown that potential users of knowledge platforms adopt the use behavior of their organizational climate (Purvis, Sambamurthy, and Zmud 2001). The studied telecommunications company lacked active championing and advocacy of the Intranet by senior management. Therefore, the possibilities of knowledge platforms have not been exploited. However, knowledge platforms that are created through the cost effective benefits of advanced information technologies can support essential information activities (Davenport 1994; Huber 1991; Purvis et al. 2001). Nevertheless, although many organizations do have the technical capabilities to handle the information, very often the appropriate human processes are not instituted. Individuals are limited with respect to their cognitive processing skills (Davenport 1994; Simon 1979). Installing technical applications to facilltate information pracessing is not enough. Companies have to encourage their employees on the one 
thand to employ these technical opportunities and on the other hand to acquire and share information more frequently (Cross and Baird 2000; Davenport 1994; Jarvenpaa and Ives 1994). Therefore, we expect that the larger the fit between the information processing requirements and the information processing capabilities the more project team members will learn (Daft and Lengel 1986; Tushman 1979).

P4: The higher the fit between information processing requirement and capabilities, the more the level of project learning will be enhanced.

\subsubsection{Nature of Communication}

The nature of communication has a substantial effect on project learning. In the starting phase, the new service was only a vague idea. Hence, the project teams organized brainstorm sessions and creative meetings to shape their ideas. When an idea was generated, the team members had to clarify whether the development was technically possible and feasible. Thereafter, they started to design the service, followed by a testing phase. During all these phases, the nature of communication was characterized by a high level of creativity. In the later stages of the development process, the core service was defined and the team members mainly organized the launch activities. Every involved department needed to be instructed about its tasks and about the functioning of the service itself. Thus, we observed that the nature of communication changed. First, people mainly had brainstorming sessions and creative meetings where they generated ideas and developed a particular concept for the new service. In the later stages of the development process, communication became more formal for the coordination of technical and commercial aspects. This is in line with a proposed classification within innovation research (Blazevic and Lievens 2004; Hauptman 1986; Souder and Moenaert 1992): innovative versus coordinative communication.

innovative communication contains the creative search for solutions of problems. Thus, innovative communication includes finding answers to new evolving customer demands (Greenbaum 1974; Hauptman 1986). Consequently, it should stimulate idea generation (Souder and Moenaert 1992) initiating the new service development process. Throwgh innovative communication companies react to new information coming from the environment, e.g. new technical possibilities, changing customer requirements, movements of the competitor. Thus, the project team is actively engaged in problem solving and new idea processing. Thinking creatively about evolving problems helps companies initiate the innovation process and stimulate information processing behavior.

Coordinative communication is associated with controls, orders, procedures and feedback between subordinates and superiors and across functional units. Thus, it handles the organizing of an innovation project through task division, individual responsibilities and conflict handling (Greenbaum 1974; Hauptman 1986). It is mainly 
needed to facilitate effective leaming. Moreover coordinative communication is needed to coordinate the different expertise, i.e. the specialized knowledge and abilitles that each individual within the team possesses (Faral and Sproull 2000). Coordinative communication is especially important for an efficient handling of budgets and schedules. It is important to find a balance between innovative communication and coordinative communication, as both are essential for learning within service innovation. Thus, we expect the following:

P5: The level of project learning will be positively related to both the level of innovative and coordinative communication.

\subsubsection{Antecedents of Time-to-Market}

In our case study research analysis, we identified several factors influencing innovation speed. The following antecedents emerged from our analysis: project complexity, top management support, information power of the supplier and technollogical synergy.

\subsubsection{Project Complexity}

The studied innovation projects revealed that project complexity has an important impact on time-to-market. The Interviewed managers described the level of project complexity in terms of technological complexity, e.g. a lot of technically complex processes and products were involved, and the newness/innovativeness of the project, e.g. the project was a pioneering innovation. The virtual private network project (III) faced a very high technical level, which is one of the reasons why this project is regarded as being very complex. Technical problems were hard to solve and took a long time. The new content on SMS project (II) on the other hand was not regardied as complex mainly because it was involved with the development of a standardized 'me-too' service. Another aspect influencing complexity is the size of a project. The new content on SMS project (II) had a small amount of persons and departments involved, which resulted in clear task and role division contributing to a faster project life cycle time. Both, the new content on SMS and the information and entertainment services projects (II and IV), showed that working together with many persons on a technically complex service resulted in a lot of dysfunctional conflict among the team members, especially since the team members originated from diverse backgrounds. The consequences of these different personal characteristics and the resulting frictions became increasingly evident throughout the project life cycle. Team members were less willing to share information or to communicate with each other. Moreover, the high turnover of team members during the VPN project caused uncertainty and ambiguity. 
Thus, there are a number of factors that determine the level of complexity. Extant research illustrated that project complexity has a significant impact on cycle-time reduction efforts (Clift and Vandenbosch 1999; Griffin 1997). Project complexity can be defined as "consisting of many varied interrelated parts" (Baccarini 1996, p. 201) and possesses two main features, differentiation and interdependency (Baccarini 1996; Williams 1999). With differentiation, we mean that many, different ellements have to be considered. Interdependency on the other hand refers to the degree of interrelatedness between these elements. Consequently, the size of a project, the number af connections between project members, the radicalness of an innovation and the amount of uncertainty are important factors that may increase the project complexity. By reducing project complexity, companies can speed up the time-to-market of a service innovation. Thus, we deduce the following proposition:

P6: Time-to-market will be inversely related to the level of project complexity.

\subsubsection{Top management support}

Top management support is a substantial mechanism to accelerate time-tomarket. The interviewed project team members ellucidated that top managlement support is characterized by the commitment, involvement and resources that top management devotes to the project. In the voice and fax mail project, the company developed a standardized service that was an absolute necessity to compete in the market as every company offers these services. Therefore, this 'me-too' service had very high priority for top management. Consequently, enough resources were assigned to the project to bring the basic service as fast as possible to the market. After the core service was launched, the additional service features had to be developed. These additional features however possessed only a low priority and got less top management attention. We observed that the core service was introduced in the market very quickly, whereas the development of the additional services took a long time. The other projects confirmed that the priority assigned to a project by top management influences the time-to-market of a service. The assigned priority determines the amount of resources a project will receive. Moreover, the motivation of the project team members suffers when top management assigns low priority to a project..

Thus, by assigning priority to projects and by establishing the strategic objectives, top management determines the degree of support a project team receives. The given support affects the assigned amount of resources as well as the motivation of project team members. Research has found that a medium arnount of slack is good for innovation (Nohria and Gulati 1996). Top management performs a motivating role in achieving competitive advantage through a fast time-to-market innovation. The project team members will try to maximize their performance to finish the project in time. 
Therefore, top management support has a strong influence on the time-to-market of a new service (Kessler and Chakrabarti 1999). Consequently, we expect the following:

PX: Time-to-market will be positively related to the level of top management support given to project teams.

\subsubsection{Information power of the supplier}

The information power of a supplier can have an essential negative impact on the time-to-market of an innovation. Supplier information power deals with the willingness of the supplier involved in service innovation projects to provide the project team with specific information. The voice and fax mail services project and the virtual private network project (I and III) experienced that the supplier did not provide the promised information. In both cases, the project teams were technically dependent on a specific supplier. However, the suppliers frequently did not deliver certain services, e.g. providing answers to technical questions. As the technical department could not proceed with the design of the service, it procrastinated the service development with respect to concept testing and design. Consequently, the market launch was postponed as well. Furthermore, the virtual private network project used hardware delivered by a supplier and needed specific operational information that the supplier was unwilling to provide. The company even tried to use governmental pressure, however, without the desired effect. As a consequence, the project team had to use a trial and error approach. When the project team finally received the technical specification, it became apparent that it was very complex. Thus, the technical department needed a lot of time to understand all details.

Nevertheless, project II -which had a fast time-to-market- showed that outsourcing can have a very positive effect on the cycle time of an innovation project. Certain tasks were performed by other parties, e.g. providing content to customers. This project showed that the right balance between insourcing and outsourcing is very important in order to control the supplier information power. Thus, companies should select their network partners carefully and have measures to prevent heavy supplier dependency. Elsenhardt and Tabrizl (1995) also ascertained that supplier involvement decreased innovation speed in the global computer industry, which is also a relatively dynamic market. Moreover, Ittner and Larcker (1997) found a negative relationship between supplier involvement and development time in product innovation projects, which contradicts other product development literature. Kessler and Chakrabarti (1999) discovered that externally generated ideas slow down innovation speed. They reason that projects without external involvement are faster as they possess a greater ownership (more control) and greater understandability and interpretableness of internally codified 
knowledge. Thiese arguments also apply to the information power of suppliers. Hence, we postulate the following:

P8: Time-to-market will be inversely related to the level of supplier information power.

\subsubsection{Technological synergy}

Especially in high technology environments, innovation projects can benefit from a high technological synergy to fasten up the innovation speed. The virtuall private network project (III) made use of bought hardware technollogy that did not at all fit to the needs of the project team. The technology the project team had to deal with was too complicated and did not correspond to the preferences and requirements of the project team. Nevertheless, the technology was already bought and the project team had to work with it. Contrary, the information and entertainment services project (IV) used a technology that had been developed at the parent company and was synergistic to the technological bases the company already incorporated. Additionally, the new content on SMS project (II) employed already present technology within the company, as it was a follow up project of the entertainment and information services project. Therefore, the existing technology fitted the requirements of the project team leading to an exploitation of their technical experiences obtained when developing this technology for the former project. Hence, technological synergy can influence the project life cycle. Technological synergy is defined as the existing fit between the needs of the project and the firm's existing technology (Cooper 1979; Cooper and Kleinschmidt 1986; Lievens et al. 1999b). Technological synergy leads to $a$ faster time-to-market as the technical development is less complex and less time-consuming. As many service innovations within the telecommunications industry are technology based, companies should exploit technological synergy. This leads to the following proposition:

p9: The time-to-market will be positively related to the level of technological syrengy.

\subsubsection{Project Learning and Time-to-Market}

Project learning is an essential factor for innovation speed. The interviewees explained that project learning occurred wherever project team members acquired, disseminated and used information. The more sources of information were used the higher the level of project learning. The voice and fax mail project (I) started when the company was just founded, thus, the project team members did not have established mechanisms for information processing activities. As a result, project learning was very low. In the new content on SMS (II) project, knowledge processes had been already instituted, as it was a follow-up project of the information and entertainment project 
(IV). Thus, specific learning mechanisms were already established. Consequently, the service was launched in the market quickly. In the virtual private network project (III) however, too much information processing occurred leading to information overload. thereby extending the development time. Managers described time-to-market as the relative time it took a project team to introduce a new service in the market. The development time should be seen in relation to the original time schedule, the industry standards and comparable service innovation projects.

Throughout all projects, we could observe that a specific level of information processing activities influences the time-to-market positively. Hence, a certain levell of learning has to be established before learning can contribute to time-to-market. First, information processing activities require time leaving less time for new service development. Once the right learning mechanisms are instituted, efficient information processing leads to a cycle time reduction. Meyer and Purser (1993) emphasize that improving organizational learning is the core of a fast cycle-time strategy. By developing new mobile services, the project team members create a knowledge base, which serves as a platform for current and subsequent projects to react on events and trends in present and prospective markets. Mobile business opportunities (e.g. tracking consumer behavior) create growing knowledge content, but the question remains how to use it effectively. However, only a medium amount of information processing is appropriate in turbulent environments in order to speed up new service development. In turbulent environments information becomes obsolete more quickly (Bhattacharya et al. 1998). The arising information load can only be managed through efficient information processing activities. Thus, proficient information processing activities are an absolute necessity in the fast development of new services. However, companies have to carefully manage their learning mechanisms as too much information processing may increase the development time because of information overload or information obsoleteness. Hence, we expect the following:

P10: Time-to-market will be curvilinear (inverted $U$ ) related to the level of project learning.

\subsubsection{A propositional framework}

The goal of the present study was the development of a propositional framework concerning the critical antecedents of project learning and time-to-market in mobile service innovations. An exploratory case study research was performed in a Dutch mobile tellecommunications organization. The research provided us with an empirical basis for theory development.

In turbulent environments, successful new services need valuable information processing activities that encourage innovation project team members to exchange their 
individual experiences. Project learning is stimulated through a project team design that faciltates learning prospects and encourages active learning behavior (Madhavan and Grover 1998; Senge 1990; Slater and Narver 1995). Especlally in turbulent mobile environments, companies need to design a fast, agille and boundarylless organizational setting in order to stay competitive (Tucker, Meyer, and Westerman 1996). Thus, a flexible decision architecture constitutes a prerequisite for information rich processes $\left(P_{1}\right)$. Furthermore, the company should employ prior knowledge, experiences and skills, thus, project team memory is important (P2). Moreover, in dynamic markets new external information has to be spread throughout the project team, thus, the company needs high information awareness (P3). In order to cope with the turbulent environment, the information processing capabilities should be coherent to the information processing requirements $(P 4)$. Additionally, communication is a necessary prerequisite for project learning (Lei, Slocum, and Pitts 1999), as without information exchange employees cannot discover other experts' know-how (Ribbens 1997; Schein 1993). A proper balance of Innovative and coordinative communication is essential, as both are needed for effective learning activities (P5).

In turbulent and dynamic markets, like the mobile market, new services have to be developed quickly (Karagozoglu and Brown 1993; Tapscott et al. 1998). Extant research has shown that a fast time-to-market can be a significant source of competitive advantage (Bayus 1997; Griffin 1997; Huff and Robinson 1994; Karagozoglu and Brown 1993; Kessler and Chakrabarti 1996; Kessler and Chakrabarti 1999; Lymn et al. 1999; Meyer and Purser 1993; Sherman et al. 2000). Especially in industries where new services have shorter life cycles, an ongoing effort to innovate in a fast manner is substantial to the survival of an organization. However, severall factors influence the time-to-market of a service innovation project. Project complexity impedes a fast service Innovation process (P6). Additionally, top management support is a necessary prerequisite to stimulate innovation speed $(P 7)$. The information power of the supplier has a negative impact on time-to-market ( $P 8$ ). Furthermore, companies in highly technical Industries can accomplish essential benefits from technological synergy of various innovation projects $(P g)$. Moreover, the ideal condition for a fast time-to-market is a medium level of project learning $(P 10)$. All relationships are summarized in figure 2.2 . 
Figure 2,2: Conceptual Framework

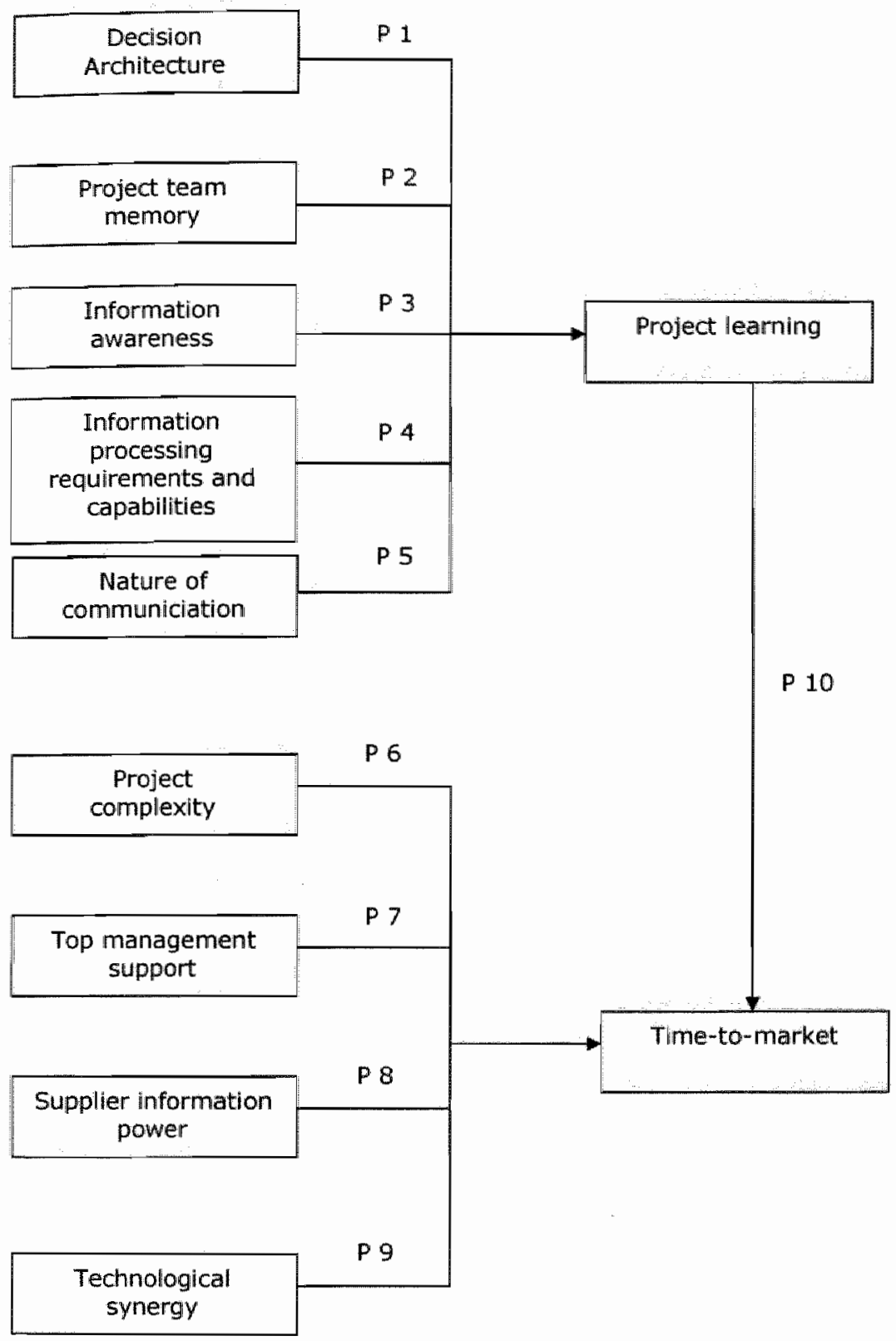




\subsection{Conclusion and Implications}

In line with the information processing view of organizations, the examined project teams can be conceived as information systems that develop organizational knowledge. Organizations need to learn continuously in order to keep up with the aforementioned technological, competitive and customer trends (Lievens et al. 1999a). The "fast" transformation of technological and market information into successful market-demanded outcomes is vital for the survival in a fast evolving mobille environment. As a result, the intersection of speed and knowledge is most critical during an organization's new product or service development. We have provided an in-depth investigation of this intersection of speed and knowledige, hence the intersection of project learning and time-to-market.

Considering the characteristics of a moblle commerce business environment, we believe our model to have theoretical generalizability in dynamic, turbulent and uncertain environments where fast new service development has shown to be a strategic key success factor. Future operationalizations within such dynamic business settings will have to evaluate and contribute to the extemal validity of our model. A lot of industries dealing with the application and innovation of information technology will have to manage the challenge of continuing speedy innovation and the lock-in of knowledge. We therefore expect our propositional framework will trigger the insight and extension of factors explaining a delicate balance between time-to-market and learning.

In terms of theory building we can also position our framework within the managerial relevance of the value chain. An increasing importance of time-to-market further pushes the deconstruction of the value chain into digital and tangible activities. Moreover, cost and efficiency purposes lead to an increased substitution of tangible activitles with digital ones. This evolution will largely influence value creation in which Information processing (l.e. learning) will constitute the value added of human processes. Therefore, we believe our framework may contribute in the puzzle of determinants thriving value creation both through fast new service development and learning.

Project learning involves information processing activities that build up a knowledge base. Hence, innovation management should steer balanced communication flows comprising both innovative and coordinative information. Moreover, information processing capabilities should match information processing requirements. The advanced Information technology of the Internet and company-wide Intranets create opportunities for better communication via e-mail and sharing material online (e.g. Microsoft Netmeeting). Thus, more information can be shared with a wider audience. Despite these advantages, our case studies demonstrated that more communication channels could be counterproductive to learning in some situations. Project team members have to deal with information overload while human capabilities sometimes cannot cope with all the 
extra information leads provided through IT-infrastructure. Therefore, coordinative communication is necessary to handle the increasing amount of information. Inhovative communication is necessary during the service innovation process, as successful innovations need experimentation and improvisation (Eisenhardt and Tabrizi 1995; Moorman and Miner 1998). The innovation process contains a lot of uncertainty that the firm has to manage by supporting creativity and the exchange of ideas. Hence, the organizational climate during the new service development is essential for stimulating project learning. Organizations should provide some slack resources that ensure the time for creativity and experimentation (Nohria and Gulati 1996). Moreover, the organizational milieu should support employees by allowing active participation, thereby creating the best conditions for vigorous learning behavior. Learning is a social process that establishes human linkages between employees. Consequently, learning should be deeply embedded in the organizational identity in order to institutionalize shared values and meanings that in turn diminish misunderstandings. Furthermore, employees will implement decisions better when they have contributed in the decision-making process. Participation supports the motivation of employees as they can achieve self-fulfillment and a higher level of job satisfaction. Hence, a more flexible and participative decislonmaking will support project learning.

Project team memory is another important factor as various team members can exchange their expertise and know-how, hence previously acquired knowledge. Moreover, when recruiting personnel, managers should sellect employees with different backgrounds and skills so that other employees can profit from their knowledge. Involving people from different departments in one project opens up boundaries that lead to a stimulating working atmosphere. Considering the turbulent nature of the telecom market and the high turnover of employees, management should pay more attention to the explicit "lock-in" of knowledge.

Additionally, innovation management should stimullate information awareness through cross-functional interfaces and the sharing of internally or externally acquired information between project team members. Employees should have a better insight in the activilties of the whole company. Thus, organizations should support employees by providing opportunities for training and rewarding for creativity in order to encourage the transfer of knowledge. Learning behavlor should be integrated in job descriptions and evaluations, i.e. the yearly review about employees' performance. Establishing a positive learning climate is a sustainable competitive advantage that is hard to imitate by competitors.

Managers within the mobile industry have to focus on speed to market as a strategic priority. A major prerequisite is top management support and priority given to a project. As top managers give future directions, they should stimulate the exchange of 
deas by showing their own interest and support with resources and investments. Considering the strong supplier dependencies that still exist within the mobile industry, future relationship building/management within the networks of the digital economy (the so-called electronic business platforms) should leverage potential information asymmetries.

Innovation management needs to handle project complexity by coordinating crucial functional and company interfaces. Managing the appropriate communication network that will fit the information processing requirements is an essential responsibility within innovation management. Moreover, innovation capacity should be enhanced by exploiting technological synergies during the service innovation process.

A medium level of learning is the optimal condition for a fast time-to-market. Organizations should establish formal and informal linkages between different departments and should ascertain enough resources in order to engage their employees in information processing activities. However, managers have to be aware that too much information creates an information overload, which will impede time-to-market. Moreover, especially in turbulent environments managers have to encourage their employees to actively perform information processing in order to avold information obsoleteness.

Furthermore, the service innovation process is not only supposed to be fast but also very flexible, as new acquired information should be incorporated also in late stages of the innovation process. Research has shown that the classical stage gate process is very effective in stable environments (Cooper and Kleinschmidt 1986), but its value in turbulent environments has been questioned (Bhattacharya et al. 1998; Iansiti and MacCormack 1997). A clear limitation of the stage gate process is that "it assumes that all information about potential design choices is known or can be discovered during concept development" (MacCormack et al. 2001,p. 134). Thus, managers should try to apply a concurrent engineering approach to achieve a high flexibility for reactions to chariges in the market also in later stages of the development process.

\subsection{Limitations and suggestions for future research}

We used multiple sources of information and an iterative analysis procedure in order to increase the validity of our constructs and the presumed correctness of our inferences (Yin 1994). The external validity of our case studies should point to analytical generalizability, which involves replication logic. The objective of the present case study has been to postulate research propositions rather than testing them. Therefore, it is necessary to test the propositional framework with a more conclusive research method, e.g. an ex-post facto survey or a longitudinal study. The latter approach may be 
advantageous as it can focus on learning and speed throughout the whole project life cycle.

Moreover, our unit of analysis within the case study research design has been the project level (i.e. the new mobile service innovation) and preliminary generalizations can hence only be formulated on the project level. Nevertheless, the nature of the antecedents discovered for learning relate strongly to organizational design. Consequently, future research designs should incorporate different units of analysis comprising both variables on the project and the organizational level.

In addition to methodological limitations, the present study is also limited with respect to theoretical clues. Although it stresses the importance of time-to-market as an important success factor of innovation success, it should be noted that the pure strive for shortening the innovation cycle time may lead to an overemphasis of uncreative incremental innovations. Although time-to-market is an important determinant of innovation performance, organizations should also consider other indicators, such as quality and costs of the innovation. Time-to-market is not supposed to be the pure strive for shortening the project life cycle, but should be approached and measured by using both a time-related and a goal-oriented measure where the latter should be stressed. Hence, future empirical research should focus on a broad spectrum of innovation speed measures.

Furthermore, project team memory supports the building of absorptive capacity and is thus favorable for project learning. Past experiences of past projects should be used to support the avoidance of 're-inventing the wheel' (Drew 1994). Project teams should also develop 'transactive memory' which enables expertise coordination. Transactive memory helps teams to locate certain knowledge areas of team members thus reducing cognitive load (Faraj and Sproull 2000). However, the question arises whether too much prior knowledge detracts from creativity, thus leading to only minor incremental changes. Moorman and Miner (1997) found that high memory levels neither improve nor rewolke product creativity. They argue that the memory level may be less important than the flexibility a firm incorporates when handling its knowledge. Thus, it is essential to not only rely on past experiences but to incorporate mechanisms that enhance flexible processing of new valuable information. Hence, future research is needled in order to define the appropriate level of project team memory and the flexible handling of knowledge within organizations.

We proposed an inverse relationship between supplier information power and the time-to-market of a project. However, in the digital economy companies need to

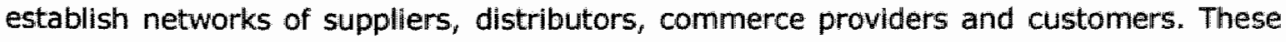
so-called electronic business communities (EBCs) build platforms for collaboration that support innovations within the mobile world (Tapscott et al. 1998). These EBCs however 
must be carefully managed as suppliers or content providers often possess necessary information that is needed for fast service development. Thus, supplier involvement can be helpfull but it involves greater coordination requirements (Kessler and Chakrabarti 1999). Future research should clarify which llevel of supplier involvement is most favorable and how organizations can achieve a beneficial supplier involvement.

Moreover, future research could incorporate other potentially important antecedents of project learning and time-to-market. Further, it is necessary to empirically confirm the critical antecedents and the relationship between project learning and time-to-market during the service innovation project life-cycle. 


\title{
Chapter 3
}

\section{THE MEDIATING ROLE OF COMMUNICATION BETWEEN PROJECT TEAM MEMORY AND NEW SERVICE PERFORMANCE}

\begin{abstract}
This chapter reports the findings of an online survey $(n=232)$ among high-tech service innovation managers on the mediating role of the type of communication between memory and project learning and time-to-market. Results indicate that especially innovative communication enhances knowledge building and development speed during service innovation.
\end{abstract}


Knowledge is of two kinds. We know a subject ourselves, or we know where we can find information upon it.

\section{Samuel Johnson (1709-1784)}

\subsection{Introduction}

Research in innovation has shown the importance of communication for innovation performance (Maltz 2000; Monge, Cozzens, and Contractor 1992; Van de Ven 1986). Communication ensures that innovation project teams receive market and technological information and reduces uncertainty (Brown and Utterback 1985). Furthermore, communication, or the processing of information, improves the existing knowledge stock of organizations (Huber 1991). However, the existing knowledge stock (i.e. memory) also has an impact on communication, especially when project team members follow a strategy of exploitation. Innovation project teams have access to a larger pool of stored information than individuals, but memory only affects project learning when team members exchange different information, i.e. communicate. Therefore, we believe that communication mediates the influence of memory on project learning. Project learning during new service development is crucial as it ensures that the organizations' knowledge base includes the most recent market and technological information. Furthermore, in the turbulent environment of high-tech services, dynamic technological progress and the relative simplicity to copy services force companiles to focus on time-to-market as an essential project outcome. The exploitation of the existing knowledge stock should also influence the development speed, as existing knowledge is often faster available. Again, the memory needs to be communicated in order to influence the time-to-market of a profect. Therefore, the purpose of this study is to investigate how memory's influence on project learning and time-to-market is mediated by communication. Following Hauptman's (1986) communication classification, we consider two types of communication: innovative communication, i.e. processing of creative and new information, and coordinative communication, i.e. processing task-dependent information. Innovative communication accounts for the amount of new information to guarantee creativity in the development process, while coordinative communication assures productivity by considering controls, orders and other forms of direction and feedback. As a result, our study aims to provide a better understanding of the importance of these two types of communication and may provide insight into how the innovative and coordinative activities can be better managed during the new service development process. 
The academic and business importance of the service sector is increasing. as services dominate most developed economies (Froehle et al. 2000). Companies benefit from new services, as they drive customer attraction, customer loyalty, increased profitability and new business opportunities (Menor et al. 2002). However, research in marketing has so far generally focused on new product development, while service innovation has largely been underresearched and is especially characterized by a paucity of empirical studies (Menor et al. 2002; Song, Di Benedetto, and Song 2000).

This study contributes to theory in three important ways. First, we seek to explore and expand the existing literature on the impact of communication during innovation by conceptualizing two different types of communication. Furthermore, we postulate that the type of communication plays an important mediating role between existing knowledge stock and the project outcomes of learning and time-to-market. Third, we propose that memory's impact on communication depends on the degree of project complexity.

This chapter is structured as follows. First, we develop our conceptual framework highlighting the impact of existing knowledge on project learning and time-to-market, mediated by communication. Subsequently, we report on the results of an empirical study with data from 232 new service development projects. Our results point to distinct mediating roles of innovative and coordinative communication. We conclude the chapter with a discussion of the implications and directions for future research.

\subsection{Conceptual framework}

Our conceptual framework is summarized in figure 3.1. We first introduce the two project outcomes, project learning and time-to-market, and their impact on new service performance. Second, we examine the effect of the type of communication on the two project outcomes. Third, we discuss the impact of generational and transactive memory on both types of communication. Fourth, we consider the moderating effects of project complexity on the generational memory-communication relationships. 
Figure 3.1: Conceptual Framework

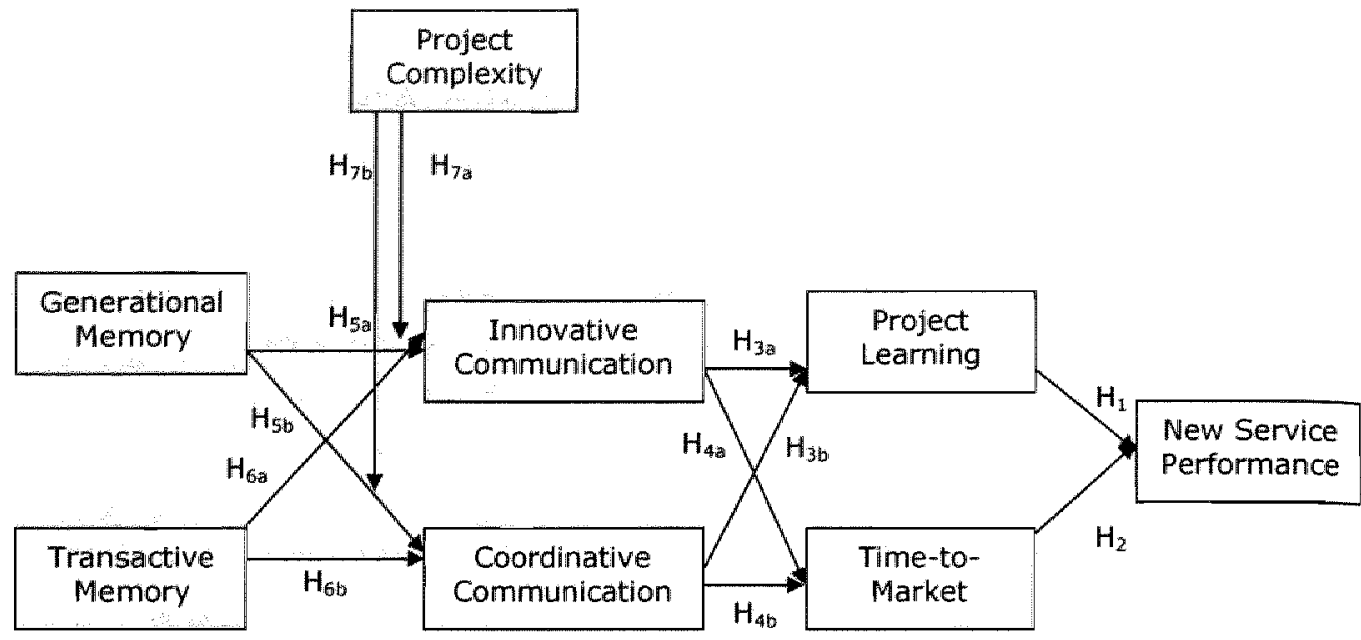

\subsubsection{Project outcomes}

\subsubsection{The impact of project learning on new service performance}

Following the information-processing view of organizations, we conceptualize project teams as information systems (e.g. Daft and Weick 1984; Moorman 1995) that build up a knowledge base as a key learning outcome (e.g. Duncan and Weiss 1979; Miner, Bassoff, and Moorman 2001). Thus, project learning is the creation of a new or updated stock of knowledge. It ensures that the newly developed service incorporates all recent knowledge of the service innovation team members. Team members change and re-invent the services to correspond to altered external conditions, new customer preferences and evolving technological possibilities (Brown and Eisenhardt 1995; Duncan and Weiss 1979). When the team has incorporated these alterations, the new service has a better fit: with the market and state-of-the-art technology, and consequently a better new service performance. New service performance is defined as the financial performance of the new service relative to other new services of the company, competitive new services, and the original financial objectives. Service innovation teams that continuous|y engage in learning activities develop value-adding core competencies. The development of a new service is in itself a knowledge-producing activity (Madhavan and Grover 1998). Project teams update the knowledge base for subsequent innovation projects, and hence ensure innovation success over a longer time period. Additionally, team members build up experience and gain greater insight into the factors that lead to new servlce success (Ayers, Dahlstrom, and Skinner 1997; Hurley and Hult 1998). These factors can cross-fertilize other innovation projects and enhance overall new service performance. Indeed, Moorman and Slotegraaf (1999) found that the financial 
performance of new products is affected by the organization's experience in product development. Therefore, project learning improves innovation performance, including superior quality, better delivery, increased market share or other tangible gains. Hence, we hypothesize:

H1: The greater the level of project learning, the greater the level of new service performance.

\subsubsection{The impact of time-to-market on new service performance}

Several researches within the new product development literature have demonstrated a positive link between time-to-market and innovation performance, using a wide variety of performance indicators, such as revenue, profitability, corporate and brand image (Menon et al. 2002), return on assets, return on sales, sales growth (Ittner and Larcker 1997), and general commercial success measures (Griffin 2002; Lynn et al. 1999). Furthermore, companies can achieve a pioneering advantage by being the first to introduce a service in the market. However, time-to-market should not only consider the timing relative to others in the industry but also the timing that was initially planned by the company. Following Kessler and Chakrabarti (1996), we define time-to-market according to two dimensions: a time-related and a goal-oriented dimension. The timerelated dimension refers to the time between the conceptualization of the new service and the commercial market introduction. The goal-oriented component includes the extent to which the service was introduced as planned by the company.

Especially in dynamic environments, time-to-market creates an essential advantage to improve business performance. First, a fast time-to-market minimizes the risk of introducing an obsolete service in a market. Second, they are able to replace their services with their own new services, diminishing the threat that custorners switch to competitors. Services are often easier to imitate than products due to generally lower capital and equipment investments and a lack of patent or copyright protection. This imitation simplicity urges innovation teams to speed up service development, as organizations must anticipate competitive reactions. Striving for a fast time to market ensures that resources are utilized in an effective manner. Consequently, timeconsuming rework and redesilgn are often unnecessary. Furthermore, short development times make resources avallable for other prospective products. Hence, we propose:

H2: The faster time-to-market, the greater the level of new service performance.

\subsubsection{The type of communication}

Communication is an essential means through which information is acquired, disseminated and processed within organizations (e.g. Duncan and Welss 1979; Ebadi and Utterback 1984; Tushman and Katz 1980). Several studies have shown the 
importance of communication during new service development (e.g. de Brentani 1989 ; Easingwood and Storey 1991; Lievens and Moenaert 2000a), nevertheless, empirical research that investigates the impact of communication on new service project outcomes has been limited. We adopt the definition of communication provided by Duncan and Moriarty (1998, p. 2): "Communication is the human activity that links people together and creates relationships. It is at the hart of meaning-making activities. [...] It serves as a way to develop, organize, and disseminate knowledge." Therefore, communication is important for the effective handing of experiential and coordinative activities. We follow the two-dimenslonal classification of Hauptman (1986) to define the type of communication throughout the innovation process, i.e. innovative and coordinative communication. Innovative communication comprises creativity in problem solving, which leads to new idea generation (Greenbaum 1974; Hauptman 1986). Hence, it should stimulate new service development. An innovative communication network provides project team members with knowledge and information for creative action. Coordinative communication mainly involves information exchange with regards to task-related interdependencies between different project members (Greenbaum 1974; Hauptman 1986). It supports the organization of an innovation project through task division, indlividual responsibilities and conflict handling. Therefore, we conceptualize coordinative communication as controls, orders, direction and feedback between subordinates and superiors and across functional units.

During new service development, communication is critical for the creation and adaptation of a knowledge base. The acquisition, dissemination and interpretation of information leads to project learning effects that are vital for the transformation of ideas into market-demanded outcomes (Barker and Camarata 1998). Communication is an integrative process that connects project team members with one another. Each service innovation team member has unique knowledge, hence, communication between the members helps to exchange this knowledge and makes it more widely avallable (Souder and Moenaert 1992). Communication provides a vehicle for otherwise isolated employees. to congregate and share their unique knowledge and apply it to the innovation task. Furthermore, communication also helps reducing uncertainty as more accurate information is available (Brown and Utterback 1985; Fidler and Johnson 1984; Lievens et al. 1999a). Through communication, team members better identify, access, and exploit emergent opportunities as they arise. Ebadi and Utterback (1984) agree that communication, which inspires creativity leads to better problem solving and develops knowledge. Hence, new ideas are produced and processed leading to increased learning. Innovative communication encourages employees to think in creative terms and initiate new and evolutionary service developments. Thus, the collaboration between these 
employees can lead to innovative problem-solving for the innovation task. Consequently. we hypothesize:

H3a: The greater the level of innovative communication, the greater the level of project learning.

Team members cannot only acquire new information from each other, they also develop a mutual understanding which facilitates subsequent tasks. The managing of the innovation task becomes easier and more structured when team members exchange coordinative communication. Similarly, coordinative communication supports information exchange between team members with different knowledge foci, l.e. the specialized experience and abilities of each team member (Faraj and Sproull 2000). Edvardsson, Haglund and Mattson (1995) found that clearly divided tasks between the project team members avoid intra-organizational conflicts and coordination problems. Therefore, coordinative communication helps to facilitate the understanding between project team members. We propose:

H3b: The greater the level of coordinative communication, the greater the level of project learning.

While the relationship between communication and project learning is relatively straightforward, the link between communication and time-to-market is less apparent. On the one hand, communication can lead to faster time-to-market (Meyer and Purser 1993). Effective communication mechanisms help project team members to better react to new information and upcoming changes during the project (MacCormack et al. 2001). The individual team members are better informed, reducing the risk of "re-inventing the wheel'. Furthermore, communicating more information reduces the risk that important: information is missing. Thus, the project team considers a more complete set of alternatives and reduces the probability that unanticipated problems may delay the service innovation. Hence, the likelihood of major errors and rework is reduced. Especially in the early stage, communication hellps in the detection and correction of errors.

On the other hand, communication can also slow down time-to-market. If not enough information is communicated, the development process might not proceed. Team members are waiting for certain information and cannot work on their tasks effectively. Similarly, too much communication can be problematic as well. In line with Tushman (1979), a project will be ineffective when the project team members' information processing capabilities do not correspond to the information processing requirements. Thus, the communication structure of the project team must ensure that information processing demands are matched. Otherwise, information overload slows down the 
service innowation speed. Additionally, service innovation project teams need to go through a time-consuming information-acquisition and consensus-creation process, which can also slow down the service innovation project (Eppinger 2001; Froehle et al. 2000). Moreover, in turbulent markets information becomes obsolete rather quickly (Battacharya, Krishnan, and Mahajan 1998; MacCormack et al. 2001). Hence, new service development teams have to carefully manage the communication frequency, as too much communication might take away resources from the actual development tasks, thus slowing down innovation speed.

Too little innovative communication will result in a slower time-to-market as the team members need to go through longer creative solution searches. This may delay important decisions and actions (Souder and Moenaert 1992). The team members might also miss crucial market and technological information, thus they cannot proceed further in the new service devellopment process. Too much innovative communication might be inefficient for the service innovation project as well and hence slow down time-to-market. The continuous search for solutions might absorb time and resources, while a solution has already been found. Team members might have to re-start and intensify their search process several times. Therefore, we hypothesize:

H4a: There exists a curvilinear (inverted U) relationship between innovative communication and time-to-market such that moderate levels of innovative communication produce the highest levels of time-to-market and high and low levels of innovative communication result in lower levels of time-to-market.

Similar to innovative communication, too little coordinative communication can slow down time-to-market. If the project team members do not coordinate and organize the tasks well that have to be performed, the service development will be delayed. If important issues are postponed by a team member, the other team members might not be able to proceed. Hence, the team members must communicate in order to coordinate. It ensures that they can work effectively and that all team members are informed about the progress of the service development project. Too much exchange of coordinative information might result in inefficiency as the team members might spend too much time on discussing task-related dependencies and formal guidelines. Hence, it might consume time and resources from the actual development effort. We propose:

H4a: There exists a curvilinear (inverted $U$ ) relationship between coordinative communication and time-to-market such that moderate levels of coordinative communication produce the highest levels of time-to-market and high and low levels of coordinative communication result in lower levels of time-to-market. 


\subsubsection{Memory dimensions}

Group memory is an essential antecedent of communication during the new service development process. For example, Argote, Gruenfeld and Naquin (2001) found that group memory is important for knowledge-sharing processes within groups. Memory has been defined inter alia as the collective beliefs, information databases, formalized procedures and routines, physical artifacts, and the formal cultural codes of acting within a company (Day 1994; Moorman and Miner 1997; Sinkula et al. 1997). Previous research has shown that memory allows companies to better identify, extract and employ information (Cohen and Levinthal 1990; Johnson, Menor, Roth, and Chase 2000). The idea of memory as an information filter traces back to Durkhellm, who claimed that as the characteristics and boundaries of the investigation field become familiar, the information search also becomes more systematic (Durkheim and Wilson 1981). Indeed, research has found that group memory influences interpersonal communication and group task performance (Rulke and Rau 2000; Wegner 1986). Additionally, group memory is a mechanism to cope with information overload. In complex problem situations, not every individual can know the complete solution. Instead, group members should be aware of how to find and apply relevant existing information (Cross and Baird 2000). Consequently, group memory is more than the sum of the individuals" memories, as groups usually remember more information than individuals, are often more precise than individuals and make fewer errors than individuals. (Argote et al. 2001). We investigate two group memory dimensions, which are independent of content, as in high-tech service industries information becomes quickly obsolete (Battacharya et al. 1998; Moorman and Miner 1998). These two types of memory are generational memory and transactive memory.

Generational memory refers to the collective knowledge of the service innovation team obtained in previous service innovation projects and applied to this project. It incorporates the knowledge of how to learn, how to integrate, and how to spread and use information. Previous research has shown disagreement on the effect of memory on creative solutions (i.e. innovative communication). On the one hand, researchers have argued that a higher level of memory might inhibit the search for innovative solutions, as team members stick to already existing cognitive patterns. This phenomenon has been called competency trap (Levitt and March 1988), core rigidity (Leonard-Barton 1992), or routine rigidity (Dickson 1992). Thus, team members might be limited in their exchange of innovative communication, as they only consider already stored knowledge. On the other hand, memory might also have a positive effect on innovative communication. For example, Hargadon and Sutton (1997) found that the application of knowledge obtained in previous innovation projects led to novel solutions. Communicating existing knowledge 
is particularly important in service innovation teams where the different members have unique past experiences and special competences, i.e. unique generational memory. Therefore, exchanging generational memory allows team members to acquire a helicopter view on the service innovation and gain more breadth of knowledge and skills. Innovation teams often consist of members from different departments that exchange more heterogeneous information. Consequently, they can expose each other to different and new stocks of knowledge. They can combine these unique experiences and hence create novel services. Similarly, theory on improvisation shows that the development of novel outcomes involves the recombination of routines (Moorman and Miner 1998). Following these research streams, we hypothesize:

H5a: The greater the level of generational memory, the greater the level of innovative communication.

Generational memory includes certain routines on how to organize and coordinate innovation activities. Thus, generational memory increases the exchange of coordinative communication; as experience from previous projects facilitates cooperation. By exchanging previous experiences with regard to managing the innovation task, group members can apply mechanisms that have been effective elsewhere to similar problems. Furthermore, it improves team members' abillity to undlerstand each other (Moorman and Miner 1997). Thus, it fosters information exchange about coordination tasks (e.g. information concerning technical instructions, time restrictions, completion dates, etc.). We predict that

H5b: The greater the level of generational memory, the greater the level of coordinative communication.

Transactive memory means that team members are aware of the knowledge other team members have. They might also use each other as memory storage lacations (Wegner 1995; Wegner 1986; Wegner, Raymond, and Erber 1991). Through transactive memory, team members rather know the locations than the exact content of specific information. Hence, they rely on social relationships to enlarge their own memory storage while at the same time decreasing their cognitive load (Faraj and Sproull 2000). Even when team members are struggling with complex problems, transactive memory provides the group with a complete system to cope with situational demands. Moreover, other team members are an effective means for storing experience (Olivera 2000). The innovation team can be considered a cohesive communication network, where every team member has specific knowledge. If another team member requires particular information, he will turn to an individual within the communication network in order to minimize his efforts (Souder and Moenaert 1992). Innovation teams often consist of 
various specialists with different backgrounds (Cohen and Levinthal 1990) who have their own individual networks. This heterogeneity of perspectives results in a better stimulation of new ideas. Therefore, transactive memory leads to innovative communication, as individual team members know diverse information. Through integrative processes new knowledge is exchanged within the group and creative solutions can be found (Yoo and Kanawattanachai 2001). We propose the following:

H6a: The greater the level of transactive memory, the greater the level of innovative communication.

Deeter-Schmelz and Ramsey (2003) state that easier information access has a positive impact on the team processes and completion of tasks. Service innovation teams can retrieve information from a larger pool of knowledge to support their coordination activities. Having access to more information facilltates the handling of task-related interdependencies. We hypothesize that

H6b: The greater the level of transactive memory, the greater the level of coordinative communication.

\subsubsection{Project complexity and generational memory}

Project complexity is expected to moderate the relationship between generational memory and communication. If a project is complex, it "consists of many varied interrelated parts" (Baccarini 1996p. 201). It includes two main features, differentiation and interdependency (Baccarini 1996; Williams 1999). Differentiation relates to many, different elements that have to be considered within the new service development project. Interdependency refers to the degree of interrelatedness between these elements. Hence, project complexity refers to the degree of task difficulty and task variability (Atuahene-Gima and Evangelista 2000; Fidler and Johnson 1984). In thigh-tech services the technical complexity, the radicalness of an innovation and the utilization of non-routine technology are important factors that may increase the project complexity: The complexity of an innovation project is related to the level of uncertainty project team members have to deal with. The more complex an innovation is, the more dimensions have to be considered (Fidler and Johnson 1984; PIch, Loch, and De Meyer 2002). Consequently, complex projects often require a greater need for external information sources (Monge et al. 1992). Project teams cannot rely on the already stored knowledge from previous projects. Instead, they must acquire and disseminate new information. Indeed, Clift and Vandenbosch (1999) found that in complex projects development teams substitute internal sources by external members while in simple projects external members are only used infrequently. Therefore, the impact of generational memory on 
communication will be lower when projects are more complex. Therefore, we hypothesize that

H7a: The greater the project complexity, the weaker the positive relationship between generational memory and innovative communication.

H>b: The greater the project complexity, the weaker the positive relationship between generational memory and coordinative communication.

\subsection{Methodology}

In order to test the aforementioned hypotheses, we conducted an empirical study. Partial least squares were used to assess the reliability and validity of our measures. Furthermore, we tested two models with partial least squares structural equation modeling. The first model includes all main effects, while the second model also considers the moderating impact of project complexity. We now discuss the sample and data collection procedure, the measurement and the data analysis.

\subsubsection{Sample and Procedure}

We conducted an online survey that was mailed to 1528 managers of high tech service firms. Based on Bogner and Barr (2000), we define high-tech service industries as being in a continuous state of change. These industries are characterized by rapid alterations in technology and ambiguous customer demands. The surveyed high-tech service firms are members of the Association for Services Management International (www.afsml.org). Although the majority of respondents came from the US (57.3\%), in total managers from 26 countries participated. The average age of the informants was 48. Table 3.1 shows the professional functions and gender demographics of the sample. Furthermore, companies from a wide variety of high-tech service industries participated, e.g. telecommunication, IT services, electronics, or medical services. The managers were requested to participate in the survey if they were regular members of service innovation projects. In case they did not fulfill this criterion, they were asked to forward our irvitation to a suitable colleagule. A reminder e-mail was sent after one week to nonrespondents, followed by another re-invitation after two weeks. In order to test for nonresponse bias, we divlded respondents into an early group, including all respondents that participated after the first invitation, and a late group, including all respondents that only filled in our survey after the second reminder. Thereafter, we tested for mean differences between the two groups. No systematic differences were found between early and late respondents (Armstrong and Overton 1977). In total, 232 firms (15\%) responded. Informants were asked to base their answers on their most recent service innovation project that would be representative of all service innovation projects the company had 
completed over the last few years and for which financial outcomes were available. Hence, the new serwice development project was the main unit of analysis.

Table 3.1: Function and gender demographics

\begin{tabular}{llcc}
\hline \multirow{2}{*}{ Function } & Frequency & Percent \\
\hline Account Manager & 3 & 1,3 \\
Business Development Manager & 35 & 15,1 \\
IT Manager & 16 & 6,9 \\
Marketing Manager & 31 & 13,4 \\
Operations Manager & 19 & 8,2 \\
R\&D Manager & 18 & 7,8 \\
Service Manager & 110 & 47,4 \\
\hline \multirow{2}{*}{ Gender } & & 25 & 10,8 \\
\hline
\end{tabular}

\subsubsection{Measurement}

For the operationalization of our constructs, we used existing scales from the marketing and innovation literature. Appendix A contains all measures, their sources, composite reliabilities and loadings. All scales except time-to-market were measured on a 7-point Likert scale. Time-to-market was measured on a 7-point semantic differentlal scale. All scales were pretested qualitatively where 4 academic experts and 4 business managers provided detailed feedback on wording, comprehensibility and flow of the questions. Thereafter, a quantitative pretest was conducted and items were reflined if necessary.

\subsubsection{Data analysis}

The measurement and the structural parameters in our structural equation model were estimated using partiall least squares, specifically PLS-GRAPH $\vee 3.00$. The usage of partial least squares is most appropriate, as our primary concern was the prediction of dependent endogenous variables (Chin 1998; Fonnell and Bookstein 1982; Fornell and Cha 1994; Lohmöller 1988). Furthermore, PLS does not require multivariate normal data, and is especially suited for smaller sample sizes. Hence, another reason for using PLS 
was the fact that our sample size in combination with our model size did not allow for the usage of maximum likelihood estimation (Bentler and Chou 1988).

Convergent validity was assessed by examining the factor loadings of the measures on their respective constructs. All factor loadings are higher than 0.50 (Hulland 1999), while most loadings are higher than 0.80. We evaluated reliability by using composite scale reliability (Chin 1998; Fornell and Larcker 1981). Composite scale rellability ranged between 0.90 and 0.97 and exceeded the suggested cut-off value of 0.7 (Nunnally and Bernstein 1994). Furthermore, all average variances extracted are above the recommended cut-off of 0.50 (Fornell and Larcker 1981), ranging from 0.68 to 0.88 . Discriminant validity was assessed for each construct by three different methods (White, Varadarajan, and Dacin 2003). First, the square root of the average varlance extracted exceeded the correlations of the construct with the other constructs in the model. Second, each correlation was less than 1 by an amount greater than twice its respective standard error (Bagozzi and Warshaw 1990). Third, we examined the theta matrix to confirm that all items loaded highest on their associated construct and not on another construct. All off-diagonall elements in the theta matrix were below 10.20 ( Falk and Miller 1992). Thus, all constructs showed discriminant validity. Table 3.2 shows composite reliabilities, average variances extracted and the intercorrelations between constructs.

For the moderator analysis, we first standardized the respective indicators in order to lower the correlation between the interaction and the original indicators and avoid computational errors. Thereafter, we created the moderating variable by calculating the cross products between each indicator of the predictor and the moderator constructs (Chin, Marcolin, and Newsted 2003). Each cross product was then used as an indicator for the moderating construct. Furthermore, we wanted to investigate whether the interaction term adds $\left(=R^{2} \Delta\right)$ to the explanation of the variance in the endogenous construct. Significance of all beta coefficients was tested with a bootstrapping method (l.e. sampling with replacement method) that delivered the corresponding t-values. 
Table 3.2

Reliabilities and correlations among constructs

\begin{tabular}{|c|c|c|c|c|c|c|c|c|c|c|}
\hline & $\mathbf{C R}$ & AVE & GM & TM & IC & $\mathrm{CC}$ & $\mathrm{PL}$ & TाM & NSP & PC \\
\hline $\begin{array}{l}\text { Generational } \\
\text { memory (GM) }\end{array}$ & 0,960 & 0,790 & 0,889 & & & & & & & \\
\hline $\begin{array}{l}\text { Transactive } \\
\text { memory (TM) }\end{array}$ & 0,970 & 0,910 & 0,436 & 0,954 & & & & & & \\
\hline $\begin{array}{l}\text { Innovative } \\
\text { communication (IC) }\end{array}$ & 0,930 & 0,830 & 0,442 & 0,421 & 0,911 & & & & & \\
\hline $\begin{array}{l}\text { Coordinative } \\
\text { communication (CC) }\end{array}$ & 0,960 & 0,880 & 0,372 & 0,505 & 0,620 & 0,938 & & & & \\
\hline Project learning $(\mathrm{PL})$ & 0,960 & 0,870 & 0,535 & 0,375 & 0,478 & 0,424 & 0,933 & & & \\
\hline Time-to-market (TTM) & 0,940 & 0,800 & 0,280 & 0,224 & 0,270 & 0,181 & 0,216 & 0,894 & & \\
\hline $\begin{array}{l}\text { New service } \\
\text { performance (NSP) }\end{array}$ & 0,950 & 0,840 & 0,328 & 0,346 & 0,477 & 0,490 & 0,457 & 0,332 & 0,917 & \\
\hline Project complexity (PC) & 0,900 & 0,680 & 0,135 & 0,139 & 0,182 & 0,136 & 0,252 & 0,062 & 0,254 & 0,825 \\
\hline
\end{tabular}

\subsection{Results}

\subsubsection{Direct effects model}

The results for the main direct effects model are provided in table 3.3, along with the $\mathrm{R}^{2}$ for each endogenous construct. The first hypothesis, which predicts that project learning positively impacts new service performance, is supported $(b=0.404, t=7.22)$. Hypothesis 2 is also supported, as time-to-market positively influences new service performance $(b=0.245, t=3.96)$. Thus, both project outcomes have a significant positive effect on the performance of a newly developed service.

Hypotheses $3 a$ and $3 b$, assuming a positive relationships between innovative communication and project learning and coordinative communication and project learning, are both supported by our data $(\mathrm{H} 3 \mathrm{a}: \mathrm{b}=0.363, \mathrm{t}=4.85 ; \mathrm{H} 3 \mathrm{~b}: \mathrm{b}=0.231, \mathrm{t}=$ 2.62). The relationship between innovative communication and time-to-market was hypothesized as being curvilinear (inverted $U$ ). Hence, we entered both the linear and the quadratic variables into our model. However, we could not find any support for $\mathrm{H} 4 \mathrm{a}$, as the quadratic term was insignificant $(b=-0.051, t=0.54)$. Instead, we found support for a positive linear rellationship between innovative communication and time-to-market $(b=0.231, t=2.18)$. Furthermore, hypothesis $4 b$ posits a curvilinear (inverted $U$ ) relationship between coordinative communication and time-to-market. Again, we find no 
support for this hypothesis $(b=0.041, t=0.02)$. Contrary to $H 4 a$, we also do not find a Iinear relationship between coordinative communication and time-to-market.

The memory dimension focused on the impact of generational and transactive memory on innovative and coordinative communication. Our data show support for hypothesis $5 a$, as the level of innowative communication relates positively to the levell of generational memory $(b=0.319, t=4.34)$. Similarly, generational memory has $a$ positive impact on coordinative communication $(b=0.186, t=2.58$ ). Furthermore, both hypotheses $\mathrm{H} 6 \mathrm{a}$ and $\mathrm{H} 6 \mathrm{~b}$ are supported by our results. Transactive memory positivelly impacts innovative communication $(b=0.282, t=3.55)$ and coordinative communication $(b=0.425, t=5.86)$.

Table $\mathbf{3 . 3}$

Direct effects: Beta coefficients and $t$-values (in parentheses)

\begin{tabular}{|c|c|c|c|c|c|}
\hline ? & $\begin{array}{l}\text { Innovative } \\
\text { communication }\end{array}$ & $\begin{array}{l}\text { Coordinative } \\
\text { communication }\end{array}$ & $\begin{array}{l}\text { Project } \\
\text { learning }\end{array}$ & $\begin{array}{l}\text { Tîme-to- } \\
\text { market }\end{array}$ & $\begin{array}{l}\text { New service } \\
\text { performance }\end{array}$ \\
\hline $\begin{array}{l}\text { Generational } \\
\text { memory }\end{array}$ & $0.319(4.34)^{* * * * * *}$ & $0.186(2.58)^{* * *}$ & & & \\
\hline $\begin{array}{l}\text { Transactive } \\
\text { memory }\end{array}$ & 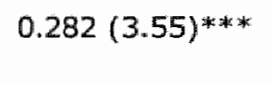 & $0.425(5.86)^{*}$ & & & \\
\hline $\begin{array}{l}\text { Innovative } \\
\text { communication }\end{array}$ & & & $\begin{array}{c}0.363 \\
(4.85)^{*} *\end{array}$ & $\begin{array}{c}0.231 \\
(2.18)^{*}\end{array}$ & \\
\hline $\begin{array}{l}\text { Innovative } \\
\text { communication }{ }^{2}\end{array}$ & & & & $\begin{array}{l}-0.051 \\
(0.54)\end{array}$ & \\
\hline $\begin{array}{l}\text { Coordinative } \\
\text { communication }\end{array}$ & & & $\begin{array}{c}0.231 \\
(2.62)^{* * *}\end{array}$ & $\begin{array}{l}-0.002 \\
(0.32)\end{array}$ & \\
\hline $\begin{array}{l}\text { Coordinative } \\
\text { communication }{ }^{2}\end{array}$ & & & & $\begin{array}{l}0.041 \\
(0.02)\end{array}$ & \\
\hline Project learning & & & & & $\begin{array}{c}0.404 \\
(7.22)^{* * * *}\end{array}$ \\
\hline Time-to-market & & & & & $\begin{array}{c}0.245 \\
(3.96)^{* * *}\end{array}$ \\
\hline Construct $\mathrm{R}^{2}$ & 0.260 & 0.284 & 0.257 & 0.078 & 0.266 \\
\hline
\end{tabular}

\subsubsection{Moderating effects model}

The results of the moderator model are provided in table 3.4, along with the $\mathbb{R}^{2}$ of each endogenous construct. Our results show that the moderating constructs add to the amount of variance explained in the endogenous constructs, i.e. innovative and coordinative communication. The $R^{2} \Delta$ of innovative communication is 0.056 while the $R^{2}$ 
$\Delta$ of coordinative communication is 0.029 . We conducted an F-test to assess whether the $R^{2}$ changes are significant. Both are significant (innovative communication: $F=9.29, p<$ 0.001 ; Coordinative communication: $F=4.79, \mathrm{p}<0.01$ ).

Project complexity negatively moderates the relationship between generational memory and innovative communication, providing support for hypothesis $1 \mathrm{Ha}(\mathrm{b}=$ $0.217, t=2.13$ ). No support has been found for hypothesis $H 7 b$, assuming a negative moderating impact of project complexity on the relationship between generational memory and coordinative communication $(b=-0.165, t=1.54)$. Even though the effect is in the expected direction, it is not significant at $a=0.05$.

Table 3.4

Moderating effects: Beta coefficients and t-values (in parentheses)

\begin{tabular}{|c|c|c|c|c|c|}
\hline & $\begin{array}{c}\text { Innovative } \\
\text { communication }\end{array}$ & $\begin{array}{l}\text { Coordinative } \\
\text { communication }\end{array}$ & $\begin{array}{l}\text { Project } \\
\text { learning }\end{array}$ & $\begin{array}{l}\text { Tilme-to- } \\
\text { market }\end{array}$ & $\begin{array}{l}\text { New servilce } \\
\text { performance }\end{array}$ \\
\hline $\begin{array}{l}\text { Generational } \\
\text { memory }\end{array}$ & $0.303(5.38)^{* * *}$ & $0.177(2.65)^{* *}$ & & & \\
\hline $\begin{array}{l}\text { Transactive } \\
\text { memory }\end{array}$ & $0.234(3.83)^{* * *}$ & $0.390(6.47)^{* * *}$ & & & \\
\hline $\begin{array}{l}\text { Innovative } \\
\text { communication }\end{array}$ & & & $\begin{array}{c}0.363 \\
(4.55)^{* * *}\end{array}$ & $\begin{array}{c}0.230 \\
(2.20)^{*}\end{array}$ & \\
\hline $\begin{array}{l}\text { Innovative } \\
\text { communication }{ }^{2}\end{array}$ & & & & $\begin{array}{l}-0.051 \\
(0.55)\end{array}$ & \\
\hline $\begin{array}{l}\text { Coordinative } \\
\text { communication }\end{array}$ & & & $\begin{array}{c}0.231 \\
(2.53)^{* *}\end{array}$ & $\begin{array}{l}0.000 \\
(0.00)\end{array}$ & \\
\hline $\begin{array}{l}\text { Coordinative } \\
\text { communication }\end{array}$ & & & & $\begin{array}{l}0.041 \\
(0.32)\end{array}$ & \\
\hline Project learning & & & & & $\begin{array}{c}0.404 \\
(7.00)^{* * * *}\end{array}$ \\
\hline Time-to-market & & & & & $\begin{array}{c}0.245 \\
(3.91)^{* * * *}\end{array}$ \\
\hline $\begin{array}{l}\text { Project } \\
\text { complexity }\end{array}$ & $0.090(1.19)$ & $-0.045(0.60)$ & & & \\
\hline $\begin{array}{l}\text { Project } \\
\text { complexity* } \\
\text { Generational } \\
\text { memory }\end{array}$ & $-0.217(2.13)^{*}$ & $-0.165(1.54)^{a}$ & & & \\
\hline Construct $R^{2}$ & 0.316 & 0.313 & 0.257 & 0.078 & 0.266 \\
\hline
\end{tabular}




\subsection{Discussion and Implications}

We extend the existing innovation literature by exploring the mediating role of communication between memory and the project outcomes of learning and time-tomarket and providing systematic quantitative evidence. Extant research has shown that: memory, the already existing stock of knowledge, has an influence on learning, the new stock of knowledge (Argote et al. 2001; MacCormack et al. 2001). We found that communication serves as the transformation process of existing stock of knowledge into a new stock of knowledge. Furthermore, innovative communication also mediates the impact of memory on time-to-market. Existing knowledge can speed up development projects when handled in a creative manner. Hence, the existence of innovative communication might explain why previous studies have been inconclusive on the impact of memory on innovation outcomes (Moorman and Miner 1997).

Our conceptualization of two different types of communication shows that it is important to distinguish between innovative and coordinative communication. Both types of communication positively influence the amount of project learning. However, due to our high-tech service research context, the influence of innovative communication is stronger than the one of coordinative communication. In this turbulent environment, the creative search for new solutions had a bigger impact on the creation of a knowledge base. Nevertheless, coordinative communication remains an important facilitator for project learning. The exchange of coordinative information helps project teams in coping with managerial tasks and supports the understanding and cross-fertilization of project team members from different backgrounds.

Contrary to our expectations, we did not find any curvilinear relationship between the type of communication and time-to-market. Instead, we found a positive linear relationship between innovative communication and time-to-market. It seems that creative and new information is an essential contributor to fast time-to-market. In the turbulent market of high-tech services, a fast time-to-market can be achieved when project teams exchange innovative communication and find creative solutions to speed up the innovation process. Innovative communication seems to provide a mechanism to cope with the uncertainty of this environment, as project team members can quickly learn about changes in the market and the used technology (Eisenhardt and Tabrizi 1995). The exchange of new ideas might foster information processing capabilities, leading to a better fit between capabilities and requirements. Our research shows that when time-to-market is very critical, managers need to support and foster innovative communication, instead of exchanging coordinative information. Additionally, consistent with our flindings, research on improvisation has found a positive impact of creative compositions on learning and time-to-market (Moorman and Miner 1998). 
Despite the importance of innovative communication, we found no impact of coordinative communication on time-to-market. Although coordinative communication is essential for project learning and hence new service performance, the processing of taskdependent information does not explain why projects have a faster time-to-market. Hence, it seems that a certain level of coordinative communication is necessary, but it neither speeds up nor slows down the service innovation project.

Furthermore, our results have shown that the two project outcomes, project learning and time-to-market have indeed a positive impact on new service performance. While both are important, our findings indicate that project learning has a stronger contribution to new service performance than time-to-market. Although time-to-market is important for the performance of new services, it is even more essential that the new services fit customer requirements. A fit with customer requirements is achieved through project learning, which ensures that market and technological information is transformed into market demanded outcomes. When projects teams create a knowledge base, more information has been considered. Hence, the service ideas are often better designed and the newly developed services can achieve a higher perceived service quality (Sethi 2000).

Another contribution of our study is the investigation of memory's influence on the two types of communication. We found that the already existing stock of knowledge has a positive impact on both innovative and coordinative communication. While generational memory is more important for innovative communication, transactive memory has a stronger impact on coordinative communication. We think that innovative information is mainly exchanged during the idea generation and design stages of the innovation process. The up-front activities are often more uncertain and fuzzy than the later stages of the service innovation process (Bhattacharya et al. 1998; Khurana and Rosenthal 1997). Furthermore, service innovation projects are mainly conducted by cross-functional teams where the team members have diverse backgrounds (Cohen and Levinthal 1990). Hence, during the uncertain, early stages the team members miglit only exchange information within the boundaries of the team. They rely more on memory from the participating team members, being generational memory. For the exchange of taskdependent information, thus coordinative communication, project team members might rely more on transactive memory. They use already existing knowledge outside the boundaries of the project team. Coordinative communication will be exchanged more in the later stages (Souder and Moenaert 1992) of the project, when organizing the actual development and the launch of the new service. Therefore, the team members might then not only stick to the boundaries of the team. Next to the specific project team, the team members also have their own communication network where they can make use of transactive memory. 
Moreover, we explored whether the impact of memory on the type of communication is different for simple and complex projects. Project complexity has indeed a moderating impact on the relationship between generational memory and innovative communication. Thus, when innovation projects are becoming more complex, the team members will rely more on externall sources for the exchange of new and creative information. Although the moderating impact of project complexity on the relationship between generational memory and coordinative communication was not significant; the expected effect was in the right direction. Coordinative communication is not so strongly influenced by the interaction between generational memory and project complexily. Therefore, team members still rely on generational memory for the exchange of task-dependent information despite the level of project complexity. For this kind of communication, they do not turn to more external sources when projects become more complex.

\subsection{Limitations}

Certain aspects need to be considered when interpreting our results. First, we used single informants from the 232 service innowation projects. While extant research has shown the advantages of multiple informants (van Bruggen, Lillen, and Kacker 2002), such design are also not without methodologicall concerns (Moorman and Miner 1997). Future studies might benefit from involving several members of the same service innovation projects. It would also be interesting to see whether team members from diverse backgrounds, e.g. marketing, R\&D, operations, have different perceptions.

Moreover, letting informants assess finished service innovation projects has maybe created common variance between constructs. This so-called retrospective justifleation blas arises when respondents give answers to the exogenous constructs in consideration of the relating outcome (Moorman and Miner 1997). The measurement of our constructs was part of a larger study, hence, it was less likely that informants" attention was drawn to the hypothesized relationships. Furthermore, we disguised the actual purpose of the Investigation to awoid this bias.

As we wanted to find empirical evidence from a large, international sample, we conducted a cross-sectional study. However, as communication during innovation is an information process, future research could consider a longitudinal study that could provide more insights into the interactions between the type of communication and different stages of the service innovation process. A longitudinal design would maybe also reveal how previous project learming is transformed into the memory of subsequent projects. 


\subsection{Future research guidelines}

In this study, we investigated how innovative and coordinative communication impact two important project outcomes, namely project learning and time-to-market. However, future research could allso investigate how the type of communication impacts other project outcomes. For example, extant research has recognized the trade-off between the innovation objectives of high service quality, low costs and fast time-tomarket (Bayus 1997). Hence, service quality and service development costs are other interesting outcomes that might be influenced by the type of communication.

Our investigation of the mediating role of communication has not differentiated between different stages of the development process. Recent research on the 'fuzzy front-end' has provided evidence that team members' activities might vary in the different stages (Moenaert, De Meyer, Souder, and Deschoolmeester 1995). Future research could examine whether our effects change during the different stages of the service development process.

Transactive memory is an important concept in the psychology literature, but has not found a wide application within marketing vet. Future research could provide a more extensive examination of transactive memory"s impact on innovation processes and marketing strategy formation. The communication networks within companies are increasingly facilitated by information and communication technology. Therefore, the influence of transactive memory might grow with the expansion of communication networks.

In this study, we concentrated our investigation efforts on internal communication by considering the type of communication during service innovation. However, as shown by the moderation of project complexity, external communication is also very critical. Through boundary spanning activities with external stakeholders, the organization can acquire important information that does not exist within the organization. A recent trend in industrial service settings is the stronger involvement of customers. Customers become active players and sometimes even co-developers (Prahalad and Ramaswamy 2000). These developments provide an interesting avenue for future research opportunities.

\subsection{Conclusion}

Communication is essential during new service development. Project teams need to exchange two types of communication, innovative and coordinative communication. The type of communication is very critical as both types enhance project learning and time-to-market, and ultimately new service performance. Furthermore, we have investigated the antecedent role of generational and transactive memory. In addition, project complexity moderates the impact of generational memory on the type of 
communication. Our conceptual framework was tested using information from 232 hightech service innowation projects. Our results show that while innovative communication positively affects both project learning and time-to-market, coordinative communication is mainly important as a facilitator for learning. Additionally, project learning and time-tomarket positively impact new service performance where the impact of project learning is stronger. We also could show that generational memory and transactive memory are critical antecedents of innovative and coordinative communication. Hence, the type of communication mediates the influence of memory on project learning and time-tomarket.

These results Imply that managers must address the balance of innovative and coordlinative communication for successful service innovation. Especially innovative communication needs to be fostered to achieve the service development goals of knowledge and speed in the high-tech service industries.. 


\title{
Chapter 4
}

\section{THE ROLES OF CUSTOMERS DURING KNOWLEDGE CO-CREATION IN ELECTRONIC SERVICES: AN EXPLORATORY STUDY}

\begin{abstract}
Marketing theory and practice have recognized the increasing importance of customer collaboration in services. Knowledge co-creation by customers during the service experience is an evolving phenomenon that has not yet received a lot of research attention. We have conducted a qualitative study on the roles customers play in knowledge co-creation and their respective influence on organizational knowledge and subsequently performance outcomes. Data were collected from three different electronic service channels, involving managers, engineers and customers. Based on the case study findings and an extensive literature review we have developed a conceptual framework showing the importance of knowledge co-creation by customers to substantially improve perceived service quality and provide information support for the upfront innovation activities.
\end{abstract}


A man can only attain knowledge with the help of those who possess it. This must be understood from the very beginning. One must learn from him who knows.

\section{George Gurdfieff (1877-1949)}

\subsection{Introduction}

Marketing theory has recognized the increasing importance of customer collaboration in service dellivery (Vargo and Lusch 2004). Similarly, the business press has also devoted some attention to the cooperation between companies and customers for value creation (Kambil, Friesen, and Sundaram 1999; NZ Marketing Magazine 2004). Both theory and practice suggest that collaboration with customers leads to organizational learning, better meeting customer requirements and improved performance (Prahalad and Ramaswamy 2000). Customers embody a wide base of skills, sophistication and interest (Prahalad and Ramaswamy 2004), and present an often untapped resource of knowledge. Therefore, companies that draw on the knowledge of their customer base can co-create knowledge. Our research addiresses current MSI toptier research priorities by exploring processes for the proactive understanding of customer needs and the way customer knowledge is communicated within the firm.

Customer collaboration has several facets. Research has for example investigated on customer co-production (Bendapudi and Leone 2003) and customer voluntary behavior (Bettencourt 1997) to show the convergence of consumer and company roles. Furthermore, research in innovation has suggested involving customers by providing them with toolkits that allow customers to make their own innovation (Thomke and von Hippel 2002; von Hippel and Katz 2002) or by talking to lead users during the innovation process to represent the early adopters of the innovation (Lilien et al. 2002; Nambisan 2002). Similarly, Urban and Hauser (2004) discuss advantages of "listing in" to examine new combinations of customer needs and identify opportunities for innovation. However, all this evolving research on the general premise of customer collaboration has not yet considered the dimensions and impact of knowledge co-creation by customers. Knowledge co-creation by customers is more than provilding customers access to an organization's knowledge base or seeking their involvement in innovation (Sawhney and Prandelli 2000). Hence, knowledge co-creation encompasses several unexplored dimensions, such as the roles customers play during knowledge co-creation. Furthermore, we need to examine the consequences of knowledge co-creation for organizations by considering the impact on organizational knowledge and subsequently on performance. Two performance outcomes are considered. First, increased organizational knowledge about customers enables companies to improve perceived 
service quality (Berry, Zeithaml, and Parasuraman 1990). Second, co-created knowledge is used as information input for upfront innovation activitles. Especially in the so-called fuzzy front end (i.e. the early stage of the innovation process), companies need knowledge to raise the success chances of the innovation (Moenaert et al. 1995).

Considering the exploratory nature of our research question, we have conducted a case study within a global, leading computer services company. We have investigated different electronic service support channels with varying degrees of knowledge cocreation by customers. Both desk research as well as in-depth interviews with managers, engineers and customers in combination with a literature review served as a basis for theory development.

Our chapter is structured as follows. We start by introducing our theoretical perspective. Second, we describe our case study research design that was developed within a global, leading computer services company. Thereafter, we present our findings in formulating a conceptual framework on the dimensions of knowledge co-creation and their impact on organizational knowledge increase and performance outcomes. Finally, we conclude the article by delineating managerial and research implications of this study.

\subsection{Theoretical Background}

The evolution and transformation of customers from passive buyers to active cocreators of value has been recognized (Prahalad and Ramaswamy 2003). For example, Practer \& Gamble initiated the "P\&G Advisors" program, where consumers help P\&G to develop new products by testing new items and providing feedback (Sawhney 2002). Hence, companies are exploring new sources of innovation. Customers are seen as one new source of innovation, as they communicate their knowledge, are willing to learn, and engage in active exchanges of ideas with companies (Prahalad and Ramaswamy 2000). Therefore, companies need to establish mechanisms to incorporate customers' knowledge.

This trend is to a great extent caused by the developments in information technology (Bolton, Day, Deighton, Narayandas, Gummesson, Hunt, Prahalad, Rust, and Shugan 2004). Especially in electronic service settings, the Internet has facilitated a cost effective mechanism to enable an interaction between customers and organizations as well as among customers. This communication process is increasingly characterized by a continuous dialogue (Vargo and Lusch 2004). Knowledge is not created by an individual mind, but is rather constructed through activities and interactions (Gupta and Vajic 2000). Hence, knowledge is co-created when companies engage in interactions with customers. Furthermore, information technology facilitates the global access of knowledge and gives organizations the opportunity to learn and store more information 
about the customer. Consequently, companies are able to customize and improve their services.

At the same time, the rolie of the customer has changed - "from isollated to connected, from unaware to informed, from passive to active" (Prahalad and Ramaswamy 2004, p.2). In electronic service delivery, customers are often providing the organization with a lot of information by just using the company's electronic services. Furthermore, customers increasingly provide voluntary feedback to companies. These two types of knowledge co-creation are interactions between an individual customer and the company. Knowledge is also co-created in customer communities where customers do not only interact with the company but also among each other.

\subsection{Case Study Research Design}

We have developed a case study research design at a leading, global computer company. The company has a wide variety of electronic service channels with different levels of customer co-production. Thus, we used multiple cases serving as comparison groups for one another. A case study can be defined as "... an empirical inquiry that investigates a contemporary phenomenon within its real-life context; when the boundaries between phenomenon and context are not clearly evident; and in which multiple sources of evidence are used" ( $Y$ in 1994, p. 13). An inductive manner is being used, as we move from observation to the development of hypotheses (Judd et al. 1991). Stated otherwise, the major function of our case study research effort is "discovery" in which we focus on the heuristic view in science. "The heuristic view in science emphasizes theory and interconnected conceptual schemata that are fruitful for further research. A heuristic emphasis is a discovery emphasis." (Kerlinger 1986, p. 8). Thus, a case study research and a literature review were used as a platform for theory development. Reflective reasoning (Kerlinger 1986) entered the research process during the literature analysis and has led to the design of a research set up to falsify the constructed research hypotheses. The case study data are being used for theory developiment following the process proposed by Eisenhardt (1989, p. 533) and Lievens, Moenaert and S'Jegers (1999b, p. 25):

1. Formulation of research question containing preliminary constructs: knowledge cocreation, organizational knowledge, perceived service quality, innovation

2. Theoretically useful cases were selected. Three different electronic service channels were chosen with varying degrees of knowledge co-creation (i.e. low, medium and high). As discussed in the theoretical perspective, customers co-create knowledge by using a company's systems, providing feedback and producing information in 
customer communities. Therefore, we were looking for these kinds of service channels where customers co-create knowledge to a varying degree.

A manager from the electronic service delivery team was chosen as focal contact and was informed about the case selection criteria. In order to maximize research validity, we asked the contact manager to select electronic service dellvery channels that fulfilled the following criteria:

(1) the company is currently using the electronic service channel

(2) customers are involved in varying degrees of knowledge co-creation

Following these requirements, three electronic service support channels were selected based on varying degrees of knowledge co-creation by the customer. Indepth interviews took place with inwolved managers and engineers from the company under study and some customers.

An embedded case study design was used (Yin 1994), because multiple units of analysis were defined (program level, service channel, organizational level, customers). The first channel (low level of knowledge co-creation) is a self-service technology where customers search in a knowledge database for solutions to their technical problems. Their search behavior is used to list the documents that have been used most often by customers. The second channel (medium level of knowledige cocreation) is concerned with proactive feedback provision. On every website of the company, the customer can immediately click on an online form to provide his/her opinion about the product or service. The third channel (high level of knowledge cocreation) is a virtual customer community where customers interact with other customers to ask and answer each others' questions. An extensive description of the three different channels can be found in table 4.1. 
Table 4.1: Level of customer co-production

\begin{tabular}{|c|c|c|}
\hline \multicolumn{2}{|l|}{ Low } & \multirow[b]{2}{*}{$\begin{array}{l}\text { Self-service technology } \\
\text { Customers search the knowledge content } \\
\text { websites of the organization to find } \\
\text { solutions to their problems. The online } \\
\text { search behavior is tracked and used to } \\
\text { identify the most requested documents. } \\
\text { These documents are then presented as } \\
\text { the frequently asked questions (FAQs). The } \\
\text { customers are not aware that their online } \\
\text { behavior is used as input for this service. }\end{array}$} \\
\hline & Short description & \\
\hline & Strategic objective & $\begin{array}{l}\text { The objective is to locate and present to } \\
\text { customers the documents that customers } \\
\text { used most often to solve their problems. } \\
\text { The company wants to show customers } \\
\text { how they can easily help themselves by } \\
\text { providing technical documents in a simple, } \\
\text { fast and convenient way. }\end{array}$ \\
\hline & Service delivery & $\begin{array}{l}\text { Customer usage behavior is the input for } \\
\text { this service. It is tracked which documents } \\
\text { are frequently opened and read, receive } \\
\text { positive feedback and resolve special } \\
\text { requests/situation. Customers with a } \\
\text { support contract can access this service } \\
\text { and search for solutions to their problems. }\end{array}$ \\
\hline \multicolumn{2}{|l|}{ Medium } & Proactive feedback provision \\
\hline & Short description & $\begin{array}{l}\text { Customers proactively provide feedback } \\
\text { about the company's products and } \\
\text { services. On every website of the company, } \\
\text { the customer can Immedlately click on an } \\
\text { online form to provide his/her opinion } \\
\text { about the product or service. Customers } \\
\text { will then receive a reaction by the } \\
\text { company. }\end{array}$ \\
\hline & Strategic objective & $\begin{array}{l}\text { Customers can express their concerns and } \\
\text { problems with products and services. } \\
\text { Customer feedback provides the company } \\
\text { with indications that they are right on track } \\
\text { (or not) concerning their services, products } \\
\text { and strategles. The company can gain low } \\
\text { cost information about customer } \\
\text { perceptions. Feedback provides the } \\
\text { company with input and ideas for } \\
\text { innovating existing and new products and } \\
\text { services. }\end{array}$ \\
\hline & Service delivery & $\begin{array}{l}\text { Service delivery is mainly done via e-maill } \\
\text { when customers receive a reaction by the }\end{array}$ \\
\hline
\end{tabular}




\begin{tabular}{|c|c|c|}
\hline & & $\begin{array}{l}\text { company. This reaction will include a } \\
\text { statement how their feedback has helped } \\
\text { the company to mprove the products and } \\
\text { services and especially the knowledge } \\
\text { content of the websites. }\end{array}$ \\
\hline \multicolumn{2}{|l|}{ High } & Customer virtual community \\
\hline & Short description & $\begin{array}{l}\text { The customer virtual community is an } \\
\text { online technical support forum where } \\
\text { customers provide technical advice and } \\
\text { interact socially with other customers. The } \\
\text { company provides the technical platform } \\
\text { and moderates the discussion boards to } \\
\text { avoid swearing and inappropriate language } \\
\text { (e.g. user names like "Osama bin Laden" } \\
\text { get removed). }\end{array}$ \\
\hline & Strategic objective & $\begin{array}{l}\text { The mission of the online technical support } \\
\text { community is to be the meeting place for IT } \\
\text { professionals to collaborate peer-to-peer. } \\
\text { enabling the exchange of best practices } \\
\text { and ideas. Information exchanges result in } \\
\text { an IT community that has a community- } \\
\text { wide understanding of common IT } \\
\text { problems and solutions. }\end{array}$ \\
\hline & Service delivery & $\begin{array}{l}\text { This service is freely accessible, as } \\
\text { customers mainly interact with other } \\
\text { customers. The service is dellivered via } \\
\text { online discussion boards where one can } \\
\text { freely ask and answer questions after } \\
\text { registering as user. }\end{array}$ \\
\hline
\end{tabular}

3. The data collection methods of our case study research included both desk research and field research. Firstly, desk research was based on internal company documents to obtain a good understanding of the marketing and the technology strategy of the company. Secondly, field research has been performed through in-depth interviews with key informants for each channel (e.g. electronic service program leaders, gieneral e-service business manager, marketing managers, program team members, engineers, customers of the community). Qualitative research is inclined to use purposive, conceptual sampling instead of random sampling, hence, the sampling strategy was driven from theory rather than fulfilling the criteria of representativeness (Miles and Huberman 1994). The selection dimension has not been communicated to the interviewed employees, thereby avoiding bias.

In the first channel (low degree of co-creation), we interviewed the entire worldwide team ( 9 managers) responsible for this particular service. Similarly, in the 
second channel (medium degree of co-creation) we interviewed 11 managers from the team in charge. In the third channel (high degree of co-creation), not only the responsible managers ( 7 managers) were interviewed, but also 9 engineers and 7 customers, as they are active participants in the community. The interviews lasted between one and two hours. The questionnaire consisted of open-ended questions as this research is exploratory in nature. The check-list contained the following subjects: (i) the strategy for the service channel, (ii) the role customers play in knowledge cocreation, (iii) the manner in which the company handles the customer knowledge, (iv) how customer knowledge serves as input for innovation, (v) how customers evaluate the service channel. The interviews were taped and transcripts were written out afterwards.

4. The transcripts of the interviews were used to perform a thematic content analysis. The case study research process comprised an inductive process (Kerlinger, 1986) as we moved from observation to hypotheses development. Thus, the case study data were screened for content themes relating to knowledge co-creation.

5. A model has been constructed through an iterative process involving (i) a comparison with the relevant literature and (ii) a confrontation during a feedback workshop with the interviewed employees. Relevant literature was taken from various areas, including information technology, service encounters, information processing in consumer behavior, service quality, and innovation management.

During the course of the case study research, several feedback sessions were organized with the contact manager from the electronic service delivery team. This person provided us with the necessary context variables we needed to acquire in order to obtain a more fine-grained insight in the processes and some of the findings. Moreover, the feedback sessions enabled us to steer and change our data collection procedures if necessary. Thus, we could assess the plausibility of the data Interpretation as well as search for new cues. For each service channel, we prepared a detalled report with our findings, which was sent out to all participants. The results for each case were also presented to the interview partners during feedback sessions.

Next, we generate a set of propositions that relate specific customer roles and the respective knowledge co-creation to knowledge. The increase in organizational knowledge will result in improved performance, represented by better service quality and improved information input for the upfront innovation activities. 


\subsection{Findings}

Based on the case study findings, we first define knowledge co-creation by the customer, followed by a discussion of the different roles customers play in knowledge cocreation. Second, we examine the effect of each role on two different types of organizational knowledge increase, objective knowledge and subjective knowledge. Thereafter, we present our findings on the influence of organizationall knowledge increase on perceived service quality and information input for upfront innovation activities. Our propositional framework is summarized in figure 4.1 .

Figure 4.1: Conceptual Framework

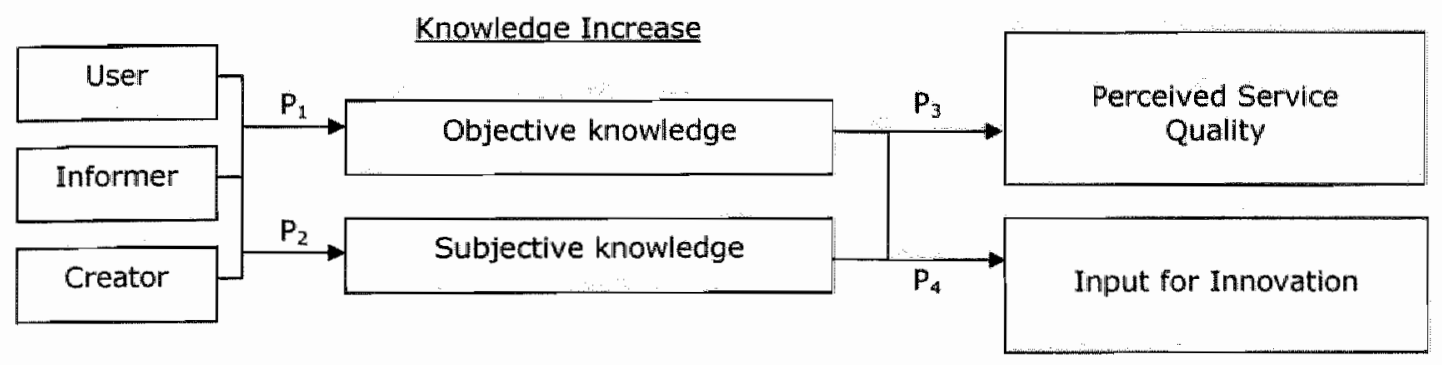

\subsubsection{Definition of knowledge co-creation}

Companies have recognized the importance of customer knowledge integration into their strategic process. As a marketing program manager realized:

Basically, customer feedback and in particular the new Internet technology are making the customer the center of our activities, instead of us delivering the strategy or product and hoping that the product meets the customer needs. Therefore, we want the customers" feedback. If our products and services do not meet customer needs, through the Internet technology, the customer will stop using our services and will go somewhere else. He has the choice and is no more bourd to geographical limitations.

As customers communicate their knowledge to companies, they become cocreators of the company's services. Hence, knowledge co-creation is defined as the degree to which customers proactively deliver information for a specific service. The company under study realized that their customers provide a so far untapped resource of knowledge. As a customer service manager stated:

We came with the idea that the knowledge is not only on the side of our company, but is also on the side of the customer. So, we need to offer them some ways to exchange their knowledge with us and also between each other.

Furthermore, knowledge CD-creation provides organizations with knowledge about both their service content as well as their service delivery. Hence, mainly knowiedge is provided on two general topics, as a marketing manager pointed out: 
We make a differentiation between feedback on the content itself and feedback on the structure of our websites. In the first level, we analyze the feedback on the quality of the content whereas in the second level we analyze the feedback searching for information on for example a missing link.

In addition to these two knowledge topics, all of the created knowledge comes from daily business in a relatively cost effective manner. Instead of organizing expensive and unrepresentative meetings with customers, e.g. focus groups for marketing research, the company recelves knowledge during their daily operations in easily tracked situations. The marketing program managers stated:

We want to gather customers" feedback on their experiences and on what could" be improved. There is also a financial aspect, as a one on one meeting where we ask customers for their opinions will cost us a lot of money. If we invite the customer to provide feedback on a normal daily business basis, we get a very sincere and open type of feedback. The feedback is not driven by the situation in which the customer is at that moment. Before, we invited customers for a trip to a mice location in another country where we were paying all the costs. In that situation, customers may have a more positive attitude about our services. So now, we receive customer feedback that is more operational and presents a cheaper solution to receive customers"opinions.

Thus, the knowledge co-creation is a process in the daily business of companies, where customers have many opportunities to deliver their information to the company. Continuously tracking customers' information provides an early alert mechanism for new and changing customer needs (Urban and Hauser 2004). Furthermore, it is much more effective and accurate to capture customer knowledge when they are in their daily business setting instead of some artificial situation (Nambisan 2002). Contingent upon the varlous electronic service channels, customers play different roles in the knowledge co-creation proces5. These roles will be identified and discussed in the next paragraph.

\subsubsection{Customer roles in knowledge co-creation}

We identified three different roles customers play during the knowledge cocreation with the company: user, informer and creator. These roles differ in the degree of active knowledge co-creation. Each role will be discussed subsequently.

\section{4 .2 .1 Customers as users}

The role of the user represents the lowest level of knowledge co-creation. Customers mainly play this role in the electronic service channel of self-services. Customers search online in the knowledge bases of the organization to find solutions to their problems. This online behavior is tracked by the company to identify the most common problems and deliver solutions to those problems on a specified site. Hence, the 
usage behavior of the customer is the input for the identification of the most common problems. The identification is done through a mathematical algorthm. Documents are identified by an automated process that inwolves an algorithm specifically designed for selecting the most requested documents. The algorithm cansiders the following parameters: (1) how many times a document was opened, (2) how long the documents have been opened (there exists a certain time window), and ( 3 ) how many unique individuals have opened the document.

When a customer performs the role of the user, he/she is not aware that his behavior is tracked and that this information is used for the creation of the described service. Hence, his/her knowledge co-creation is quite low, as they do not intend to provide knowledge. Therefore, the employees need to make conclusions from the customers' behavior, as a customer service manager stated:

You can learn a lot of things from that, although there is not a direct interaction between our company and the customer.

They [the customers] give indirect feedback through their action with the document and this action is tracked. We know exactly the sequence of action. I take the input and I look at their behavior and then try to understand the perception of customers.

Although the customers are not aware of their knowledge co-creation, when performing the role of the user, companies that have electronic service channels can still exploit their customer usage behavior as an important information source. The acquired information is very helpful, as it is representative of many customers. A manager from the customer feedback team pointed out:

I look at what customers did on this website. We have a data warehouse, where all the clicks that customers did, are stored. There, I can access the customer behavior history for all customers. Then, I can consolidate all the information for each service. The customer behavior gives us a representative picture of what customers are experiencing.

Thus, the big advantage of knowledge created by users is the large representativeness, as customer online behavior information is aggregated over all customers participating in the online self-service technology. Some research has already proposed that customers are resources that can support companies in providing an effective service delivery system (Lengnick-Hall 1996; Lengnick-Hall, Claycomb, and Inks 2000). In summary, the first role that customers can perform is the role of the user, which is a relatively low level of knowledge co-creation, as the customer is not aware that his behavior creates knowledge for the company. Furthermore, it is very representative information. 


\subsubsection{Customers as informers}

Tracking the customer behavior is useful, but does not provide the company with qualitative information. Companies also need to know the perceptions customers have of their services. Therefore, customers should also play the role of the informer, as a knowledge program manager explained:

It would be good, if we could find out what the customers really need to know. We could use it not only for this program but for our whole knowledge management program. We often use our gut feeling and try to put ourselves in the customers' shoes. If we could really find out what the customers want to know or what they need at a certain point in time, we could greatly improve our service. Our algorithm tells us which documents are accessed, but that is all. It gives us the access but not whether the document was helpful. It could be that the customer found this document and it helped him with a part of his problem. But maybe it did not fully answer his question. Furthermore, documents that are large often get a lot of hits because many keywords are found within the document. Then, ten different customers are accessing that document for ten different reasons.

Thus, the company also needs customers that perform more active roles, such as the informer. When customers are informers, they actively point to problem areas in online documentation, for service delivery or with respect to products and services. Hence, they provide information about problem areas, but do not deliver solutions. In the self-service technology, customers can always click on a feedback form. At this form, they can express their concerns, critics, and positive experiences. Similarly, in the customer community customers inform the company and other customers about their problems with products, services and the service delivery in the community. This information helps companies to specifically look for problems where customers cannot find a solution, as a customer service manager stated:

From the feedback, we learn what customers like to see in the future, we also leam what documentation is not clear to them. So there, we need to improve our documentation. We can also detect certain trends when many customers ask for similar things.

Furthermore, customers inform the company about many different aspects. A marketing program manager and a customer service manager explained:

It starts with the basic things, like it is difficult to navigate on your page, I would like to have this link upfront instead of having it ten clicks later, or customers realize our actions. For example, our availability of services was very low last year, at about $65 \%$, now it is $90 \%$. Customers come back to us and say that they see our efforts and we see that things are up and running. We are sure that we did not waste money and time. We also receive information on services that we do not provide directly, e.g. the telephone 
support has long waiting times; my call has not been answered. We take this information and transfer it to the correct person to action it.

It is interesting because we learn that in terms of content the customers are expecting much more information, for example, they are expecting more drivers for the new operating systems, and they sometimes provide feedback about the products themselves, It is very useful. There is a wide range of different information categories.

Customers perform the role of an informer as they hope that their Information will help the company to serve them better. Previous research has recogmized part of this role when discussing customers as resources (Lengnick-Hall 1996; Nambisan 2002). However, these researches perceive customers as providing input during the service process itself. We see customers as informers also when they provide feedback while currently not being engaged in a service interaction. Customers not only benefit from improved products and services, they also use their role as informer to express their frustrations, as a customer complaint manager realized:

The customers benefit from raising their voice. It is good for them because they know they have a channel where they can express their frustration as well as their happiness with the system. They also hope that the problems they had in the past will diminish, as the content and the access is improved. We have to ensure that what we do make customers happy and that we are taking the right action. And you have to send a signal to the customers that you appreciate their feedback and that you are taking this into account.

Hence, when customers are informers, they also expect the company to be more receptive to their information. Furthermore, whereas information coming from a user is not visible for other customers, information originating from an informer can be both invisible and visible. It depends on the channel choice of the customer. When the customer decides to act as an informer via the website feedback form or via e-mail, his/her information will not be visible to ather customers. However, in the community customers can also act as informers and provide similar and visible information, as the operational manager pointed out:

We certainly gain insights about customer needs. In the past, we have used the community to test new product areas. It is a very easy way to sense customers and receive information from them. The spectrum of possibilities to receive feedback has increased. Additionally, we get feedback on how well our community and our services are performing.

Thus, companies can also actively encourage customers to act as informers. Thereby, they can receive information about how their current services are perceived and whether they need to improve existing or innovate new services. Although customers as informers represent a very useful source of information, the customers have to actively 
engage themselves. Not all customers are willing to take the time and effort in providing information to the company. Hence, only a limited number of customers provide feedback. Therefore, companies need to consider that the gathered information might not be representative for all customers. A marketing manager explained:

We are used to gather information from some customers, but today this information is not always representative. That is a problem. We need a larger set of customers that confirm the information we have collected. This information would confirm that our NPD teams are developing products and services many customers want.

In summary, the second role that customers can perform is the role of the informer, which is a medium level of knowledge co-creation, as the customer reports problem areas to the company but does not bring up any solutions. However, companies need to consider whether the delivered information is applicable to a wide range of customers.

\subsubsection{Customer as creator}

In the low and medium situations of knowledge co-creation, the interaction between customers and the company is one-directional, as either the behavior of the customer triggers knowledge or his information leads to new insights. However, when customers become creators, interaction gets more bi-directional. A creator does not only inform the company about problem areas. He/she also makes suggestions and provides solutions, so that new knowledge is created. In the customer community, customers provide solutions to each other. These solutions often extend the knowledge provided by the company, as two customers pointed out:

In the company services, questions sometimes arise that the company support never answered satisfyingly. In contrast, in the community you get at least some hints and stimulation and sometimes even answers from other customers. Moreover, the company employees also learn in the commumity, especially the technical engineers.

There are definitely some important people in the community that have real-life experience; they share their context knowledge and experience, they obtain knowledge, they go out to see what people have done, to see certain problems and certain issues.

This knowledge is not focused on a specific aspect. Instead, a wide range of topics is covered, as two other customers explained:

There is a wide range of information, specifically when the community started, it was primarily used to exchange information on operating systems, but now there are all kinds of different topic categories where you can access a lot of different knowledge.

The questions that are asked in the community are very mixed. Some are surprisingly new and really creative. Issues are discussed that I never had thought of doing or even asking about. 
Furthermore, customers as creators add knowledge, as they exchange their experiences on working with the products and services. They can inform other customers and the company about how the different products and services are applied in the customer environments and provide contextual information. Furthermore, especially in technicall environments, customers use combinations of products and services companies might not have been tested before, as two customers and one engineer stated:

The community and the presented solutions are better, as customers often really have the experience on what definitely works. Sometimes the people in the support center do not necessarily know what is going on in our (customers) environments. A lot of times there is more real time information.

Often the company engineers may know the products very well, but they do not know the real world applications of these products. The customer community goes beyond just problem solving because it offers experience and backup, it is one thing to know how a product works but it is another thing to know how a product works in the real world and in relation to ather products.

There is a lot of interaction and there are many experiences that we (company) do not have, as we cannot test all scenarios with mixed equipment. We test our operating system on the most common things and we cannot help with everything, if customers are running applications that we have not tested: The users all have different environments, which allow them to give their two cents and help other people by telling them their experiences. If we cannot help these customers, they might go to another company.

Despite providing knowledge about different applications and environments, the customers often also show multiple answers to the same problems, increasing the learning possibilities for both the company and other customers. Three customers explained:

The technical knowledge database and the community are still different as sometimes the database gives specific textbook answers whereas the community people are a bit more conversational, For example, they state: "if you have this, watch out for this." So, the community people are more interactional and you receive more information. In the community you get multiple answers.

Every person has another experience of a particular problem and how they solved it. When I have a problem and ten people reply, I get at least 5 different answers. $I$ can choose my own approach over there and I might not follow an approach that I have thought of before on my own.

Well, the nature for the information is quite broad, When you only take a look at the [.] category, you find many possible solution approaches for one problem. I once tried different approaches on an old machine that we had and I was really surprised that all of them worked. 
As the community provides a platform for transparent knowledge co-creation, customers are very grateful for the learning opportunities. When the customers learn in advance about potential future problems, they are better prepared and also reduce assistance costs of the company. Two customers and the operational manager of the community stated:

I continue to learn from the community, there is not a single day where I do not discover something that I did not know before. There is so much knowledge; I continue to be impressed by the value of the community.

$I$ can expand my existing knowledge without devoting a lot of time and creating costs. The leaming effect is enormous, sometimes $I$ read things and $I$ wonder why $I$ never tried that myself.

The customers spent some time in the community to learn. So, in the future when the problem will come, they will know the solution immediately.

Whereas the previous two roles, user and informer, have a purely functional focus, the creator is also interested in social interaction. The community provides an ideal place where customers (and company) cannot only exchange task-related information, but where they can also form interpersonal relationships, as several customers indicated:

We feel a sense of belonging. In the community, you meet other people, who have the same interests. You have an opportunity to get together and discuss things.

I have also met people from the community in person at the annual conference last year and I have gained several new friends.

You have a personal touch with people who have the same experience, who run into the same kinds of problems and who know what to do and what not to do.

I like the community because of the social interaction with people from different companies and different backgrounds. We also have social interactions, for example on career opportunities or jokes related to our jobs.

A study by Nambisan (2002) has also recognized the qualification of customers to support each other. He agrees that customers often acquire experience and knowledge, especially on the usage of products and services. Furthermore, the co-creation of knowledge is facilitated, as peer customers often have simllar service experiences. Hence, they have a better understanding for each other contributing to the product support success (Brown and Reingen 1987). In summary, the third role that customers can perform is the role of the creator, which represents a high level of knowledge cocreation, as the customers contribute to problem solving and create new knowledge themselves. 


\subsubsection{Organizational knowledge: Objective vs: subjective knowledge}

The intense participation of customers in the electronic senvice delivery process co-creates knowledge for the company. Hence, organizational knowledge increases. Research in consumer behavior has a long tradition of distinguishing between objective knowledge, i.e. the accuracy of knowledge, and subjective knowledge, i.e. the confidence in the knowledge (e.g., Brucks 1985). We use this distinction, as we found these two types of knowledge in the organizational context of our cases when customers co-create knowledge. One business development manager stated:

The customer gives us his knowledge, for example, impravement suggestions. So, we can realize which processes do not work correctly. Sometimes, we also get to know where we provide things that customers do not want and where we are not sure what they actually want.

The first kind of knowledge this manager describes refers to objective knowledge, while the second kind of knowledge implies subjective knowledge. Following Alba and Hutchinson (2000), we define objective knowledge as how accurate the knowledge is that the employees have about customer perceptions of the product and services. Subjective knowledge is how confident the employees are that the knowledge about the customers' perceptions of the product and services is correct. The different customer roles during knowledge co-creation generate different kinds of knowledge. Therefore, the impact on objective and subjective knowledge is distinct for each role. We first discuss objective knowledge and how the different customer roles increase objective knowledge. Thereafter, we turn to subjective knowledge and the various impacts of customer roles on subjective knowledge.

\subsubsection{Objective know/edge}

Organizations have the opportunity to use the information from customers in order to increase their awn knowledge. One knowledge manager explained:

We can capture knowledge. It is interesting to see the perspective of the customer and how engineers are capturing the information and accordingly create documents. Engineers become further educated, it's kind of a real-time training. We also benefit from the wider view of the customer, specifically how different products are integrated. A lot of our engineers only have the organizational perspective on products, while customers are integrating our praducts with ather products. So, seeing their experiences is very helpful.

Consequently, organizations can use the customer information to train their engineers. Furthermore, they can introduce new employees to their jobs and raise their awareness of current customer problems. One engineer stated:

I actually recommend the online community when we get new people. It is really a very good training. They get a good insight into the wide variety of issues that our 
customers are dealing with. Receiving customer knowledge also helps us to know what our users are doing right now. We can see what is really going on out there and it gives us a feeling for what the users are actually using and doing right now today.

Thus, employees get a wider view on their tasks, as they have more information available. The knowledgle co-creation by customers means that employees" knowledge together with customer knowledge is combined into a superior organizational knowledge base (Sawhney and Prandelli 2000). Alba and Hutchinson (2000) agree that greater amounts of knowledge should result in more fully informed decisions. Therefore, the more knowledge customers co-create, the higher the increase in objective knowledge. During the role of the user, customers co-create the least knowledge relative to informers and creators: One customer service manager stated about the user:

There have been some issues that we could identify through the tracking of the customer behavior, like seeing which documents are perceived as useful and which ones are not used at all. But beyond, we do not get a lot of information on how customers see our products and services.

In contrast to the information that the user provides through his behavior, the informer already has a higher impact on objective knowledge. As an informer provides more focused information, the employees can build up their knowledge base in a more specific manner. The creator has an even bigger impact on the increase of objective knowledge. One operations manager explained:

Our engineers receive a higher variety of answers. The customers are using the products and typically the best information is from people who have literally done that and maybe nat our official textbook support. We know the products but the vast majority of our engineers have never used them in a production environment.

Similarly, an engineer stated:

I learn lots of stuff from customers knowledge, things a customer tried and how it worked. I get alternatives sources of information.

Therefore, employees learn from customer co-creation of knowledge, where the role of the creator has the highest impact on objective knowledge. This is also fostered by the social relationships that develop between customers and employees in the virtual community. Social relationships increase the knowledge sharing behavior (Mclure Wasko and Faraf 2000; Thomas-Hunt, Ogden, and Neale 2003). Hence, the capturing of customer knowledge fuels the knowledge creation process (Nambisan 2002). Therefore, we propose:

$P_{1}$ : Knowledge co-creation by customers increases the organizational objective knowledge, where the knowledge co-created by the user has the lowest impact, the informer has a medium impact and the creator has the highest impact on abjective knowledge. 


\subsubsection{Subjective knowledge}

Organizations do not only increase their objective knowledge, but they also improve the confidence in their knowledge base, i.e. they are able to increase their subjective knowledge.

Thus, the knowledge co-creation increases employees" confidence that the knowledge is correct. A marketing manager explained:

The knowledge created by customers is a validation of what we already know. It is easier for us to improve our knowledge when customers give us a lot of feedback. We can assure that we are working on the hot issues.

Subjective knowledge is created when persons become more self-confident about their own abilities (Bearden, Hardesty, and Rose 2001). Hence, in an organizational context such as our case study, employees become more self-confident about their own knowledge. The three user roles co-create different types of knowledge; thus, the impact of each user rale on subjective knowledge is also different. Confidence in knowledge is mainly created through two knowledge features: representativeness of the information and perceived trust in the information. When employees think certain information is representative and applicable to many customers, their confidence in that information will increase. Furthermore, when employees feel that they can trust the customer to provide correct knowledge, their confidence in that knowledge will increase likewise. Projecting these two knowledge features on the customer roles during knowledge cocreation shows that the user co-creates highly representative knowledge, whereas the creator co-creates knowledge with a high perceived trust.

The knowledge created by a user mainly reflects customer behavior and is characterized by a very high representativeness due to the accumulated data of many customers. Thus, the impact of knowiedge created by a user on subjective knowledige is relatively high. A customer service manager pointed out:

The information from tracking customers' behavior is very representative. Therefore, we can be sure that the knowledge we build from that information is widely applicable to many customers.

In contrast, the informer does not have such a big influence on subjective knowledge, as employees are aware that the feedback often only comes from a small group of customers and has hence a low degree of representativeness. Therefore, their confidence in the knowledge co-created by informers is lower. As one customer service managers stated:

We really use the feedback that customers send to us, but the feedback itself is not enough, because it is not representative at all. Only a small number of customers 
send us feedback at the moment. We camnot be sure that our conclusions from the feedback are really correct.

Although the knowledge co-created by the creator also often originates from a small group of customers, the interactions between customers and employees are perceived more intensely. When the customer provides not only information, but specific knowledge, employees feel that their customers are highly educated and knowledgeable about the products, services and their real-life applications. As one engineer pointed out:

Whereas often engineers may know the products very well, we do not know the real world applications of these products. That is one of the reasons why we think that the customer knowledge is very useful. It goes beyond just pointing out problems because it offers experience and backup. It is one thing to know how a product works but it is another thing to know how product works in the real world and in relation to other products.

Another engineer explained:

Through the customer knowledge that we receive, I can improve my individual technical knowledge but also the knowledge for the company. You have to see that the provided information is often very accurate and correct, if someone posts a wrong thing, the community is self-regulating and other customers come and correct it.

Furthermore, most of the knowledge is co-created in the online community, as it is a very good outlet for experience sharing between customers and the company and among customers. In the community, social relationships develop (Bagozzi and Dholakia 2002). The social relationships add a human dimension to the service, both for customers as well as for the participating employees. Subsequently, the employees feel mucth closer to the customers (Armstrong and Hagel III 1996). This closeness will increase their confidence in the co-created knowledge. Summarizing, we think that knowledge co-created by the user and the creator have a higher positive impact on subjective knowledge than the knowledge created by the informer. Therefore, we propose:

$P_{2}$ : Knowledge co-creation by customers increases the organizational subjective knowledge, where the knowledge co-created by the user and the creator has a higher impact than the knowledge created by the informer on subjective knowledge.

\section{4,4 Outcomes: Perceived service quality and input for innovation}

The increase in objective and subjective knowledge positively impacts perceived service quality and stimulates and shapes the innovation activities. As an operations manager explained:

When we learn from customer knowledge, we can improve our existing service capabilities, as well as gather insights for our development projects. 


\subsubsection{The impact of organizational knowledge on perceived service quality}

Research on service quality has shown that the more knowledgeable an organization is about customer expectations and needs, the better it can service these customers (Berry et al. 1990; Sheth, Sisodia, and Sharma 2000). Based on Zeithaml, Parasuraman, and Malhotra (2002) and Parasuraman, Zeithaml, and Berry (1988), we define electronic service quality as the extent to which electronic services are perceived to be excellent and superior. Knowledge co-creation by customers and the resulting increase in organizational knowledge influences perceived service quality through various means. First, the organization discovers customer requirements and service expectations. A marketing manager pointed out:

Once we have received all the customer created knowledge, we know about customers' experiences with our products and services, what they did and whether they found the necessary information. For example, we gain knowledge about broken hyperlinks, whether all URLs on our sites are accessible. We also get to know how and for what purposes the customers use our sites and what technical issues are important. We can use this knowledge to deliver better services, as we get a better feeling for what they want.

So, knowing the customer requirements better helps organizations to delliver better services (Berry et al. 1990; Sheth et al. 2000). Furthermore, organizations can exploit the dynamics of electronic services by providing the most recent information to their customers. A customer service manager explained:

Customers can get information on the latest problems, the latest updates, so they receive very recent information. Usually they get higher quality documents, as we received feedback on these documents and incorporated that into the documents.

Hence, the more knowledge the customers co-create, the more the organization will learn about their requirements and the better they are able to serve them. Furthermore, customers co-create knowledge that entalls unlque perspectives and unique sources of competence. Companies can use these experiences to improve their existing services and hence raise service quality perceptions. If they do not encourage the knowledge cocreation, they miss opportunities, as a business development manager stated:

By discarding the customer feedback and comments we miss the opportunity of improving the quality of our support content, enhancing our service delivery tools, and increasing overall customer satisfaction.

Consistent with existing literature, more knowledgeable employees are better in delivering services that match customer needs (Roth and Jackson III 1995). The employees' knowledge improves service quality by reducing organizational uncertainty, decreasing process variabillty, and advancing a firm's ability to adjust to new conditions.. 
Furthermore, when knowledge is co-created by customers, they feel part of the service and closer to the organization. Hence, they often have a better understanding of the organization's situation and might become more tolerant towards mistakes (Bearden, Maihotra, and Uscategui 1998).

$p_{3}$ : The increase in organizational knowledge positively impacts perceived service quility.

4.4.4.2 The impact of organizational knowledge on the information input for the upfront innovation activities

More knowledgeable emplayees are not only better in delivering services that are consistent with customer needs, but also in designing new processes, products and services (Roth and Jackson III 1995). The knowledge co-creation by customers helps companies to increase their organizational knowledge and subsequently, they can use the co-created knowledge to improve the information input for the upfront innovation activities. Companies can identify problem areas, as a knowledge manager, a customer service manager, and the inbound marketing manager explained:

Based on the customer input, we have developed some new praducts and services. e.g. the usage of the web interface has been improved. Through the customer feedback, we realized that a certain document type created problems, so we developed a salution for that.

We always receive information on problem areas, both in our products and services as well as in the service delivery. We can then check this information and initiate an innovation project to eliminate these problems.

We get some learning in terms of new product directions and certainly people that use this community like focus groups get insights into where should they take their products in the future. So, to a certain extent customer information serve as an input for the development of new services.

Customers do not only help companies to identify problem areas. They also provide concrete suggestions and ideas. The operational community manager and the North Aimerican regional community representative stated:

I actually go out there regularly and solicit feedback and look for enhancements and ideas suggestions. Accordingly, a roadmap is created and the developers will have their action items.

There are suggestions and good ideas. We keep in contact with a lot of customers and we encourage feedback on the community and also other services. This information heips us to explore new issues and commit resources.

Furthermore, the company can proactively ask customers for new features and requirements, as a marketing manager and an operations manager pointed out: 
The worldwide team that is responsible for the community made inquiries with the community by asking general questions, like "What do you think about our services, what shall we improve", to ask feedback from the commumity members. They provide their input and there are a number of innovations that came from customers. So, it is very useful to ask customers for their feedback.

In the past we have used the community to test new product areas. So, we have an easy way to engage customers in our innovation activities. We have seen development groups that have used customer feedback. Our development teams were thinking about some new ideas for a product or tool or also software, and they asked things like "how would you like that in the future" or "what do you think about this feature?". So, we can save thousands of dollars by just asking these people and not organizing a focus group for every littie feature.

Hence, companies can actively engage customers in their upfront innovation activities to provide informational input and especially encourage customers to generate innovation ideas. Research in innovation has argued that customers should play an essential role in innovation (Lilien et al. 2002; Morrison, Roberts, and von Hippel 2000). In knowledge cocreation, customers provide knowledge during their service experience. The monitoring of Internet behavior, where customers are in their natural settings, has the potential to reveal opportunities for innovation (Urban and Hauser 2004). Furthermore, a larger group of customers participates compared to focus groups and market surveys, enhancing the representativeness of the information.

Additionally, in highly dynamic market situations, changes might be so rapid that information collected at the beginning of an innovation project becomes obsolete during the project (Bhattacharya et al. 1998). Using repeated interactions with customers helps to validate new products and services while developing them. Thus, monitoring changing market conditions, like changing customer needs, enhances market knowledge of an organization and the degree to which market knowledge changes over time improves innovation effort (Marinova 2004). We propose:

$P_{4}$. The increase in organizational knowledge positively impacts the information input for the upfront innovation activities.

\subsection{Conclusions and implications}

Knowledge co-creation by customers is an evolving phenomenon within the domain of customer collaboration. The proliferation of information technology has opened up opportunities for companies to co-create knowledge with customers in a daily business setting under natural conditions. Hence, organizations have the advantage to capture knowledge from their customers in a cost effective marner and use it to improve 
their performance, by enhancing service quality and the information input for their upfront innovation activities.

We extend the existing literature on customer collaboration by providing a first examination into the phenomenon of knowledge co-creation by customers. We develop a propositional framework that identifies the different roles customers play during knowledge co-creation in electronic service delivery. The first role, the user, is characterized by a relatively low degree of knowledge co-creation. The co-created knowledge emerges from tracking customers' behavior in the electronic self-services of the organization. The customer is not aware and does not intend to contribute knowledge and the employees have to infer customers' perceptions from their behavior. The second role, the informer, represents a medium degree of knowledge co-creation, as customers provide information about products and services, but do not bring up solutions. The third role, the creator, corresponds to a high degree of knowledge co-creation because customers provide concrete solutions and transfer their knowledge to the company. While the information from users is representative, it does not directly capture customer perceptions. In contrast, organizational knowledge originating in the knowledge cocreation of informers and creators directly captures customer perceptions, but might sometimes lack customer representativeness. Hence, organizations need to consider how they can integrate the information gained from users with the information and knowledge from informers and creators. Companies need to stimulate more customers to act as informers and creators to collect more representative Information. Firms could consider rewarding customers for helpful feedback with, for example, bonuses, discounts or the status of preferred customers. Furthermore, customers that provide knowledge in the online community of the company under study are rewarded by receiving points. Thus, their status within the community increases the more points they accumulate.

We also contribute to the marketing literature by linking these roles to organizational knowledge and subsequently to performance outcomes. Hence, we show how companies can benefit from knowledge co-creation. The knowledge co-creation by customers increases objective and subjective organizational knowledge. However, companies need to ensure and stimulate internal knowledge exchange, so that the cocreated knowledge diffuses within the organization. Innovation teams can explore and exploit the co-created knowledge to invent new products and services. The organization needs to establish processes to dlstribute this kind of information to the employees that need it. Furthermore, the co-created knowledge helps organizations to better tailor their communication strategy to customers. Through the knowledge co-creation process, companles are closer to their customers and can better assess how products and services should be promoted. 
Finally, when companies react to customers that acted as informers or creators, they need to clearly communicate when a suggestion or idea cannot be implemented. Customers need to be informed about what is a realistic suggestion in order to manage the expectations the customers might have. When companies just disregard the customers' comments without communicating the reasons to them, they might feel disappointed when their ideas have not been implemented.

\subsection{Suggestions for future research}

There are some issues that our initial inquiry into knowledge co-creation by customers did not consider. We used multiple sources of information and an iterative analysis procedure in order to increase the validity of our constructs and the presumed correctness of our inferences (Yin 1994). The external validity of our case studies should point to analytical generalizability, which involves replication logic. The objective of the present case study has been to postulate research propositions rather than testing them. Therefore, it is necessary to test the propositional framework with a more conclusive research method, e.g. an ex-post facto survey or a longitudinal study. The latter approach may be advantageous as it can focus on the organizational knowledge increase over time.

Our case study research findings have explicitly shown how the knowledge cocreation by each customer role impacts objective and subjective knowledge. However, we could not draw any conclusions on the individual impact of objective and subjective knowledge on service quality and the information input in the upfront innovation activities based on our case study material. Future research could investigate whether objective and subjective knowiledge have different effects on service quality and the information input for the upfront innovation activities.

Finally, we did not investigate the motivation of customers to engage in knowledge co-creation. However, it is important for companies and for marketing theory to examine why customers would take the time and effort to share their information and knowledge. The interviewed customers in our case study spent on average 13 hours per week in the community to help others customers and provide advice. It would be linteresting to investigate their motivation and find out why customers co-produce information and knowledge. 


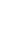




\title{
Chapter 5
}

\section{SERVICE CO-CREATION BY CUSTOMERS IN AN ELECTRONIC SERVICE SUPPORT SETTING}

\begin{abstract}
This stuidy investigates the motivational antecedents and performance consequences of service co-creation by customers in an electronic service support setting. This empirical study intends to contribute to the services marketing literature, as extant research has not yet focused on the antecedents and consequences of service cocreation by customers. We have conducted an online survey in a virtual technical support community of a leading global computer company. Our results show that fun and relational embeddedness are important motivations for service co-creation by customers. Furthermore, service co-creation and especially social interaction increase perceived service quality. Finally, we find that flow as a moderator contributes to our understanding of service co-creation by customers.
\end{abstract}


Knowledge is to be acquired only by a corresponding experience. How can we know what we are told merely? Each man can interpret another's experience only by his own.

\section{Henry David Thoreau (1817-1862)}

\subsection{Introduction}

Marketing is changing to a new lagic where the exchange of specialized skills and knowledge among a company's customers is becoming increasingly important (Vargo and Lusch 2004). Hence, customers need to actively participate in the delivery of services. Yet, the notion of customer participation is not new. Already in 1979, Lovellack and Young stress the importance of customers' participative behavior to increase productivity. Other research in marketing has examined customers as partial employees. (Mills and Morris 1986), the role of customers in service encounters (Kelley et al. 1990), the effects of customers' attitudes and behaviors on customer participation (Risch Rodie and Schultz Kleine 2000), customer voluntary performance (Bettencourt 1997) and the psychological impllications of customer participation (Bendapudi and Leone 2003). However, all these studies considered customer participation as a joint production between the customer and the firm. The recent technological developments and especially the upcoming of the Internet have made it possible to move from joint production beyond customer production to service co-creation by customers. In joint production, the service is produced as a co-operation between the company and the customer, whereas in customer production customers produce the service for themselves, often enabled by self-service technologies (Meuter and Bitner 1998). Whille customer production is resembled by self-services, we define service co-creation by customers as the degree to which the customer produces a specific service for other customers. Organizations benefit from service co-creation by customers, as they can acquire much more information about their customers. Furthermore, as inbound customer service costs are increasing, service co-creation by customers can help to reduce customer service costs while Improving the customer service process (Bettencourt, Ostrom, Brown, and Roundtree 2002; Bowers, Martin, and Luker 1990). Prahalad and Ramaswamy (2000) agree that nowadays corporations need to see customers as a new source of competence. The competence of the customer is contingent upon their knowledge and skills and their willingness to learn. Therefore, companies need to encourage a dialogue with their customers, create customer communities and co-create personalized experiences. So far, to our knowledge no research has considered and empirically investigated this type of service co-creation by customers. Service co-creation requires the customer to provide either information or effort to the company. But why would 
customers take the time and effort to provide information to other customers? Furthermore, how do customers evaluate a service provided to them by other customers?

In this study, we examine the motivations of service co-creation by customers and its impact on service quality in a high-tech service environment. We chose the context of an online technical support community, in which customers help others customers with their technical problems. In these communities, service co-creation by customers is the key feature due to the interaction between customers (Achrol and Kotler 1999). Furthermore, we introduce flow as contingency factor to better understand why customers spend their precious time and help other customers.

Thus, the contribution of this chapter is to extend existing literature on customer participation by considering the motivations that drive customers to co-create a service for other customers. Furthermore, we contribute to existing services marketing theory by examining the impact of service co-creation on perceived service quality. We develop a contingency framework on the motivations of service co-creation and social interaction and its subsequent impact on service quality based on different states of mind identified by flow theory.

This chapter is structured as follows. First, we discuss the concept of service cocreation by customers, highlighting the benefits for companies and customers. Next, we discuss the impact of service co-creation and social interaction on perceived service quality, before turning to the antecedents of service co-creation. After introducing the impact of flow theory on our conceptual model, we subsequently report on the results of an empirical study conducted in an online technical support community. We conclude the chapter with a discussion of the implications and directions for future research.

\subsection{Theoretical background}

\subsection{Service co-creation by customers}

Meuter and Bitner (1998) proposed a service production continuum with three different types of production: firm production, joint production and customer production. For example, in a restaurant customers are served with all they desire (firm production, low end of the continuum). In a fast-food restaurant, customers order and pay for their food at the counter and then take the food and seat themselves (Joint production, middle of the continuum). A typical example of customer production (high end of the continuum) is when a customer deposits money at an ATM, rather than using a teller. Here, the service is produced entirely by the customer, with no direct particlipation by the corresponding company. Previous studies have explored joint production (e.g., Bendapudi and Leone 2003; Kelley et al. 1990) as well as customer production of selfservices (e.g. Bitner et al. 2000; Meuter et al. 2000). We extend this continuum by introducing service co-creation by customers, which we define as the degree to which 
92 Chapter 5

customers produce a specific service for other customers. Figure 5.1 shows the extended continuum:

Figure 5.1: Extended Service Continuum, based on Meuter and Bitner (1998)

\begin{tabular}{|c|c|c|c|}
\hline production & $\begin{array}{c}\text { Joint } \\
\text { production }\end{array}$ & $\begin{array}{c}\text { Customer } \\
\text { production }\end{array}$ & $\begin{array}{c}\text { Service co-creation } \\
\text { by customers }\end{array}$ \\
\hline
\end{tabular}

Low

\begin{tabular}{|c|c|c|c|}
\hline $\begin{array}{c}\text { Firm produces } \\
\text { service }\end{array}$ & $\begin{array}{c}\text { Firm and customer } \\
\text { produce service }\end{array}$ & $\begin{array}{c}\text { Customer produces } \\
\text { service for himself }\end{array}$ & $\begin{array}{c}\text { Customer } \\
\text { produces serwice } \\
\text { for other customer }\end{array}$ \\
\hline
\end{tabular}

As we are interested in investigating this extended form of customer production, we have chosen the context of online technical support communities, where customers provide technical advice for other customers. These customers generate content for other customers rather than only consuming it as a self-service. Following Wiertz, de Ruyter and Streukens (2003), we define commercial virtual communities as online aggregations of customers who collectively co-produce content about a topic central to their interest. Online communities are platforms where customers interact with other customers by exchanging information. As technical advice is the central issue of the service, customers produce the core service for other customers and engage in service co-creation.

Extant literature on customer participation has focused on its positive outcomes for companies, such as cost reduction (Bowers et al. 1990), increased productivity (Lovelock and Young 1979), and customer satisfaction (Bendapudi and Leone 2003; Meuter et al. 2000). Whereas the first two outcomes focus on monetary gains, the latter examines more the psychological effects of customer participation. A second research stream has concentrated on the strategies to manage customer participation. Here, researchers have argued that customers should be treated as partial employees (Kelley et al. 1990; Mills and Morris 1986). In a similar vein, literature on the service encounter emphasizes the mutual understanding between employees and customers (e.g. Mohr and Bitner 1991). Another stream of literature within this area focuses on the roles customers need to perform (e.g. Bitner, Faranda, Hubbert, and Zeithaml 1997). Besides the roles that customers perform, Bettencourt (1997) examines customer voluntary behavior, such as cooperation, where the customer is a human resource, and participation, where the customer acts as organizational consultant. 


\subsubsection{Benefits to companies}

Service co-creation offers many benefits to companies. First, the customers generate technical content, which can be used as a knowledge base and results in organizational learning (Constant et al. 1994). Second, the company receives valuable feedback about their products and services. This feedback is often an important stimulus for innovation (McLure Wasko and Faraj 2000). The company can also actively seek feedback on newly developed ideas, thereby integrating the customer further in their innovation process. Third, the technical problem solving interaction between customers reduces the company's call center traffic. Fourth, the active service co-creation increases the technical knowledge of the community customers, thereby, lowering the actuall level of technical support needed by customers. The latter two will reduce the company's inbound service costs (Bettencourt et al "2002). However, decreasing costs are often associated with reduced service quality. Therefore, we need to explore whether service co-creation by cuistomers enhances or degrades service quality perceptions.

\subsubsection{Benefits to customers}

Not only companies achieve gains, also customers can realize compensation for their participation. Customers benefit from their active co-creation mainly through noneconomic consequences. Constant et al. (1994) propose that sharing expertise leads to increased self-esteem and pride, raised self-efficacy, more respect from others and a better reputation within the community. Hence, customers will feel they can express themselves, which raises their self-actualization. Furthermore, many customers percelve the online community as a deeper information environment compared to online published content (Hagel 1999). Often, a customer asking a question receives a diversity of viewpoints for the problem solution and the community members can learn which solutions solved the problem. The customers also interact with like-minded peers and hence feel a certain sense of belonging. Thus, they feel that the human interaction with other customers provides added value within the service offering.

\subsection{Hypotheses}

Our conceptual framework is summarized in figure 5.2 . We first discuss the impact of service co-creation on perceived service quality. Second, we examine the effect of social interaction on perceived service quality. Thereafter, we consider the motivational antecedents by discussing the impact of fun on service co-creation and social interaction, followed by the influence of relational embeddedness on service cocreation and social interaction. Fourth, flow theory is introduced by examining the contingency of our model based on different states of mind. 
94 Chapter 5

Figure 5.2: Conceptual Framework

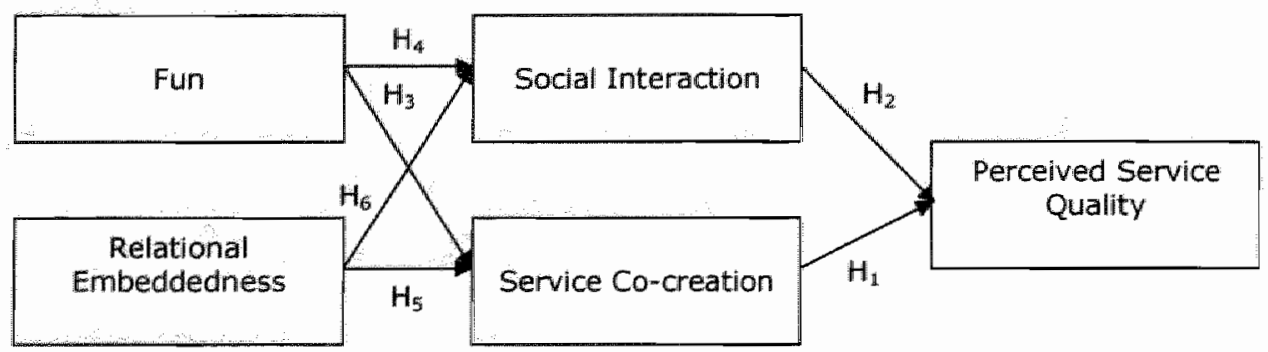

\subsubsection{The impact of service co-creation on perceived service quality}

Service co-creation in our context means that customers provide technical advice to other customers. Hence, they produce information. This information production shapes their expectations of the service. Furthermore, the active customer participation results in an identification with the service, as their own input becomes part of the service. Customers will evaluate the service better, the more they have contributed to the service themselves.

Similarly, service co-creation results in more committed customers, who tend to contribute to higher service quality (Kelley et al. 1990). The participative nature of the information production lets customers co-assure the quality of the service (Kellogg, Youngdahl, and Bowen 1997). Bendapudi and Leone (2003) find that customer satisfaction is contingent upon the customers" assessment of their own input. Therefore, we expect that service co-creation by customers will increase the customer's service quality perceptions. Thus, we hypothesize

H1: Serwice co-creation has a positive impact on perceived service quality.

\subsubsection{The impact of social interaction on perceived service quality}

Besides the production of informational content, the participation in the online technical support community involves also the interpersonal aspects of social interaction. Soclal interaction is defined as the exchange of social information, such as the discussion of personal problems, exchange of humor, etc. In the online technical community, the customers exchange their problems with regard to their jobs and specific activity-related humor. Social benefits have been identified as an important contributor to relationship building (Gwinner, Gremler, and Bitner 1998; Reynolds and Beatty 1999). According to Burnett (2000), sodial interaction consists of neutral behavior (pleasantries and gossip), humorous behavior (games and other types of play) and empathic behavior (emotional support). Similarly, Wellman and Gulla (1999) stress that social interaction in virtual 
communities helps to develop intimate and supportive relationships. It adds a human dimension to the interaction (Bumett 2000). Research has shown that the human dimension is very important for a high service quality perception (Price, Arnould, and Tiemey 1995; Zeithaml et al. 2002). Hence, the social interaction fulfils a specific human need (Reynolds and Beatty 1999). Furthermore, service encounter literature proposes that customers view the encounter as the service itself (Meuter et al. 2000). If the encounter is enriched with pleasant emotions through social interaction, the perceived quality of the service will increase. We hypothesize

H2: Social interaction has a positive impact on perceived service quality.

\subsubsection{Motivational antecedents}

An investigation of the motivations to co-create services and engage in social interaction is important in understanding why customers spend time for these activities. We have chosen to examine two intrinsic motivations, fun and relational embeddedness, as members in a social system often feel allienated when the system relies on extrinsic rewards only (Csikszentmihalyi 1975). A typical extrinsic reward would be a monetary incentive, while intrinsic rewards focus on benefits recelved through the activity itself (Deci and Ryan 1980). Osterioh and Frey (2000) found that intrinsic motivation is cruciai for the transfer of knowledge. We first discuss the impact of fum on service co-creation and social interaction, before turning to social network theory by considering the effect of relational embeddedness.

\subsubsection{The antecedent impact of fun}

Fun is defined as the extent to which the participation in the online technical support community is perceived to be enjoyable in its own right. Mathwick (2002) found that interactions in a community are often motivated by fun. Customers co-create information because they like to interact with other customers, they enjoy the participative nature of the community and/or they want to increase their self-esteem and reputation. Holbrook, Chestnut, Oliva and Greenleaf (1984) show that customers value the enjoyment aspect of computer software and games. Furthermore, they lifustrate the importance of hedonic aspects for customer consumption. The online technical support community offers certain playing aspects. These fun elements motivate the customers to be part of the experience. Hence, the customer behavior must be understood in terms of the hedonic benefits the online technical support community can offer. Similarly, Dabholkar (1996) argues that some people enjoy playing with machines, thus, customers who belong to that group may prefer the online technical support community over other service delivery options. Thus, fun creates an experience that engages customers in a 
personal, memorable way (PIne and Gilmore 1998) and increases social interaction and service co-creation. Thus, we propose

H3: Fun has a positive impact on service co-creation.

H4: Fun has a positive impact on social interaction.

\subsubsection{The antecedent impact of relational embeddedness}

We apply social network theory by considering the degree of connection between customers, i.e. relational embeddedness. Relational embeddedness is defined as the degree of reciprocity and closeness among the virtual community members (Rindfleisch and Moorman 2001). Social network theory has aliready been studied in the context of virtuall communities (Wellman 1997; Wellman and Gulia 1999). These studies have mainly concentrated on the discussion of strong thes versus weak ties within virtual groups. Furthermore, extant research has shown the importance of social relationships for information acquisition (e.g., Borgatti and Cross 2003), task-oriented learning (e.g., Brown and Duguid 1991) and complex problem-solving (e.g., Weick and Roberts 1993). Social network theory regards information flows among individuals as contingent upon both their social structure and their motivation to exchange information (Rindfleisch and Moorman 2001). Relational embeddedness is an intrinsic motivator, as it shifts people's motivations from the pursuit of immediate economic gains to the creation and improvement of relationships (Uzzi 1996). Hence, it supports the gaining of fine-grained information, as individuals who share direct connections know each other better (Gulati 1998) and understand better what the other one needs. Furthermore, individuals who are more relationally embedded in the network, are more familiar with other members than those who are less relationally embedded (Thomas-Hunt et al. 2003). The familiarity between members stimulates service co-creation, as they want to help those members they know. The interpersonal connections between customers increase their information sharing readiness to provide support to other customers (Bagozzi and Dholakia 2002).

Uzzil and Lancaster (2003) find that relational embeddedness leads to behavioral expectations of trust and cooperation. Similarly. Gulati (1998) shows that relational embeddedness establishes direct cohesive connections as mechanism for gaining information and relationally embedded people develop a shared understanding of the utility of certain behavior. Consequently, the establishment of direct connections diminishes uncertainty and promotes trust (Gulati 1998). In a similar vein, we think that relational embeddediness results in positive information production behavior and more social interaction. If the individuals feel more connected with like-minded peers, they will be imore motivated to produce information and interact socially. The interaction with likeminded people makes the rather technical Internet experience more human, as the 
members start to feel connected to each other (Sproull, Subramani, Kiester, Walker, and Waters 1996). Therefore, we hypothesize

H5: Relational embeddedness has a positive impact on service co-creation.

H6: Relational embeddedness has a positive impact on social interaction.

\subsubsection{The impact of different states of mind: flow theory}

Some researchers strongly recommend the investigation of moderating effects (e.g. Baron and Kenny 1986; James and Brett 1984). Following this recommendation, we investigate how the concept of flow acts as a contingency factor for our model. We think that the direct effects will be conditional to the general perception of flow that customers experience in the virtual community. Flow theory has already been used as a basis for studying compelling web experiences (Hoffman and Novak 1996; Novak, Hoffman, and Yung 2000). Novak, Hoffman and Duhacheck (2003) have found that flow is especially applicable for online experiences with goal-directed objectives. Csikszentmihalyi (1975) defines flow as an intrinsically motivated optimal state. Flow includes an intrinsic interest dimension, where the customer's participation is pleasurable and enjoyable as an end in itself. An often observed consequence of flow is that the customer works for the joy of the activity, not some other reward (Csikszentmihalyi 1975). Research has found that for computer users this activity results in greater experimentation and exploratory behavior (Ghani and Despande 1994). Especially, the fast interaction possibilities of online technical support communities contribute to the perceived enjoyment.

People are in flow when their skills match a task's challenge and both are above $a$ certain threshold (Csikszentmihalyi 1975; Ghani and Despande 1994; Mathwick and Rigdon 2004). Csikszentmihalyi (1990, p. 3) argues that "the best moments usually occur when a persons body or mind is stretched to its limits in a voluntary effort to accomplish something difficult or worthwhile". When challenges and skills experienced in the community are matched above some critical threshold, customers feel more active, alert, happy, satisfied and creative, regardless of the activity they are pursuing (Mathwick and Rigdon 2004). Furthermore, they often show a higher level of concentration. However, if skills and challenges do not correspond above that threshold, the quality of the experience begins to deteriorate. Following Massimini and Carli (1988), we concentrate on a four channel model about flow, which identifies four states of mind: flow (high challenges and high skills), apathy (low challenges and low skills), anxiety (high challenges and low skills), and boredom (llow challenges and high skills).

Flow. Virtual community members, who are in a state of flow, become highly concentrated on the task and feel more involved, creative and satisfied (Massimini and Carli 1988). Furthermore, the experience of flow has been associated with fun, 
participatory customer behaviors, future voluntary computer interactions, the amount of time consumers spend online and positive subjective experiences (Hoffman and Novak 1996; Novak et al. 2000). These flow outcomes suggest that fun, service co-creation, social interaction and percelved service quality will increase in environments where customers experience high challenges and high skills. We think that relational embeddedness is not influenced by the state of mind, as it rather reflects the connections between customers. These connections develop over time. Customers who participate in the online technical support community for the first time will have no connections yet, but can still experience flow.

Apathy. Apathy is the opposite of flow, as both challenges and skills are low. Concentration, creativity and satisfaction are decreasing substantially (Massimini and Carli 1988). Customers will show little intrinsic interest in the activity. Hence, in comparison to flow, customers will experience less fun, have a lower level of service cocreation, have a lower level of social interaction and will perceive a lower level of service quality in an apathetic state.

Anxiety. The state of anxiety is characterized by high involvement, concentration difficulties and a lack of control (Massimini and Carli 1988). Customers of the online technical support community might experience a very challenging technical problem, but lack the skills to find al solution. Hence, they feel that they cannot master the situation. In this anxious state, they will experience less fun, have a lower level of service cocreation, have fewer social interactions and perceive a lower level of service quality, compared to customers in a state of flow.

Boredom. When skills develop, customers might not feel challenged anymore by the tasks of the online technical support community. They replace mastery of the situation with boredom. Customers, who feel bored, will have a mare passive experience, as boredom is characterized by below-average concentration, a sufficient sense of control and other average mood states (Massimini and Carli 1988). They feel that nothing is at stake. Hence, in a state of boredom, customers will perceive lower levells of fun, have a lower level of service co-creation, have fewer sociall interactions and perceive lower levels of service quality, compared to customers in flow.

H7: The perceptions of the level of fun, the amount of service co-creation, social interaction and the level of service quality will be significantly higher for persons operating in a state of flow than for those in the other three states (i.e. apathy, anxiety, and boredom). 


\subsection{Methodology}

In order to test the aforementioned hypotheses, we conducted an empirical study among the members of an online technical support community, moderated by a leading computer services company. Partial least squares were used to assess the reliability and validity of our measures. Furthermore, we used ANOVA and partial least squares to test our hypotheses. We now discuss the sample and data collection procedure, the measurement and the data analysis.

\subsubsection{Sample and Procedure}

Our data were collected by means of an online survey that was advertised and linked to the community's main starting page. On this starting page, the community has a specific box where news and special links are promoted. Furthermore, we posted a thread in the 23 most active discussion forums of that same community explaining the rationale of the study and inviting the members to participate. We offered participants an extrinsic incentive to participate by raffling Amazon vouchers. In addition, we provided an intrinsic incentive by promising to publish the results. In total, 195 questionnaires were completed. The majority of the respondents were from the US, but in total people from 25 countries participated. Furthermore, participants came from a wide variety of industries, such as agriculture, pharmaceutical, telecommunication. On average, participants are in the community for 5.49 hours per week. $13 \%$ spent more than 10 hours per week. $70 \%$ of the respondents stated that more than half of their problems are solved in the community. An overview of the demographics is provided in table 5.1. 
100 Chapter 5

Table 5.1: Demographics

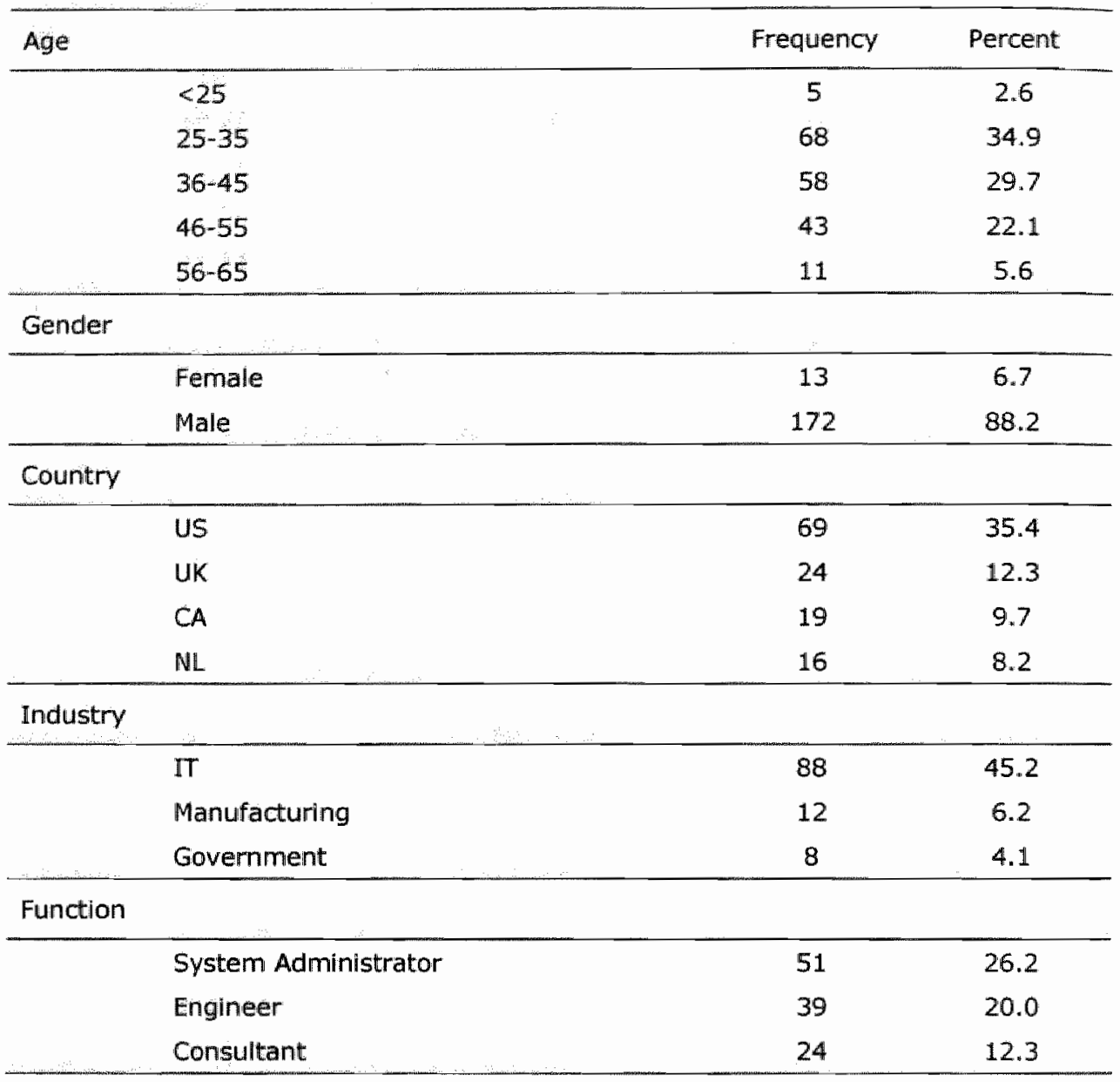

\subsubsection{Measurement}

For the operationalization of our constructs, we used existing scales from the marketing literature. Appendix B contains all measures, their sources, composite reliabilities and loadings. As proposed by literature (Parasuraman et al. 1988), perceived service quality is $a 2^{\text {nd }}$ order construct consisting of the dimensions of tangibility, rellabillty, responsiveness, assurance, and empathy. All scales except fun were measured with a 7-point Lkert scale. Fun was measured with a 7-point semantic differential scale. All scales were pretested qualitatively where 4 academic experts and 4 community managers provided detailed feedback on wording, comprehensibility and flow of the questions. Thereafter, we conducted a quantitative pretest with students $(n=105)$ in a laboratory setting. These students were presented with an example community and then 
asked to consider themselves as a member of the community before answering the questions. The data from the pretest were analyzed and items were refined if necessary.

\subsubsection{Data analysis}

The measurement properties were estimated using partial least squares (PLS), specifically PLS-GRAPH $\vee 3.00$. Convergent validity was assessed by examining the factor loadings of the measures on their respective constructs. All factor loadings are higher than 0.50 (Hulland 1999). We evaluated reliability by using composite scale reliability (Chin 1998; Fornell and Larcker 1981). Composite scale reliability ranged between 0.92 and 0.97 and exceeded the suggested cut-off value of 0.7 (Nunnally and Bernstein 1994). Furthermore, all average variances extracted are above the recommended cut-off of 0.50 (Fornell and Larcker 1981 ), ranging from 0.71 to 0.91 . Discriminant validity was assessed for each construct by three different methods (White et al. 2003). First, the square root of the average variance extracted exceeded the correlations of the construct with the other constructs in the model. Second, each correlation was less than 1 by an amount greater than twice its respective standard error (Bagozzi and Warshaw 1990). Third, we examined the theta matrix to confirm that all items loaded highest on their associated construct and not on another construct. All off-diagonal elements in the theta matrix were below | 0.20 | (Falk and Miller 1992). Thus, all constructs showed discriminant validity. Table 5.2 shows composite reliabilities, average variances extracted and the intercorrelations between constructs.

Table 5.2

Reliabilities and correlations among constructs

\begin{tabular}{|c|c|c|c|c|c|c|c|c|c|}
\hline & CR & AVE & Fun & $R E$ & $\mathrm{SCC}$ & 51 & $5 Q$ & $\mathrm{CHA}$ & Skill \\
\hline Fun & 0.94 & 0.71 & 0.84 & & & & & & \\
\hline $\begin{array}{l}\text { Relational } \\
\text { Embeddedness (RE) }\end{array}$ & 0.92 & 0.78 & 0.289 & 0.88 & & & & & \\
\hline $\begin{array}{l}\text { Service Co-creation } \\
\text { (SCC) }\end{array}$ & 0.97 & 0.91 & 0.263 & 0.452 & 0.95 & & & & \\
\hline $\begin{array}{l}\text { Social } \\
\text { interaction (SI) }\end{array}$ & 0.97 & 0.85 & 0.454 & 0.589 & 0.410 & 0.92 & & & \\
\hline $\begin{array}{l}\text { Service } \\
\text { Quality (SQ) }\end{array}$ & 0.93 & 0.72 & 0.467 & 0.429 & 0.331 & 0.493 & 0,933 & & \\
\hline Challenge (CHA) & 0.96 & 0.83 & 0.294 & 0.254 & 0.304 & 0.314 & 0.394 & 0.91 & \\
\hline Skill & 0.94 & 0.85 & 0.238 & 0.280 & 0.404 & 0.335 & 0.349 & 0.211 & 0.92 \\
\hline
\end{tabular}


102 Chapter 5

We used partial least squares to estimate the structural parameters in each sample. The usage of partial least squares is most appropriate, as our primary concem was the prediction of dependent endogenous variables (Chin 1998; Fornell and Bookstein 1982; Fornell and Cha 1994; Lohmöller 1988). Furthermore, PLS does not require multivariate normal data, and is especially suited for small sample sizes. Significance of all beta coefficients was tested with a bootstrapping method (i.e. sampling with replacement method) that delivered us corresponding t-values.

Hierarchical clustering was used as an exploratory step to validate the theoretically proposed four-cluster solution. K-means cluster analysis was then applied to associate each respondent with one of the four states of mind (i.e. flow, apathy, anxiety. boredom). We then used ANOVA to compare the means of fun, service co-creation, social interaction and service quality for the four states. Thereafter, we used the cluster membership to split our sample. Finally, we tested the model in each state again using PLS.

\subsection{Results}

\subsubsection{Partial least squares analysis: Full sample}

Our data show support for the first hypothesis, which predicts that service cocreation positively impacts perceived service quality $(b=0.135, t=1.87)$. Furthermore, social interaction positively influences perceived service quality ( $b=0.432, t=6.23$ ), as proposed by $\mathrm{H} 2$. Fun has a positive impact on service co-creation $(\mathrm{H} 3: \mathrm{b}=0.176, \mathrm{t}=$ 2.44) and a positive impact on social interaction ( $H 4: b=0.309, t=4.88$ ). Moreover, the second antecedent, relational embeddedness has a positive impact on service cocreation ( $\mathrm{H} 5: \mathrm{b}=0.406, \mathrm{t}=6.14)$ and a positive influence on social interaction $(\mathrm{H} 6: \mathrm{b}=$ $0.517, t=8.70)$. An overview of the results is provided in table 5.3.

Table 5.3: Results for full sample

\begin{tabular}{|c|c|c|c|}
\hline \multicolumn{4}{|c|}{ Direct effects: Beta coefficients and $t$-values (in parentheses) } \\
\hline & Social Interaction & Service Co-creation & Service Quality \\
\hline Fun & $0.309(4.88) * * *$ & $0.176(2.44) * *$ & \\
\hline $\begin{array}{l}\text { Relational } \\
\text { Embeddedness }\end{array}$ & $0.517(8.70) * * *$ & $0.406(6.14) * * *$ & \\
\hline $\begin{array}{l}\text { Soclal } \\
\text { Interaction }\end{array}$ & & & $0.432(6.23) * * *$ \\
\hline $\begin{array}{l}\text { Service Co- } \\
\text { creation }\end{array}$ & & & $0.135(1.87)^{*}$ \\
\hline Construct $\mathrm{R}^{2}$ & 0.455 & 0.237 & 0.258 \\
\hline
\end{tabular}




\subsubsection{Cluster analysis}

K-means clustering was used to classify the respondents into four states of mind according to their variation on challenge and skill. The four clusters were interpreted and labeled as flow, apathy, anxiety, and boredom in line with the theoretical definition provided by Csikszentmihalyi (1975; 1990). ANOVA results indicate that challenge (F = 213.862, $\mathrm{p}=.000)$ and skill $(\mathrm{F}=96.389, \mathrm{p}=.000)$ are significant contributors to the cluster solution. The cluster means are reported in table 5.4 .

Table 5.4

Final Cluster Means

\begin{tabular}{|c|c|c|c|}
\hline \multicolumn{2}{|c|}{ Flow $(n=72)$} & \multicolumn{2}{|c|}{ Apathy $(n=33)$} \\
\hline \multicolumn{2}{|c|}{ Cluster means } & \multicolumn{2}{|c|}{ Cluster means } \\
\hline Skill & 5.94 & Skill & 4.52 \\
\hline Challenge & 5.84 & Challenge & 2.74 \\
\hline \multicolumn{2}{|c|}{ Anxiety $(n=43)$} & \multicolumn{2}{|c|}{ Boredom $(n=47)$} \\
\hline \multicolumn{2}{|c|}{ Cluster means } & \multicolumn{2}{|c|}{ Cluster means } \\
\hline Skill & 4.30 & Skill & 6.06 \\
\hline Challenge & 5.09 & Challenge & 4.01 \\
\hline
\end{tabular}

\subsubsection{ANOVA analysis}

ANOVA results indicate a significant between-subjects effect of the state of mind on the level of fun ( $F=8.996, p=.000$ ), the amount of service co-creation ( $F=8.839$, $\left.p={ }_{.000}\right)$, the amount of social interaction $(F=9.719, p=.000)$, and perceived service quality $(F=10.276, p=.000)$. The means for the different states of mind are shown in graph 1. The post-hoc tests showed that the mean differences for fun, social interaction and perceived service quality are significant for the differences between flow and the other states of apathy, anxiety and boredom. For service co-creation, the mean differences between flow and apathy, and flow and anxiety are also significant. However, we did not find a significant mean difference between flow and boredom. A graphical representation of the different means is provided in chart 5.1 . 


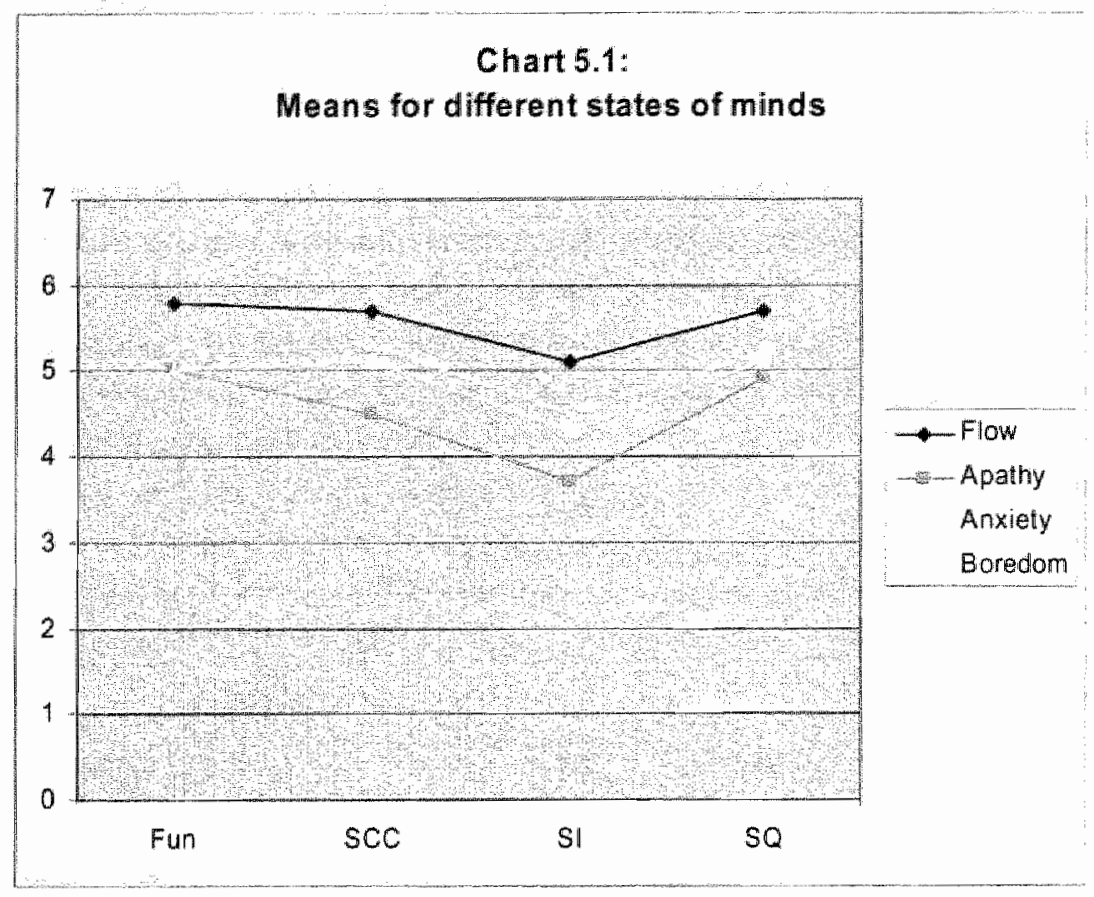

\subsubsection{Partial least squares analysis: Subsamples}

The cluster membership was used to split the sample into four subsamples (i.e. flow, apathy, anxiety, and boredom). For each subsample, we estimated the model with partial least squares. The results for each subsample are presented in table 5.5

Table 5.5: Results for four subsamples

Results Flow

Direct effects: Beta coefficients and t-values (in parentheses)

\begin{tabular}{|c|c|c|c|}
\hline & Soclal Interaction & Service Co-creation & Service Quality \\
\hline Fun & $0.301(3.09)^{* *}$ & $-0.151(1.20)$ & \\
\hline $\begin{array}{l}\text { Relational } \\
\text { Embeddedness }\end{array}$ & $0.530(6.59) * * *$ & $0.422(3.72)^{* *}$ & \\
\hline $\begin{array}{l}\text { Social } \\
\text { Interaction }\end{array}$ & & & $0.572(8.15) * * *$ \\
\hline $\begin{array}{l}\text { Service Co- } \\
\text { creation }\end{array}$ & & & $-0.033(0.25)$ \\
\hline Construct $\mathbb{R}^{2}$ & 0.454 & 0.167 & 0.316 \\
\hline
\end{tabular}




\section{Results Apathy}

Direct effects: Beta coefficients and $t$-values (in parentheses)

\begin{tabular}{|c|c|c|c|}
\hline & $\begin{array}{c}\text { Social } \\
\text { Interaction }\end{array}$ & Service Co-creation & $\begin{array}{l}\text { Service } \\
\text { Quality }\end{array}$ \\
\hline Fun & $0.289(2.32)^{*}$ & $0.342(1.56)$ & \\
\hline $\begin{array}{l}\text { Relational } \\
\text { Embeddedness }\end{array}$ & $0.616(5.35) * * *$ & $0.293(2.21)^{*}$ & \\
\hline $\begin{array}{l}\text { Social } \\
\text { Interaction }\end{array}$ & & & $0.584(2.54) *$ \\
\hline $\begin{array}{l}\text { Servilice Co- } \\
\text { creation }\end{array}$ & & & $0.038(0.15)$ \\
\hline Construct $\mathrm{R}^{2}$ & 0.780 & 0.268 & 0.356 \\
\hline
\end{tabular}

\section{Results Anxiety}

Direct effects: Beta coefficients and $t$-values (in parentheses)

\begin{tabular}{|c|c|c|c|}
\hline & $\begin{array}{c}\text { Social } \\
\text { Interaction }\end{array}$ & Service Co-creation & $\begin{array}{l}\text { Service } \\
\text { Quality }\end{array}$ \\
\hline Fun & $0.260(1.14)$ & $0.373(2.19)^{*}$ & \\
\hline $\begin{array}{l}\text { Relational } \\
\text { Embeddedness }\end{array}$ & $0.487(2.78)^{* *}$ & $0.052(0.27)$ & \\
\hline $\begin{array}{l}\text { Social } \\
\text { Interaction }\end{array}$ & & & $0.116(0.39)$ \\
\hline $\begin{array}{l}\text { Service Co- } \\
\text { creation }\end{array}$ & & & $0.327(1.88) *$ \\
\hline Construct $\mathrm{R}^{2}$ & 0.319 & 0.144 & 0.138 \\
\hline
\end{tabular}




\section{Results Boredom}

Direct effects: Beta coefficients and $t-v a l u e s$ (in parentheses)

\begin{tabular}{|c|c|c|c|}
\hline & $\begin{array}{c}\text { Social } \\
\text { Interaction }\end{array}$ & Service Co-creation & $\begin{array}{l}\text { Service } \\
\text { Quality }\end{array}$ \\
\hline Fun & $0.218(1.75) *$ & $0.180(1.11)$ & \\
\hline $\begin{array}{l}\text { Relational } \\
\text { Embeddedmess }\end{array}$ & $0.530(5.51) * * *$ & $0.510(4.31)^{* * *}$ & \\
\hline $\begin{array}{l}\text { Social } \\
\text { Interaction }\end{array}$ & & & $0.533(5.66)^{* * * *}$ \\
\hline $\begin{array}{l}\text { Service Co- } \\
\text { creation }\end{array}$ & & & $0.008(0.07)$ \\
\hline Construct $R^{2}$ & 0.409 & 0.356 & 0.281 \\
\hline
\end{tabular}

\subsubsection{Results for flow}

The first hypothesis, which predicts that service co-creation positively impacts percelved service quality, is not supported $(\mathrm{b}=-0.033, \mathrm{t}=0.25$ ). Hypothesis 2 is supported, as social interaction positively influences perceived service quality $(b=0.584$, $t=8.15$ ). Hypothesis 3 , assuming a positive impact of fun on service co-creation is not supported $(b=-0.151, t=1.20)$. However, fun has a positive impact on social interaction $(b=0.301, t=3.09)$, as proposed in $\mathrm{H} 4$. The second antecedent, relational embeddedness has a significant positive impact on service co-creation (H5: $b=0.422, t$ $=3.72)$, and on social interaction ( $\mathrm{H} 6: \mathrm{b}=0.530, \mathrm{t}=6.59)$.

\subsubsection{Results for apathy}

Our data show again no support for hypothesis 1 , predicting a positive impact of service co-creation on service quality ( $b=0.038, t=0.15$ ). The second hypothesis is supported, as social interaction has a positive impact on service quality $(b=0.584, t=$ 2.54). We find no support for $\mathrm{H} 3$, assuming a positive influence of fun on service cocreation ( $\mathrm{b}=0.342, \mathrm{t}=1.56$ ). Hypothesis 4 is supported, as fun has a positive impact on social interaction $(b=0.289, t=2.32)$. Furthermore, relational embeddedness positively influences service co-creation ( $\mathrm{H} 5: b=0.293, t=2.21$ ) and social interaction $(0.61, t=5.35)$. 


\subsubsection{Results for anxiety}

Our data in this sample show support for hypothesis 1. Service co creation has a positive impact on service quality $(b=0.327, t=1.88$ ). However, social interaction has no impact on service quality $(\mathrm{H} 2: b=.116, t=0.39)$. Whille fun has a positive impact on service co-creation (H3: $b=0.373, t=2.19$ ), it does not have an impact on social interaction ( $\mathrm{H} 4: \mathrm{b}=0.260, t=1.14)$. On the other hand, relational embeddedness does not have an impact on service co-creation ( $H 5$ : $b=0.052, t=0.27$, but positively impacts social interaction ( $H 6: b=0.482, t=2.78$ ).

\subsubsection{Results for boreaiom}

In our last subsample, we do not find support for H1. Service co-creation does not impact service quality $(b=-0.008, t=0.07$ ). Hypothesis 2 , assuming that social interaction has a positive influence on service quality is supported $(b=0.533, t=5.66)$, We do not find support for hypothesis 3, as fun does not impact service co-creation ( $b=$ $0.180, t=1.11$ ). Social interaction is positively influenced by fun ( $H 5: 0.218, t=1.75$ ). Furthermore, relational embeddedness has a strong positive impact on both service cocreation $(b=0.510, t=4.31)$ and social interaction $(b=0.530, t=5.51)$.

\subsection{Discussion and Implications}

One purpose of this study was the examination of motivations for service cocreation by customers. The results of the full sample show that fun and relational embeddedness stimulate service co-creation by customers and the social interaction between customers. Especially relational embeddedness is a very strong motivator for active customer behavior. Therefore, soclal network theory is highly applicable for explaining the motivation of service co-creation by customers. Companies that manage customer communities must provide mechanisms for custamers to develop connections with each other, as inter-customer connections stimulate co-creation. Furthermore, when customers co-create content and interact socially with other customers, perceived service quality increases. Hence, we were able to show that active customer participation in services can result in a better evaluation of the respective service. Despite the importance of service co-creation, social interaction was found to be an extremely strong driver of service quality perceptions. The social interaction between members adds a human dimension to the service and customers feel a stronger sense of belonging to the community and the company. Therefore, organizations should encourage social interaction between customers. Companies can provide technological means to stimulate social interaction between customers, as well as supplement the online experience with offline meeting possibilities. Social interaction is an important mechanism for providing a pleasant experience. 
We Include a contingency element by showing how the motivations, the impact of service co-creation, and the service quality evaluation change for different states of mind Identified by flow theory. In a state of flow, the customers perceptions of the level of fun, the amount of social interaction, and the perceived service quality are substantially heightened. Except for the state of boredom, the amount of service co-creation is also increased for people who are in flow, compared to persons who are anxious or apathetic. Bored customers might produce as much information as people in a state of fllow, as they want to compensate for the lack of challenge within the task. Furthermore, they have very high skils and would probably like to show them to other community members through information production.

We showed that the balance between challenge and skill is important for engaging customers in an enjoyable experience. Companies need to keep the challenges high. They should encourage customers of the online technical support community to first search the archives before asking a question and hence, maximize the amount of new questions and discussion topics. Furthermore, they need to stimulate customers to develop their skills. If companies offer education and training services to customers, they could promote these services in the customer community.

When dividing our full sample into the subsamples of flow, apathy, anxiety, and boredom we find that fun does not motivate service co-creation in the states of flow, apathy and boredom. However, in the state of anxiety, fun triggers service co-creation. For people in a state of flow fun is no additional motivator for service co-creation. The state of flow makes it already an enjoyable experience; hence, more fun will not further increase their information production behavior, while they still have the highest level of fun. Apathetic customers might be peoplle who are not so interested in the customer community. They are not challenged by the community environment, and also feel that their skills are not appropriate. Therefore, increased enjoyment cannot motivate them to produce information. Only the connections with ather customers increase their Information sharing readiness. People in a state of boredom are probably experts who do not feel challenged enough by the questions in the online technical support community. However, they might want to compensate for the missing challenge by still producing as much information as people in a state of flow. Producing information in the community makes their high knowledge levels transparent for other customers. Customers in an anxious state are probably nowices who feel overwhelmed by the challenges of the discussions. Therefore, in this state fun will be a motivator for service co-creation, as customers who enjoy the community will feel that despite their lack of skills they can contribute to the solving of problems.

While in the state of flow, apathy, and boredom fun has a positive impact on social interaction, in the state of anxiety fun does not motivate social interaction. Again, 
this might be due to the knowledge level of customers. Anxious customers might not be ready yet to participate in the exchange of social information, no matter how enjoyable the experience is. Similarly, anxious customers' service quality perceptions are raised when these customers produce content, not when they interact socially. It seems that when anxious customers produce information, they are proud that despite the high challenges they were able to help other customers. They have overcome the high challenge and, hence, feel that they have contributed to the service and evaluate the service quality higher. For customers in flow, apathy or boredom service quality perceptions are increased when they interact socially, not when they produce content. These customers consider the information production as the core activity within the community environment. Therefore, this activity does not add to service quality perception. The social interaction is something additional and does provide them with added value. Consequently, social interaction increases their service quality perception.

Introducing the contingency factor of different states or mind and the respective analysis of the subsamples shows the importance of flow theory for challenging web experiences. Furthermore, it adds to our understanding of how our proposed model and the hypothesized relationships change in different states of mind. The experience of service co-creation is highly sensitive to the balance of challenges and skills.

\subsection{Managerial implications}

Our research has several important managerial implications. Companies can use electronic services to engage their customers activeiy in the service delivery process. They can provide online platforms for service co-creation to improve perceived service quality. The involvement of customers is especially positive when companies are able to create an environment where customers are willing and motivated to contribute. A first required, but not sufficient condition for such an environment is that the virtual community has a good availability and performance. Availability ensures that the community is always reachable, when a customer has a problem and needs help. Furthermore, performance guarantees that the customers have a relatively quick build up time and they do not have to wait for the particular sites. Secondly, these communities should provide features and functionalities that increase the fun. For example, the participating customers should be able to setup their personal profiles to represent themselves. Furthermore, the community should have spaces for humorous exchanges. The features and functionallies can also be used to increase the challenges within the community, thereby providing the company with a mechanism to influence the flow experience of their customers. For instance, the company can install a point system, so that the question asker can rate each answer he/she receives. The points then show how experienced the customer is in the community and also represents an indication of the 
$110 \|$ Chapter 5

customer's knowledge. Additionally, the company can provide awards to stimulate participation and a competitive, playful feeling. The moderators of the community can initiate new up to-date discussions to challenge customers and should also provide answers if there is a question that did not receive an answer within a certain amount of time. The time threshold can be set from past experiences.

Our investigation has shown that relational embeddedness is an important contributor to service co-creation by customers and social interaction. Hence, companies could create offline meeting possibilities in addition to the virtual encounters. Depending on the topic of the community, the company could organize yearly events, e.g. conferences. These offline meeting possibilities would support the creation of relational ties between the customers.

\subsection{Limitations and future research guidelines}

When interpreting our results, certain aspects need to be considered. First, our investigation has been conducted in one community, an online technical support community. The customers are mainly system administrators who need the interaction with like-minded people beyond their company boundaries. Future research could examine whether our relationships can be found in other co-creation situations.

Furthermore, we concentrated on one outcome of active customer participation, namely perceived service quality. Other outcomes, such as loyalty to the community, continuance intentions for the company's services, and/or positive word of mouth might be interesting to consider. The community might also be an interesting mean to promote other services of the company. Another important future research area would be to consider other moderating variables to see how the impact of service co-creation on perceived service quality changes in certain situations or for specific customers.

Our cluster analysis finds a solution consistent with our expectations. Nevertheless, the cluster analysis does not assure that respondents were in the state of mind Identified by the classlfication. Future research in marketing may consider using Csikszentm/halyi's experience sampling method (ESM) to corroborate our findings and capture flow and the other states of mind in marketing activities.

Finally, the customer community produces content that is very interesting for the company. The customers also exchange perceptions about existing products and services. This knowledge needs to be distributed within the company to improve the existing products and services and might also be used as stimulus for the development of new products and services. Thus, future research could investigate how companies handlle this kind of information. 


\subsection{Conclusion}

The importance of service co-creation by customers is increasing, as customers are becoming a new source of competence (Prahalad and Ramaswamy 2000). We have investigated why customers actively co-create content in an online technical support community. They are motivated when they experience fun and when they feel a certain degree of connection with other customers, i.e. when they are relationally embedded. Our results show that the behavior of service co-creation by customers and social interaction increases the perceived quality of the service. However, our results differ for different states of mind. Using flow theory, we have shown that customers who are in flow have the highest level of fun, create more information, engage in more social interaction and have the highest level of perceived service quality. In the states of flow, apathy, and boredom relational embeddedness is a stronger motivator for service cocreation and only social interaction increases the perceived service quality. In a state of anxiety, customers are mainly motivated by fun to produce information and service cocreation contributes more to perceived service quality than social interaction. 

Chapter 6

ConClusion 
114 Chapter 6

\section{A little knowledge that acts is worth infinitely more than much knowledge that is idle.}

\section{KahVil Gibran (1881-1931)}

\subsection{Synopsils}

In this dissertation, we have focused on knowledge creation in high-tech services. The overall objective was to uncover how knowledge is created in different knowledge interfaces within companies, interactions between companies and customers as well as interactions between customers. We investigated how companies can influence the dynamic stock of knowledge. Attention was also paid to the impact the created knowledge has on organizational performance. In the introduction, we formulated the main research problem as follows:

\section{What is the role of knowledge interfaces during knowledge creation in high-tech services?}

The main research problem was addressed in four interrelated research projects. Each project was described in one chapter of this dissertation. Chapter 2 discussed the critical antecedents of project learning and time-to-market during new mobile service development. In Chapter 3, we investigated how communication mediates the impact of memory on project learning and time-to-market in high-tech service development. Chapter 4 examined the roles of customers during knowledge co-creation and the respective impact on organizational knowledge increase. Chapter 5 dealt with the motivations of customers to co-create a service and the evaluation of customer cocreated services. In sum, we have considered various antecedents and performance consequences of knowledge creation in high-tech services. Antecedents ranged from organizational design variables and innovation team characteristics within the area of intraorganizational interfaces to specific customer roles and customer motivations in the knowledge linterface with customers. In terms of performance outcomes, we mainly considered 1) innovation project outcomes, 2) service innovation performance as well as 3) perceived service quality.

In this final chapter, we will present a general overview of the four projects ${ }^{*}$ findings including theoretical and managerial implications. Finally, the chapter concludes with general suggestions for future research. 


\subsection{Organizational fascination of knowledge creation}

Organizations are fascinated with knowledge creation, as knowledge is a key primary resource that can lead to competitive advantage. Companies are aware that nowadays they need to create knowledge to stay competitive. Therefore, they are interested in how knowledge is created, transferred and sustained within their organizations. We have shown that knowledge is created through activities of marketing employees with other employees in the organization and through interactions with customers. The big advantage of knowledge as a resource is that it increases with usage. The more knowledge is consumed, the wider the transfer of knowledge within the organization. As a consequence, this unique characteristic needs to be exploited.

Our studies have shown that knowledge creation improves new service performance, provides an important stimulus for innovation activities and helps to raise percelved service quality. When employees learn throughout the service innovation process, and hence, build up knowledge, new service performance is considerably improved. Furthermore, when customers co-create knowledge during the delivery of electronic services, organizational knowledge is increased. Subsequently, employees can use this new organizational knowledge to improve the existing services to customers. Consequently, customers perceive the quality of the services as superior. The co-created knowledge also provides employees with an important stimulus for innovation activities, as customers communicate their current problem areas and ideas and suggestions for future services. Finally, when customers co-create services by participating, for example, in an online technical support community, they increasingly identify themselves with the service. This higher identification also leads to an improved perception of service quality.

\subsection{Knowledge Interfaces within the organization}

The knowiedge interfaces within the company have been examined during the service innovation process. The innovation task can be considered as an organizational activity directed at the creation of a knowledge base, so that the company can act on events and trends in present and prospective markets. Furthermore, in most service innovation projects employees with different functional backgrounds participate in this innovation task. Therefore, the innovation task is the ideal process to study knowledge interfaces within organizations. High-tech service companies strive for a fast time-tomarket to introduce competitive services into the market. At the same time, the need to process information and subsequently learn is another important innovation project outcome. We have shown that both project outcomes are important drivers for new service performance. The seemingly existing paradox between project learning and timeto-market can be solved by encouraging innovative communication. Both time-to-market and project learning are positively influenced by innovative communication (i.e. the 
exchange of creative and novel information). Innovative communication helps to create not only new services but also process innowation. In process innovation, the process itself might be shortened. Innovative communication entails creativity in problem solving and supports the effectiveness of high-quality solutions. Especially in high-tech services, companies need to exchange creative and novel information, be open to experimentation and improvisation. Despite the importance of innovative communication, coordinative communication is also important to manage the information overload that exists within the high-tech environment. Coordinative communication helps isolated employees to manage the information task.

Communication has also an important mediating function. We found that communication serves as the transformation process of existing stock of knowledge (ii.e. memory) into a new stock of knowledge (i.e. knowledge creation). Without communication, memory of the service innovation team cannot result in the pasitive outcomes of project learning and time-to-market. Within this memory dimension, marketing theory and practice needs to distinguish between generational memory and transactive memory. Generational memory refers to the collective, existing knowledge of the service innovation team while transactive memory means that these team members are aware of other knowledge locations. For the concept of transactive memory, we have drawn on psychology literature and introduced it to the marketing domain. The communication networks within companies are expanded due to the increased usage of information technology. Hence, organizations can further exploit the transactive memory within their organization. While we have shown the importance of memory for communication, companies need to consider that in complex projects, external information becomes critical. Therefore, when project complexity is high, employees should search for information beyond the boundaries of the firm.

Not only communication is important for knowledge creation, but there should also be a match between information processing capabilities and information processing requirements. The advanced information technology of the Internet and company-wide Intranets create opportunities for better communication via e-mail and sharing material online. Thus, more information can be shared with a wider audience allowing global companies to work in world-wide teams. Futhermore, the generall organizational climate should support learning behavior. Companies can stimulate a favorable organizational climate by providing slack resources and fostering active participation of employees. Some slack resources allow employees to experiment and improvise. Active participation improves employees. identification with the projects. Furthermore, learning is a social process where employees need to interact with each other. Therefore, the aspiration for knowledge creation should be institutionalized in the organizational values and norms. 


\subsection{Knowledge interfaces with customers}

The knowledge interfaces with customers have two important dimensions: an information dimension and an experience dimension. Both dimensions are driven by the realization that customers have transformed from passive buyers to active co-creators of value. On the one hand, this knowledge interface is important for the exchange of information with the customer. On the other hand, companies can use this knowledge interface to create memorable experiences for customers.

Customers communicate their knowledge, are willing to learn, engage in active exchanges of ideas with companies, and become service co-creators. In electronic service delivery, customers are often providing the organization with a lot of information by just using the company's electronic services. Furthermore, customers increasingly provide voluntary feedback to companies. Using the services and providing feedback represent interactions between an individual customer and the company. Knowledge is also cocreated in customer communities where customers do not only interact with the company but also among each other. Consequently, companies can establish mechanisms to incorporate customers' knowledge. Customers co-create knowledge during daily business and within their natural setting. Hence, companies do not need to invite customers for specific focus groups or as respondents for market research, where customers are out of their daily business situation. Rather, companies can exchange knowledge with their customers at the moment where a certain problem occurs in the customers' environment. This co-created knowledge impacts the knowledige of employees within the organization. Here, the breadth and depth of information from customers is especially important for the objective knowledge of employees. Objective knowledge represents the accuracy of knowledge. The representativeness and trust of information is critical for subjective knowledge, where subjective implies the confidence in the knowledge. Both objective and subjective knowledge help to deliver better services and provide input for the upfront innovation activities. The co-creation of knowledge in virtual communities also provides the advantage of being a platform for the promotion of new services. Hence, companies can exploit the possibilities of closer customer contact and benefit from service co-creation of customers.

We have extended the service production continuum based on Meuter and Bitner (1998) by adding a fourth production dimension (l.e. service co-creation), where customers produce services for other customers. Virtual customer communities provide the ideal platform for these kinds of services. In a virtual community, the problem solving interaction between customers can reduce a company"s call center traffic. Moreover, the active service co-creation increases the technical knowledge of the community customers, thereby, lowering the actual level of technical support needed by customers. 
The experience dimension of the knowledge interface with customers ensures that customers consume services that are memorable. Experience can be a sensation as well as a knowledge acquisition resulting from a customer's participation in daily activities. Customers participate in self-services as well as in service co-creation. However, while self-services offer customer benefits such as convenience and faster service provision, the motivation for customers to help other customers is more intrinsic in nature. We have shown that fun as well as relational embeddedness between customers are important drivers of co-creative behavior. Fun makes the service experience enjoyable in Itself. Relational embeddedness connects customers with other customers and subsequently stimulates them to help each other. We found that especially relational embeddedness has a strong impact on co-creative behavior. Companiles offering cocreated services need to manage customer motivations. Therefore, they should encouraige the connection of customers with other customers and include, for example, technological means to raise the fun factor in the community. Another important finding of this dissertation is the importance of social interaction as a driver of perceived service quality in highly participatory services. Social interaction adds a human dimension to the service that customers seem to appreciate. Companies could consider introducing a social dimension also in other services.

We included a contingency element by showing how the motivations, the impact of service co-creation by customers, and the service quality evaluation change for different states of mind identified by flow theory. In a state of flow, the customers" perceptions of the level of fun, the amount of sociall interaction, and the perceived service quality are substantially heightened. Introducing the contingency factor of different states of mind and the respective analysis of the subsamples shows the importance of flow theory for challenging web experiences. Furthermore, it adds to our understanding of how our proposed model and the hypothesized relationships change in different states of mind. The experience of service co-creation is highly sensitive to the balance of challenges and skills. The balance between challenge and skill is important for engaging customers in an enjoyable experience. Companies need to keep the challenges high. They should maximize the amount of new questions and discussion topics within the wlitual community. Furthermore, they need to stimulate customers to develop their skills. If companies offer education and training services to customers, they could promote these services in the customer community.

\subsection{A perspective on future research}

Specific suggestions for future research have been discussed at the end of each chapter. We would also like to provide some general directions for future research in the area of knowledge creation in marketing, service innovation and customer collaboration. 
We have illustrated how critical knowledge creation is for innovation performance. However, knowledge creation during innovation is not only important for building a competitive advantage, but aiso enhances the capabilities and competences of organizations. In innovation research, the distinction between incremental and radical innovation is widely accepted. Sometimes, radical innovation may obsolesce the existing knowledge stock, thereby, destroying capabilities and competences. Hence, an important area for future research could deal with issues in competence-enhancing versus competence-destroying innovations. Is there a knowledge vacuum after a competencedestroying innovation? Does competence-destroying innovation increase new knowledge creation, as the demand for knowledge is higher? Do companies also have to newly educate their customers for these kinds of radical innovations?

We have shown the importance of knowledge co-creation with customers for innovation activities in the context of electronic services. However, as markets are rapidly evolving into networks (Achrol and Kotler 1999), collaboration with suppllers can become essential as well. In our first chapter, we have shown that supplier information power might delay the fast development of mobile service development. Research on supplier involvement in innovation activities has been inconclusive with respect to the impact on time-to-market. While Eisenhardt and Tabrizi (1995) find that supplier involvement fastens innovation projects, Ittner and Larcker (1997) discover that it slows down time-to-market. Hence, future research could investigate inhibiting and contributing factors for joint development with suppliers. Furthermore, the interface with suppliers is another knowledge interface that goes beyond the boundaries of a firm. Hence, knowledge is also created in this interface. What are the conditions for knowledge creation? What rolles do suppliers and the organization have to play to maximize performance outcomes? How can companies motivate their supplying firms to cooperate in innowation projects?

Despite the opportunities to co-create knowledge with customers in electronic services, as demonstrated by this dissertation, companies might also be interested in collaborating even closer with customers in developing new services. However, due to logistical reasons companies can only cooperate with a small number of customers. Therefore, they want to ensure that they cooperate with customers, who are creative and motivated. In addition, they want to collaborate with customers who represent the mass market to optimize the later adoption and diffusion of the newly developed service. The advances in internet technology can help to identify creative and representative customers, especially in a business-to-consumer setting, as they allow for interactive communication. The electronic service delivery could support the identification of consumers appropriate for involvement in service innovation. Therefore, future research could examine how companies can identify these customers. What characteristics should 
$120 \mid$ Chapter 6

these customers have? How can they motivate these customers to collaborate in intensive innovation projects?

We identified the roles customers play in knowledge co-creation, as well as the impact on organizational (objective and subjective) knowledge. Another important issue is how this co-created knowledge is communicated within organizations? Should companies establish formal processes or rather rely on informal knowledge sharing? How can information technology help in disseminating the co-created knowledge? What are inhibiting and facilitating factors for a widespread transfer of customer co-created knowledge?

Online customer collaboration, as discussed in this dissertation, creates organizational knowledge. However, not all employees might be the right person to collaborate with customers. Some employees enjoy the close contact with customers, while others might prefer to rather work in the back office of the organization. Future research might investigate how to identify employees that are especially suitable for online customer collaboration. What characteristics should these employees fulfill? How can companies motivate these employees? How can they better train employees to cooperate with customers?

Just like employees, not all customers enjoy the active participation in, for example, virtual communities. We have shown the importance of customer collaboration for knowledge creation and performance outcomes. Companies wanting to exploit online customer collaboration need to promote participatory services to the "right" customers. Therefore, they should segment their customer base accordingly and only target those customers who enjoy online participation. Hence, future research could identify customer characteristics, customer traits as well as situational factors that influence customers" decision to co-create electronic services.

Finally, the investigation of knowledge interfaces during knowledge creation could be further advanced by using a social network analysis approach. The knowledge interfaces within organizations as well as with customers can be considered as social networks, where individuals arre connected with each other. Social network analysis could study the characteristics of the online social relations between customers and relate it to knowledge creation. Hence, social network analysis could further advance the research fleld of knowledge creation in customer-company networks as well as in online customer support networks. 


\section{References}

Achrol, Ravi S. and Phillp Kotler (1999), "Marketing in the network economy, "Journal of Marketing, 63 (Special Issue), 146-63.

Alba, Joseph W. and J. Wesley Hutchinson (2000), "Knowledge calibration: What consumers know and what they think they know " Journal of Consumer Research, 27 (September), 123-56.

Argote, Linda, Deborah Gruenfeld, and Charles Naquin (2001), "Group learning in organizations," in Groups at work: Theory and research, Marlene E. Turner, Ed. Malwwah: Lawrence Erlbaum Associates, Inc.

Armstrong, Arthur and John Hagel III (1996), "The reall vallue of on-line communities," Harvard Business Review, 74 (3), 134-41.

Armstrong, 3. Scott and Terry S. Overton (1977), "Estimating non-response bias in mail surveys," Journal of Marketing Research, 14 (August), 396-402.

Atuahene-Gïma, Kwaku and Felicitas Evangellsta (2000), "Cross-functional influence in new product devellopment: An expioratory study of marketing and R\&D perspectives," Management Science, 46 (10), 1269-84.

Ayers, Doug, Robert Dahlstrom, and S.J. Skinner (1997), "An exploratory investigation of organizational antecedents to new product success," Journal of Marketing Research, 34 (February), 107-16.

B

Baccarini, David (1996), "The concept of project complexity - a review, International Journal of Project Management, 14, 201-04.

Bagozzi, Richard P and Paul R. Warshaw (1990), "Trying to consume," Journal of Consumer Research, 17 (September), 127-40.

Bagozzi, Richard P, and U.M. Dholakia (2002), "Intentionall social action in virtual communities," Journal of Interactive Marketing, 16 (2), 2-21.

Baker, William E. and James M. Sinkula (1999), "The synergistic effect of market orientation and learning orientation on organizational performance," Journal of the Academy of Marketing Science, 27, 411-27.

Barker, Randolph T. and Martin R. Camarata (1998), "The role of communlication in creating and maintaining a learning organization: Preconditions, indicators and disciplines," Journal of Business Communication, 35 (4), 443-67.

Barnes, Stuart J. (2002), "The mobile commerce value chain: Analysis and future developments," International Journal of Information Management, 22.

Barnes, Stuart J. and Richard Vidgen (2001), "An evaluation of cyber-bookshops: The webqual method," Intemational Journal of Electronic Commerce, 6 (1), 11-30.

Barnett, Nick, Stephen Hodges, and Michael 1. Wilshire (2000), "M-commerce: An operator's manual, "MCKinsey Quarterly (3), 163-73. 
122 References

Baron, Reuben M. and David A. Kenny (1986), "The moderator-mediator variable distinction in social psychological research: Conceptual, strategic, and statistical considerations," Journal of Personality and Social Psychology, 51 (6), 1173-82.

Barwise, Patrick (2001), "TV, PC, or mobile? Future media for consumer ecommerce, Business Strategy Review, 12 (1), 35-42.

Battacharya, S., V. Krishnan, and V. Mahajan (1998), "Managing new product definition in highly dynamic environments " Management Science, 44 (11), 550-564.

Bayus, B. L. (1997), "Speed-to-market and new product performance trade-offs," Journal of Product Innovation Management, 14, 485-97.

Bayus, B.L., S. Jain, and A.G. Rao (1997), "Too little, too early: Introduction timing and new product performance in the personal digital assistant industry," Journal of Marketing Research, 34, 50-63.

Bearden, William O., David M. Hardesty, and Randall L. Rose (2001), "Consumer self confidence: Refinements in conceptualization and measurement," Journal of Consumer Research, 28 (June), 121-34.

Bearden, William O., Manoj K. Malhotra, and Kelly H. Uscategui (1998), "Customer contact and the evaluation of service experiences: Propositions and implications for the design of services," Psychology \& Marketing, 15 (8), 793-809.

Bendapudi, N. and R.P. Leone (2003), "Psychological implications of customer participation in co-production," Journal of Marketing, 67 (January), 14-28.

Bentler, Peter M. and Chih-Ping Chou (1988), "Practical issues in structural equation modeling, "in Common problems/proper solutions: Avoiding error in quantitative research, J. Scott Long, Ed. Newbury Park, CA: Sage Publications.

Berry, Leonard L., Valarie A. Zeithaml, and A. Parasuraman (1990), "Five imperatives for improving service quality," Sloan Management Review (Summer), 29-38.

Bettencourt, Lance A. (1997), "Customer voluntary performance: Customers as partners in service delivery " Journal of Retalling, 73 (3), 383-406.

Bettencourt, Lance A., Amy L Ostrom, Stephen W. Brown, and Robert I. Roundtree (2002), "Client co-production in knowledge-intensive business services," California Management Review, 44 (4), 100-28.

Bhattacharya, Shantanu, Vish Krishnan, and Vijay Mahajan (1998), "Managing new product definition in highly dynamic environments," Management Science, 44 (11), S50564.

Bitrier, Mary Jo, Stephen W. Brown, and Matthew L. Meuter (2000), "Technology infusion in service encounters," Academy of Marketing Science, 28 (1), 138-49.

Bitner, Mary Jo, William T. Faranda, Amy R. Hubbert, and Valerie A. Zeithaml (1997), "Customer contributions and roles in senvice delivery," Intemational Journal of Service Industry Management, 8 (3), 193-205.

Blazevic, Vera and Annouk Lievens (2004), "Learning during the new financiall service innovation process: Antecedents and performance effects," Journal of Business Research, $57(4), 374-91$. 
Bogner, William and Pamela S. Barr (2000), "Making sense in hypercompetitive enviromments: A cognitive explanation for the persistence of high velocity competition," Organization Science, $11(2), 212-26$.

Bolton, Ruth NN., George S. Day, John Deighton, Das Narayandas, Event Gummesson, Shelby D. Hunt, C. K. Prahalad, Roland T. Rust, and Steven M Shugan (2004), "Invited commentaries on "Evolving to a new dominant logic for marketing" " Journal of Marketing, $68(1), 18-27$.

Borgatti, Stephen P. and Rob Cross (2003), "A relational view of information seeking and learning in social networks," Management Science, 49 (4), 432-45.

Bowers, Michael R., Charles L. Martin, and Alan Luker (1990), "Trading places:

Employees as customers, customers as employees, "Jownal of Services Marketing, 4 (2), 55-69.

Brown, Jacqueline Johnson and Peter $H$. Reingen (1987), "Social tiles and word-of-mouth referral behavior, Journal of Consumer Research, 14 (December), 350-62.

Brown , James W. and James M. Utterback (1985), "Uncertainty and technlcal communication patterns," Management Science, 31 (3), 301-11.

Brown, John Seely and Paul Duguid (1991), "Organizational learning and communities of practice: Toward a unified view of working, learning and innovation," Organization Science, $2(1), 40-57$.

Brown, Shona L. and K.M. Elsenhardt (1995), "Product development: Past research, present findings, and future directions," Academy of Management Review, 20 (2), 34378.

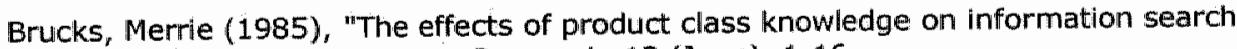
behavior," Journal of Consumer Research, 12 (June), 1-16.

Burnett, Gary (2000), "Information exchange in virtual communities: A typology," Information Research, 5 (4).

C

Capon, Noel and Rashi Glazer (1987), Marketing and technology: A strategic coalignment," Journal of Marketing, 51 (July), 1-14.

Chin, Wynne W. (1998), "The partial least squares approach to structural equation modeling," in Modern business research methods, G.A. Marcoulides, Ed. Mahwah, new Jersey: Lawrence Erlbaum Associates.

Chin, Wynne W., Barbara L. Marcolin, and Peter R. Newsted (2003), "A partial least squares latent variable modeling approach for measuring interaction effects: Results from a Monte Carlo simulation study and voice mail emotion/adoption study, "Information Systems Research, 14 (2), 189-218.

Clift, Thomas B. and Mark B. Vandenbosch (1999), "Project complexity and efforts to reduce product development cycle time," Journal of Business Research, 45, 187-98.

Cohen, Michael D. (1991), "Individual learning and organizational routine," Organization Science, 2 (1), 135-39. 
Cohen, Wesley M. and Daniel A. Levinthal (1990), "Absorptive capacity: A new perspectiwe on learning and innovation," Administrative Science Quarterly, 35, 128-52.

Constant, Davild, Sara Kiesler, and Lee Sproull (1994), "What"s mine is ours, or is it? A study of attitudes about information sharing," Information Systems Research, 5 (4), 40021.

Cooper, Robert G. (1979), "The dimensions of industrial new product success and fallure," Journal of Marketing, 43, 93-103.

Coopier, Robert G. and Elko J. Kleinschmidt (1986), "An investigation into the new product process: Steps, deficiencies and impact," Journal of Product Innovation Management, 3, 71-85.

Cross, Rob and Lloyd Baird (2000), "Technology is not enough: Improving performance by building organizational memory," Sloan Management Review, 41, 69-78.

Csikszentmihalyi, Mihalyi (1975), Beyond boredom and anxiety. San Francisco: JosseyBass Inc.

-..- (1990), Flow: The psychology of optimal experience. New York: Harper \& Row.

Cyert, Richard M. and James G. March (1963), A behavioral theory of the firm. Englewood Cliffs, NJ: Prentice-Hall, Inc.

D

Dabholkar, Pratibha A. (1996), "Consumer evaluations of new technology-based selfservice options: An investigation of alternative models of service quality," International Journal of Research in Marketing, 13 (1), 29-51.

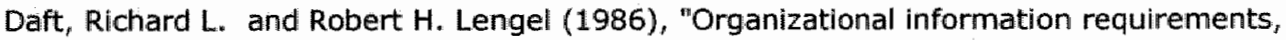
media richness and structural design," Management Science, 32, 554-71.

Daft, Richard L. and Karl E. Weick (1984), "Towards a model of organizations as interpretation systems," Academy of Management Review, 9, 284-95.

Dahan, Ely and John R. Hauser (2002), "The virtual customer," Journal of Product Innovation Management, 19, 332-53.

Davenport, Thomas H. (1994), "Saving IT's soul: Human-centered information management," Harvard Business Review, March-April, 119-31.

Day, George S. (1994), "The capabilities of market-driven organizations," Journal of Marketing, 58 (October), $37-52$.

de Brentani, Ulrike (1989), "Success and fallure in new industrial services," Journal of Product Irnovation Management ${ }^{6}$ 6, 239-58.

Decl, Edward L. and Richard M. Ryan (1980), "The empirical exploration of intrinsic motivational processes," Advances in experimental social psychology, 13, 39-80.

Deeter-Schmelz, Dawn R. and Rosemary P. Ramsey (2003), "An investigation of team information processing in service teams: Exploring the link between teams and customers," Journal of the Academy of Marketing Science, 31 (4), 409-24. 
Deighton, John and Kent Grayson (1995), "Marketing and seduction: Building exchange relationships by managing social consensus, "Journal of Consumer Research, 21 (March).
$660-76$.

Deshpande, Rohit and Gerald Zaltman (1982), "Factors affecting the use of market research information: A path analysis," Journal of Marketing Research, 19 (February), 14-31.

Dickson, Peter R. (1992), "Towand a general theory of competitive rationality," Journal of Marketing, 56 (January), 69-83.

Drew, Stephen (1994), Business re-engineering in financial services. London: Pitman Publishing.

Duncan, Robert and Andrew Weiss (1979), "Organizational learning: Implications for organizational design," Research in Organizational Behavior, 1, 75-123.

Duncan, Tom and Sandra E. Moriarty (1998), "A communication-based marketing model for managing relationships," Journal of Marketing, 62 (April), 1-13.

Durkheim, Émille and Everett K. Wilson (translator) (1981), "The realm of sociology as a science," Social Forces, 59 (4), 1054-72.

Durlacher (2000), "Mobile commerce report", http://www .durlacher "com, retrieved on 2001 , May 20

-.-- (2001), "Umts report", http://www.durlacher.com, retrieved on 2001, May 20

Easingwood, Christopher 3. and Chris Storey (1991), "Success factors for new consumer financial services," International Journal of Bank Marketing, 9, 3-10.

Ebadi, Yar M. and James M. Utterback (1984), "The effects of communication on technological innovation," Management Science, 30 (5), 572-84.

Edmondson, Amy C. (1999), "Psychological safety and learning behavior in work teams," Administrative Science Quarterly, 44, 350-83.

Edvardsson, Bo, Lars Haglund, and Jan Mattsson (1995), "Analysis, planning, improvisation and control in the development of new services," International Journal of Service Industry Management, 6, 24-35.

Eisenhardt, Kathleen M. (1989), "Building theories from case study research," Academy of Management Review, $14(4), 532-50$.

Eisenhardt, Kathleen M. and Jeffrey A. Martin (2000), "Dynamic capabilities: What are they?," Strategic Management Joumal, 21 (October-November), 1105-21.

Eisenhardt, Kathleen M. and Behnam N. Tabrizi (1995), "Accelerating adaptive processes: Product innovation in the global computer industry, "Administrative Science Quarterly, 40 (March), 84-110.

Eppinger, Steven D. (2001), "Innovation at the speed of information," Harvard Business Review (January), 149-58. 
Evans, P.B. and T.S. Wurster (1999), "Getting real about vintual commerce," Harvard Business Review; 71-82.

-... (1997), "Strategy and the new economics of information," Harvard Business Rewiew, $71-82$.

$F$

Falk, R. Frank and Nancy B. Miller (1992), A primer for soft modeling. Akron, Ohio: The University of Akron Press.

Faraj, Samier and Lee Sproull (2000), "Coordinating expertise in software development teams," Management Science, 46 (12), 1554-68.

Fidler, Lori A. and J. David Johnson (1984), "Communication and innovation implementation," Academy of Management Review, 9 (4), 704-11.

Fornell, Claes and Fred L. Bookstein (1982), "Two structural equation models: Lisrel and PLS applied to consumer exit-voice theory," Journal of Marketing Research, 19 (4), 44052 .

Fornell, Claes and Jaesung Cha (1994), "Partial least squares," in Advanced methods of marketing research, R.P. Bagozzil, Ed. Cambridge: MA: Blackwell.

Fornell, Claes and David F. Larcker (1981), "Evaluating structural equation models with unobservable variables and measurement error, "Journal of Marketing Research, 18 (February), 39-50.

Froehle, Cralg M., Aleda V. Roth, Richard B. Chase, and Christopher A. Voss (2000), "Antecedents of new service development effectiveness, " Joumal of Service Research, 3 (1), 3-17. 
Garvin, David A. (1993), "Building a learning organization," Marvard Business Review, $71,78-91$.

Gatignon, Hubert and Jean-Marc Xueneb (1997), "Strategic orientation of the firm and new product performance," Journal of Marketing Research, 34 (1), 77-91.

Ghani, Jawaid A. and Satish P. Despande (1994), "Task characteristics and the experience of optimal flow in human-computer interaction, "Journal of Psychology, 1.28 (4), 381-92.

Glazer, Rashi (1991), "Marketing in an information-intensive environment: Strategic implications of knowledge as an asset," Journal of Marketing, 55 (October), 1-19.

Greenbaum, Howard H. (1974), "The audit of organizational communication," Academy of Management Journal, 17, 739-54.

Griffin, Abbie (1997), "The effect of project and process characteristics on product development cycle time," Journal of Marketing Research, 34 (1), 24-35.

-..- (2002), "Product development cycle time for business-to-business products," Industrial Marketing Management, 31, 291-304.

Gulati, Ranjay (1998), "Alliances and networks," Strategic Management Journal, 19, 293317.

Gupta, Ashok K., Klaus Brockhoff, and Ursula Weisenfeld (1992), "Makling trade-offs in the new product development process: A German/US comparison," Journal of Product Innovation Management, $9(1), 11-18$.

Gupta, Sudheer and Mirjana Vajic (2000), "The contextual and dialectical nature of experiences," in New service development: Creating memorable experiences, James A. Fitzsimmons and Mona J. Fitzsimmons, Eds. Thousand Oaks: Sage Publications, Inc.

Gwinner, Kevin P., Dwayne D. Gremler, and Mary Jo Bitner (1998), "Relational benefits in services industries: The customer's perspective," Journal of the Academy of Marketing Science, $26(2), 101-14$.

H

Hagel, John (1999), "Net gain: Expanding markets through virtual communitles," Journal of Interactive Marketing, 13 (1), 55-66.

Hansen, Morten T., Nitin Nohria, and Thomas Tierney (1999), "What's your strategy for managing knowledge," Harvard Business Review (March-April), 106-16.

Hargadion, Andrew and Robert I. Sutton (1997), "Technology brokering and innovatlon in a product development firm," Administrative Science Quarterly, 42 (December), 716-49.

Hauptman, Oscar (1986), "Influence of task type on the relationship between communication and performance: The case of software development," R\&D Management, $16,127-39$.

Hoffman, Donna L. and Thomas P. Novalk (1996), "Marketing in hypermedia computermediated environments: Conceptual foundations," Journal of Marketing, 60 (jully), 50-68. 
Holbrook, Morris B., Robert W. Chestnut, Terence A. Oliva, and Eric A. Greenleaf (1984), "Play as consumption experience: The roles of emotions, performance, and personality in the enjoyment of games," Journal of Consumer Research, 11, 728-39.

Huber, George P. (1991), "Organizational learning: The contributing process and the literatures," Organization Science, $2,88-115$.

Huff, Lenard C. and William T. Robinson (1994), "Note: The impact of leadtime and years of competitive rivalry on pioneer market share advantages, "Management Science, 40 (10), $1370-77$.

Hulland, John (1999), "Use of partial least squares (PLS) in strategic management research: A review of four recent studies," Strategic Management Journal, 20 (2), 195204.

Hurley, Robert Fu and G. Tomas M. Hult (1998), "Innovation, market orientation and organizational learning: An integration and empirical examination," Journal of Marketing, 62 (Jully), 42-54.

Iansiti, Marco and Alan MacCormack (1997), "Develloping products on Internet time," Harvard Business Review, 108-17.

IDC-Research (2000), "Dutch cellular services market assessment 1999-2004", http://www.telecom.paper.nl, retrieved on 2002, February 20

International-Telecommunication-Union (2002), "World telecommunication development report: Reinventing telecoms", http://WwW.itu.int/ITU-

D/ict/publications/wtdr_02/material/WTDR02-Sum_E.pdf, retrieved on 2002, May 23rd

Ittmer, Christopher D. and David F. Larcker (1997), "Product development cycle time and organizational performance," Journal of Marketing Research, 34 (1), 13-23.

James, Lawrence R. and Jeanne M. Brett (1984), "Mediators, moderators, and tests for mediation," Journal of Applied Psychology, 69 (2), 307-21.

Jarvenpaa, Sikka L. and Blake Ives (1994), "The global network organization of the future: Information management opportunities and challenges," Journal of Management information Systems, 10, 25-57.

Jaworski, Bernard J. and Ajay K. Kohli (1993), "Market orientation: Antecedents and consequences," Journal of Marketing, 57 (July), 53-71.

Johnson, Jean L., Ravipreet S. Sohil, and Rajdeep Grewal (2004), "The role of relational knowledge stores in interfirm partnering," Journal of Marketing, 68 (3), 21-36.

Johnson, L.W. and A.L. Frohman (1989), "Identifying and closing the gap in the middle of the organization," Academy of Management Executive, 3 (2), 107-15.

Johnson, Susan Paul, Larry J. Menor, Aleda V. Roth, and Richard B. Chase (2000), "A critical evaluation of the new service development process - integrating service innovation and service design," in New service development - creating memorable experiences, James A. Fitzsimmons and Mona J. Fitzsimmons, Eds. Thousand Oaks: Sage publications, Inc. 
Judd, Charles M., Elliot R. Smith, and Louise H. Kidder (1991), Research methods in social relations (Sixth ed.). Forth Worth: Harcourt Brace Jovanovich College Publishers.

$\mathbf{K}$

Kalakota, Ravi and Marcia Robinson (2002), M-business: The race to mobihty. New York: McGraw-Hill.

Kambil, Ajit, G. Bruce Friesen, and Arul Sundaram (1999), "Co-creation: A new source of value," Outlook Magazine (2), 38-43.

Karagozoglu, Necmi and Warren B. Brown (1993), "Time-based management of the new product development process," Journal of Product Innovation Management, 10, 204-15.

Kehoe, C.F. (2000), "M-commerce: Advantage, europe" McKinsey Quarterly (2), 43-45.

Kelley, Scott W., James H. Donnelly Jr., and Steven J. Skinner (1990), "Customer participation in service production and delivery, "Journal of Retalling, 66 (3), 315-35.

Kellogg, Deborah L., William E. Youngdahl, and David E. Bowen (1997), "On the relationship between customer participation and satisfaction: Two frameworks," International Joumal of Service Industry Management, 8 (3), 206-19.

Kerlinger, Fred N. (1986), Foundations of behavioral research (Third ed.): Holt, Rinehart \& Winston, Inc.

Kessler, Eric H. and Alok K. Chakrabartil (1996), "Innovation speed: A conceptual model of context, antecedents, and outcomes," Academy of Management Review, 21, 1143-91.

-.-- (1999), "Speeding up the pace of new product development," Journal of Product Innovation Management, 16, 231-47.

Khurana, Anil and Stephen R. Rosenthal (1997), "Integrating the fuzzy front-end of new product development," Sloan Management Review, 38 (2), 103-20.

Kogut, Bruce and Uido Zander (1992), "Knowledge of the firm, combinative capabilities, and the replication of technology," Organization Science, $3,383-97$. 
L

Lail, D., D.C. Pitt, and A. Beloucif (2001), "Restructuring in European

telecommunications: Modeling the evolving market, "European Business Review, $13(3)$, $152-56$.

Lawrence, Paul and Jay Lorsch (1967), Organizations and environment: Harvard University Press.

Lel, David, John W. Slocum, and Robert A. Pitts (1999), "Designing organizations for competitive advantage: The power of unlearning and learning," Organizational Dynamics, $27,24-38$

Lengnick-Hall, Cynthia A. (1996), "Customer contributions to quality: A different view of the customer-oriented firm," Academy of Management Review, 21 (3), 791-824.

Lengnick-Hall, Cynthia A., Vincentia Claycomb, and Lawrence W. Inks (2000), "From recipient to contributor: Examining customer roles and experiences outcomes," European Journal of Marketing, 34 (3/4), 359-83..

Leonard-Barton, Dorothy (1992), "Core capabilities and core rigidities: A paradox in managing new product developments," Strategic Management Journal, 13 (Summer), $111-25$.

Levitt, Barbara and James G. March (1988), "Organizational learning," Annual Review of Sociology, 14, 319-40.

Li. Tiger and Roger J. Calantone (1998), "The impact of market knowledge competence on new product advantage: Conceptualization and empirical examination," Journal of Marketing, 62 (October), 13-29.

Llevens, Annouk, Ko de Ruyter, and Jos Lemmink (1999a), "Learning during new banking service development: A communication network approach to marketing departments," Journal of Service Research, 2, 145-63.

Lievens, Annouk and Rudy K. Moenaert (2000a), "Communication flows during financial service innovation," European Journal of Marketing, 34 (9/10), 1078-110.

-... (2000b), "Project team communication in financial services innovation," Journal of Management Studies, 37 (5), 733-66.

Lievens, Annouk, Rudy K. Moenaert, and Rosette S"Jegers (1999b), "Linking communication to innovation success in the financial services industry: A case study analysis," International Journal of Service Industry Management, 10, 23-47.

Lllien, Gary L., Pamela D. Morrison, Kathleen Searls, Mary Sonnack, and Eric von Hippel $(2002)$, "Performance assessment of the lead user idea-generation process for new product development," Management Science, 48 (8), 1042-59.

Lohmöller, Jan-Bernd (1988), "The PLS program system: Latent variables path analysis with partial least squares estimation " Multivariate Behavioral Research, 23, 125-27.

Lovelock, Christopher H. and Robert F. Young (1979), "Look to consumers to increase productivity," Harvard Business Review, 57/3 (May/June), 168-78. 
Lynn, Gary S., Richard B. Skov, and Kate D. Abel (1999), "Practices that support team learning and their impact on speed to market and new product success," Journal of Product Innovation Management, 16, 439-54.

MacCormack, Alan, Roberto Verganti, and Marco Iansiti (2001), "Developing products on "Internet time": The anatomy of a flexible development process," Management Science, 47 (1), 133-50.

Madhavan, Ravindranath and Rajiv Grover (1998), "From embedded knowledge to embodied knowledge: New product development as knowledge management" "Journal of Marketing, 62, 1-12.

Mahajan, Jayashree, Asoo J. Vakharia, Pallab Paul, and Richard B Chase (1994), "An exploratory investigation of the interdependence between marketing and operations functions in service firms," International Journal of Research in Marketing, 11, 1-15.

Maltz, Elliot (2000), "Is all communication created equal? An investigation into the effects of communication mode on perceived information quality, "Journal of Product Innovation Management, 17, 110-27.

Marinova, Detelina (2004), "Actualizing innovation effort: The Impact of market knowledge diffusion in a dynamic system of competition," Journal of Marketing, 68 (July), $1-20$.

Massimini ${ }_{n}$ Fausto and Massimo Carli (1988), "The systematic assessment of flow in dailly experience," in Optimal experience: Psychological studies of flow in consciousness, Mihalyi Csikszentmihalyi and Isabella Csikszentmihalyi, Eds. New York: Cambridge University Press.

Mathwick, Charla (2002), "Understanding the online consumer: A typology of online relational norms and behavior," Joumal of Interactive Marketing, 16 (1), 40-55.

Mathwick, Charla, Naresh Malhotra, and Edward Rigdon (2001), "Experiential value: Conceptualization, measurement and application in the catalog and Internet shopping environment," Journal of Retailing, 77, 39-56.

Mathwick, Charla and Edward Rigdon (2004), "Play, flow, and the online search experience," Journal of Consumer Research, 30 (September).

McLure Wasko, M. and Samer" Faraj (2000), "It is what one does: Why people participate and help others in electronic communities of practice," Joumal of Strategic Information Systems, $9(2-3)$, 155-73.

Mendelson, Haim (2000), "Organizational architecture and success in the information technology industry," Management Science, 46, 513-29.

Mendelson, Haim and Ravindran R. Pillail (1999), "Information age organizations, dynamics and performance," Joumal of Economic Behavior and Organization, 38, 253 81.

Menon, Ajay, Jhinuk Chowdhury, and Bryan A. Luikas (2002), "Antecedents and outcomes of new product development speed: An interdisciplinary framework, "Industrial Marketing Management, 31, 317-28. 
Menor, Larry J., Mohan V. Tatikonda, and Scott E. Sampson (2002), "New service development: Areas for exploitation and exploration," Journal of Operations Management, 20, $135-57$.

Meuter, Matthew L. and Mary Jo Bitner (1998), "Self-service technologies: Extending service frameworks and identifying issues for research, "in AMA Winter Educators' Conference, Dhruv Grewal and Connie Pechmann (Eds.). Chicago: American Marketing Association.

Meuter, Matthew L., Amy L Ostrom, Robert I. Roundtree, and Mary Jo Bitner (2000), "Self-service technologies: Understanding customer satisfaction with technology-based service encounters," Journal of Marketing, 64 (3), 50-64.

Meyer, Christopher and Ronald E. Purser (1993), "Six steps to becoming a fast cycle-time competitor," Research Technology Management, 41-48.

Miles, Matthew B. and A. Michael Huberman (1994), Qualitative data analyses (2nd ed.). Thousand Oaks, CA: Sage Publications.

Mills, Peter K. and James H. Morris (1986), "Clients as partial employees of service organizations: Role development in client participation," Academy of Management Review, 11 (4), 726-35.

Millson, Murray R, S.P. Raj, and David Wilemon (1992), "A survey of major approaches for accellerating new product development," Journal of Product Innovation Management, $9(1), 52-69$.

Miner, Anne, Paula Bassoff, and Christine Moorman (2001), "Organizational improvisation and learning: A field study," Administrative Science Quarterly, 46, 304-37.

Moenaert, Rudy K., Filip Caeldries, Annouk Lievens, and Elke Wauters (2000), "Communication flows in international product innovation teams," Journal of Product Innovation Management, 17 (5), 360-78.

Moenaert, Rudy K., Arnoud De Meyer, William E. Souder, and Dirk Deschoolmeester (1995), "R\&D/marketing communication during the fuzzy front-end " IEEE Transactions on Engineering Management, 42 (3), 243-58.

Moenaert, Rudy K., Dirk Deschoolmeester, Arnoud De Meyer, and William E. Souder (1992), "Information styles of marketing and R\&D personnel during technological Unnovation projects," R\&D Management, 22 (January), 21-39.

Mohr, Lois A. and Mary Jo Bitner (1991), "Mutual understanding between customers and employees in service encounters," Advances in Consumer Research, 18, 611-17.

Monge, Peter R., Michael D. Cozzens, and Noshir S. Contractor (1992), "Communication and motivational predictors of the dyramics of organizational innovation, "Organization Science, $3(2), 250-74$.

Moorman, Christine (1995), "Organizational market information processes: Cultural antecedents and new product outcomes," Journal of Marketing Research, 32, 318-35.

Moorman, Christine, Rohit Deshpande, and Gerald Zaltman (1992), "Relationships between providers and users of market research: The dynamics of trust within and between organizations," Joumal of Marketing Research, 29 (August), 314-28. 
Moorman, Christine and Anne Miner (1998), "The convergence of planning and

execution: Improvisation in new product development, "Journal of Marketing, 62, 1-20.

- (1997), "The impact of organizational memory on new product performance and creativity," Journal of Marketing Research, 34, 91-106.

Moorman, Christine and Roland T. Rust (1999), "The role of marketing, ${ }^{\text {" Journal of }}$ Marketing, 63 (Special Issue), 180-97.

Moorman, Christine and Rebecca J. Slotegraaf (1999), "The contingency value of complementary capabilities in product development," Journal of Marketing Research, 36 (May), 239-57.

Morrison, Pamela D., John H. Roberts, and Eric von Hippel (2000), "Determinants of user innovation and innovation sharing in a local market, "Management Science, 46 (12), 1513-27.

\section{$\mathbf{N}$}

Nambisan, Satish (2002), "Designing virtual customer environments for new product development: Towards a theory," Academy of Management Review, 27 (3), 392-413.

Network-World (2001), "Nothing can stop next-generation wireless", http://www.ayg.com/wireless/Article.po?id $=214795$, retrieved on 2002, April 24th

Nevis, Edwin C., Anthony J. DiBella, and Janet M. Gould (1995), "Understanding organizations as learning systems," Slaan Management Review, 73, 73-85.

Nohria, Nitin and Ranjay Gulati (1996), "Is slack good or bad for innovation?," Academy of Management Journal, 39, 1245-64.

Novak, Thomas P., Donna L. Hoffman, and Adam Duhachek (2003), "The influence of goal-directed and experiential activities on online flow experiences," Journal of Consumer Psychology", 13 (182), 3-16.

Novak, Thomas P., Donna L. Hoffman, and Ylu-Fai Yung (2000), "Measuring the customer experience in online environments: A structural modeling approach," Marketing Science, $19(1), 22-42$.

Nunnally, Jum C. and Ira H. Bernstein (1994), Psychometric theory (Third Edition ed.): MoGraw Hill.

NZ Marketing Magazine (2004), "C.K. Prahalad on co-creating the future," in NZ Marketing Magazine Vol. February. 
Oliver, Richard L., Roland T. Rust, and Sajeev Varki (1997), "Customer delight: Foundations, findings, and managerial insight, "Journal of Retailing, 73 (3), 311-36.

Olivera, Fernando (2000). "Memory systems in organizations: An empirical investigation of mechanisms for knowledge collection, storage and access," Journal of Management Studies, $37,6$.

Osterloh, Margit and Bruno S. Frey (2000), "Motivation, knowledge transfers and organizational forms," Organization Science, 11 (5), 538-50.

\section{$\mathbf{p}$}

Parasuraman, An, Valarie A. Zelthaml, and Leonard L. Berry (1988), "SERVQUAL: A multiple-item scale for measuring consumer perceptions of service quality, "Journal of Retailing, 64 (1), 12-40.

Peter, J. Paul (1981), "Construct validity: A review of basic issues and marketing practices," Journal of Marketing Research, 18 (2), 133-45.

Pich, Michael T., Christoph H. Loch, and Arnoud De Meyer (2002), "On uncertainty, ambiguity, and complexity in project management, "Management Science, 48 (8), 100823.

Pine, Joseph and James H. Gilmore (1998), "Welcome to the experience economy," Harvard Business Review (July-August), 97-105.

Prahalad, C. K. and Venkatram Ramaswamy (2004), The future of competition: Cocreating unique value with customers. Boston: Harvard Business Sichool Press.

Prahalad, C.K. and Venkatram Ramaswamy (2000), "Co-opting customer competence," Harvard Business Review (January-February), 79-87.

...- (2003), "The new frontier of experience innovation," Sloan Management Review (Summer), 12-18.

Price, Linda L. "Eric J. Arnould, and Patrick Tierney (1995), "Going to extremes: Managing service encounters and assessing provider performance," Journal of Marketing, 59 (April), 83-97.

Purvis, Russell L., V. Sambamurthy, and Robert W. Zmud (2001), "The assimilation of knowledge platforms in organizations: An empirical investigation," Organization Science, $12(2), 117-35$.

$\mathbf{R}$

Reynolds, Kristy E. and Sharon E. Beatty (1999), "Customer benefits and company consequences of customer-salesperson relationships in retailing, "Journal of Retailing, 75 (1), 11-32.

Ribbens, Barbara A. (1997), "Organizational learning styles: Categorizing strategic predispositions from learning," International Journal of Organizational Analysis, $5,59-73$. 
Ridings, Catherine M., David Gefen, and Bay Arinze (2002), "Some antecedents and

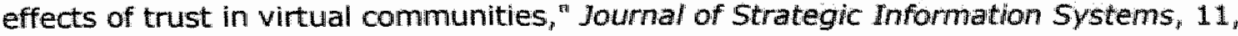
$271-95$.

Rindfleisch, Aric and Christine Moorman (2001). "The acquisition and utilization of information in new product alliances: A strength-of-ties perspective," Journal of Marketing, 65 (April), 1-18.

Risch Rodie, Amy and Susan Schultz Kleine (2000), "Customer participation in services production and delivery, "in Handbook of services marketing and management, Teresa Swartz and Dawn Iacobucci, Eds. Thousand Oalks, CA: Sage Publications.

Rogers, Everett M. and D. Lawrence Kincail (1981), Communication networks: Towards a new paradigm for research. New York: The Free Press.

Roth, Aleda V. and William E. Jackson III (1995), "Strategic determinants of service quality and performance: Evidence from the banking industry," Management Science, 41 (11), 1720-33.

Ruekert, Robert W, and Orville C. Walker (1987), "Marketing"s interaction with other functional units: A conceptual framework and empirical evidence, "Journal of Marketing, 51 (January), 1-19.

Rulke, Daine Liang and Devaki Rau (2000), "Investigating the encoding process of transactive memory development in group training, "Group \& Organization Management, 25 (4), 373-96.

Rust, Roland T. (1998), "What is the domain of service research?," Journal of Service Research, 1 (2), 107.

\section{$\mathbf{s}$}

Sarin, Shikhar and Vijay Mahajan (2001), "The effect of reward structures on the performance of cross-functional product development teams," Journal of Marketing, 65 (April), 35-53.

Sawhney, Mohanbir (2002), "Don't just relate - collaborate," Sloan Management Review (Spring), 96.

Sawhney, Mohanbir and Emanuela Prandelli (2000), "Communities of creation: Managing distributed innovation in turbulent markets," California Management Review, $42(4), 24$ 54.

Schein, Edgar H. (1993), "How can organizations learn faster? The challenge of entering the green room," Sloan Management Review; 34, 85-95. Senge, Peter M. (1990), The fifth discipline: The art and practice of the learning
organization. New York: Currency Doubleday.

Sethi, Rajesh (2000), "New product quality and product development teams," Journal of Marketing, 64 (April), 1-14.

Sherman, J. Daniel, William E. Souder, and Svenn A. Jenssen (2000), "Differential effects of the primary forms of cross functional integration on product development cycle time," Journal of Product Innovation Management, 17, 257-67. 
Sheth, Jagdish N., Rajendra S. Sisodia, and Arun Sharma (2000), "The antecedents and consequences of customer-centric marketing, "Journal of the Academy of Marketing science, $28(1), 55-66$.

Siehl, Caren and David E. Bowen (1992), "Service encounters as rites of integration: An information processing model, "Organization Science, 3 (4), 537-55.

Simon, Herbert A. (1979), "Rational decision making in business organizations," American Economic Review, 69, 493-513.

Sinkula, James M. (1994), "Market information processing and organizational learning" Journal of Marketing, 58, 35-45.

Sinkulla, James M., William E. Baker, and Thomas.A. Noordewier (1997), "Framework for market-based organizational learning: Linking values, knowledge and behavior," Academy of Management Stience, 25, 305-18.

Slater, Stanley F, and John C. Narver (1995), "Market orientation and the learning organization," Journal of Marketing, 59, 63-74.

Song, Michael X., C. Anthony Di Benedetto, and Lisa Z. Song (2000), "Pioneering advantage in new service development: A multi-country study of managerial Implications," Journal of Product Innovation Management, 17, 378-92.

Souder, William E. and Rudy K. Moenaert (1992), "Integrating marketing and R\&D project personnel within innovation projects." An information uncertainty model, "Journal of Management Studies, 29 (4), 485-512.

Sproull, Lee, Mani Subramani, Sara Kiesler, Janet H. Walker, and Kelth Waters (1996), "When the interface is a face," Human-computer interaction, 11 (2), 97-125.

Srivastava, Rajendra K., Tasadduq A. Shervani, and Llam Fahey (1998), "Market-based assets and shareholder value: A framework for analysis, "Journal of Marketing, 62 (Jainuary), 2-18.

Tapscott, Don, Alex Lowy, and David Ticoll (1998), Blueprint to the digital economy: Creating wealth in the era of e-business. New York: McGraw-Hill.

Teece, David J., Gary Pisano, and Amy Shuen (1997), "Dynamic capabilities and strategic management," Strategic Management Journal, 18 (August), 509-33.

Thomas-Hunt, Melissa C., Tonya Y. Ogden, and Margaret A. Neale (2003), "Who's really sharing? Effects of social and expert status on knowledge exchange within groups," Management Science, 49 (4), 464-77.

Thomke, Stefan and Eric von Hippel (2002), "Customers as innovators: A new way to create value," Harvard Business Review, 80 (4), 74-81.

Tucker, M.L., G.D. Meyer, and J.W. Westerman (1996), "Organizational communications: Development of internal strategic competitive advantage," Journal of Business Communication $33,51-62$.

Tushman, Michael L. (1979), "Work characteristics and subunit communication structure: A contingency analysis," Administrative Science Quarteriy, 24 (82-97). 
Tushman, Michael L. and Ralph Katz (1980), "External communication and project performance: An investigation into the role of gatekeepers, Management Science, 26 (11), 1071-85.

\section{$\mathbf{u}$}

Urban, Glen L. and John R. Hauser (2004), "tilistening in" to find and explore new combinations of customer needs, "Journal of Marketing, 68 (April), 72-87.

Uzzi, Brian (1996), "The sources and consequences of embeddedness for the economic performance or organizations: The network effect, "American Sociological Review, 61 (August), 674-98.

Uzzi, Brian and Ryon Lancaster (2003), "Relational embeddedness and learning: The case of bank loan managers and their clients," Management Science, 49 (4), 383-99.

$\mathbf{v}$

van Bruggen, Gerrit H., Gary L. Lilien, and Manish Kacker (2002), "Informants in organizational marketing research: Why use multiple informants and how to aggregate responses," Journal of Marketing Research, 39 (November), 469-78.

van de Ven, Andrew H. (1986), "Central problems in the management of innovation," Management Science, 32, 590-607.

Vargo, Stephen L. and Robert F. Lusch (2004), "Evolving to a new dominant logic for" marketing," Journal of Marketing, 68 (January), 1-17.

von Hippel, Eric and Ralph Katz (2002) "Shifting Innovation to users via toolkits," Management Science, $48(7), 821-33$.

w

Walsh, John P. and G. Ungson (1991), "Organizational memory," Academy of Management Review, 16 (1), 57-91.

Wegner, Daniel M. (1995), "A computer network model of human transactive memory," Social Cognition, $13(3), 319-39$.

-..- (1986), "Transactive memory: A contemporary analysis of the group mind," in Theories of group behavior, B. Mullen and G.R. Goethais, Eds. New York: Springerverlag.

Wegner, Daniel M., Paula Raymond, and Ralph Erber (1991), "Transactive memory in close relationships," Journal of Personality and Social Psychology, 61 (6), 923-29.

Weick, Karl E. (1979), The social psychology of organizing (2nd ed.). New York: Random House.

Welck, Karl E. and Karlene H. Roberts (1993), "Collective mind in organizations: Heedful interrelating on flight decks," Administrative Science Quarterly, 38, 357-81.

Wellman, Barry (1997), "An electronic group is virtually a social network," in Culture of the Internet, Sara Kiesler, Ed. Hillsdale, N]: Lawrence Erlbaum. 
Wellman, Barry and Milena Gulia (1999), "Net surfers don't ride alone: Virtual communities as communities " in Networks in the global village, Barry Wellman, Ed. Boulder, CO: Westwiew.

White, Chris I., Rajan Varadarajan, and Peter A. Dacin (2003), "Market situation interpretation and response: The role of cognitive style, organizational culture, and information use," Journal of Marketing, 67 (3), 63-79.

Wiertz, Caroline, Ko de Ruyter, and Sandra Streukens (2003), "On the role of normative influences in commercial virtual communities, "in METEOR Research Memoranda. Maastricht: METEOR, Maastricht University.

Williams, T.M. (1999), "The need for new paradigms for complex projects," International Journal of Project Management, 17, 269-73.

$\mathbf{Y}$

Yin, Robert K. (1994), Case study research: Design and methods (Second ed.): Sage Publications.

Yoo, Youngfin and Prasert Kanawattanachai (2001), "Developments of transactive memory systems and collective mind in virtual teams," The International Journal of Organizational Analysis, $9(2), 187-208$.

$\mathbf{z}$

Zeithaml, Valarie A., A. Parasuraman, and Arvind Malhotra (2002), "Service quality delivery through web sites: A critical review of extant knowledge, "Journal of the Academy of Marketing Science, 30 (4), 362-75.

Zirger, B. J. and Janet L. Hartley (1994), "A conceptual model of product development cycle time, "Journal of Engineering and Technology Management, 11, 229-51. 


\section{Appendix A: Scale items chapter 3}

New service performance $(C R=.95)$

Adapted from (de Brentani 1989; Gatignon and Xwereb 1997)

Relative to other new service innovations of our firm, this one had a better retum on investment.

Relative to our competitors' new service innovations, this one had a

better return on investment.

The service innovation exceeded market shame objectives.

The service innovation exceeded sales growth objectives.

Project Learning $(C R=.96)$

(Blazevic and Lievens 2004)

Our experience and learning in this service innovation project proved to be essential for the successful creation and completion of

0.88

subsequent projects.

The knowledge acquired during the innovation process of this service innovation project served as an essential input for other new service. developments.

The development of this new service created a general development expertise that eased the development and introduction of subsequent new services.

The expertise of developing and launching this service lead to an enhanced know-how for future innovation projects.

Time-to-Market $(C R=.94)$

With regard to the speed of development, please rate the degree to which the new service generated by your team was ....

far behlnd our time goals - far ahead of our time goals

slower than the industry norm - faster than the industry norm

much slower than we expected - much faster than we expected

much slower than our typical service development time - much faster

0.77

than our typical service development time

Innovative communication $(C R=.93)$

Adapted from (Hauptman 1986; Souder and Moenaert 1992)

Serwice innovation team members were well informed about the latest

commercial information.

Information from other departments provided our project team

members in my department with more insights and understanding to

solve specific problems.

Creative information was transferred that was helpful in solving

project-related problems. 

$(C R=.96)$

Service innowation team members had a good insight of what everybody efse involved in this project was actually doing.

Service innovation team members had a goad overwiew of the specific actiwities that other team members were performing.

Service innovation team menbers were informed and updated concerning the time restrictions and completion dates of the planned activities.

Generational memory $(C R=0.96)$

(Blazevic and Lievens 2004

Experiences and learning absorbed from former new serwice

development projects were directly applied to this sevice innovation

project.

New service development routines from former projects were

preserved and made avaliable to this service innowation project.

This service innovation team comprised members of successfully completed previous service innovation projects.

Lessons learned from past service nnovations were thoroughlly shared and discussed with other service innovation team members.

The existing knowledge from previaus service innovation projects was

used to devellop this service innowation project

Our service innovation team exploited lessons learned from past

Transactive memory $(C R=97)$

The service imnowation team had a good plcture of each other's talents and skillis.

Service innovation team members knew what task-|related skilis and knowledge they each possessed.

Service innovation team members knew who on the team had speciallized skills and knowledge that were relevant to the service innovation project.

The service developed by our senvice innovation team was technically

complex to develop.

Our service ininovation team had to use non-foutine technology to

develop the service.

Development of this service innovation required pioneering

The service deweloped by our service innovation team was hintricate. 


\section{Appendix B: Scale items of chapter 5}

Perceived service quality

$(C R=93)$

Tangibility:

(Bames and Vidgen 2001)

(loading of $2^{\text {nd }}$ onder construct)

0.771

0.67

The online technical support community has an attractive

The online technical support community has an appropriate

The online technical support community provides tangible

cues to evaluate the service via the point/hat system.

Reliability:

The online technical support community can be depended on

to provide whatever is promised

The online technical support community provides up-to-date

(loading of $2^{\text {thd }}$ onder construet)
0.849

0.75

0.70

information

The online technical support community delivers the services

0.66

in time

Responsiveness:

The online technical support community has a fast navigation

(loading of $2^{\text {nd }}$ order construct)
0.887
0.72

(loading of $2^{\text {nd }}$ order construct)
0.887
0.72

to information

The online technical support community provides a

0.82

professional and competent image

It is easy to find your way around in the online techinical

support community

Assurance:

The online technical support community is a site with a good reputation

The online technical support community guarantees services

(n)

(loading of $2^{\text {thd }}$ onder construct)
0.869

0.70

0.70

offered

The online technical support community gives confidence that

0.74

it will deliver the promised services

(loading of $2^{\text {nd }}$ order construct)

Empathy:

The online technical support community provides information

at an appropriate level of detail

0.71

The online technical support community provides content

0.76

tailored to the individual

The online technical support community customizes the

ansiwers to specific technicall questions

Service co-creation ( $C R=.97)$

Adapted from (Ridings, Gefen, and Arinze 2002)

I come to the online technical support community to give other

I come to the online technicants information I know about a particular subject.

I participate in the online technical support comm

0.92

skills and abilities with other members.

I go to the online technical support cormmun
members on how to perform a certain task.

Social interaction $(C R=.97)$

Adapted from (Reynolds and Beatty 1999)

The social aspects of the online technical support community are

important to me

In the online technical support community, I get to know other people

in the field. 
I wallue the human aspects of the onfine technical support community.

I enjoy the conversational interactions in the ondine technical support community.

I enjoy communicating with other online technical support community members.

Fun (CR $=94$ ) Adapted from(Ghani and Despande 1994)

Participating in the community is

interesting - uninteresting

fun - not fun

enjoyable - not enjoyable

exciting - dullt

entertaining - not entertaining

pleasurable - nat pleasurable

Relational embeddedness $(C R=.92)$

(Rindfleisch and Moorman 2001

I share close social relations with the other online technical support community members.

My relationship with the other online technical support community members can be defined as 'mutually gratifying".

I expect that I will be interacting with the other online technical

support community members far into the future.

Using the online technical support community challenges me.

I find that using the online technical support community stretches my

capabilities to the my limits

Uising the online technical support community provides a good test of

my skills

Using the onllne technical support community challenges me to perfortm to the best of my ability

How much does the online technical support community challenge

Q.: you, compared to other things you do on your computer?

Skill $(C R=94)$

(Novak et al. 200

I am extremely skilled at using the online technical support

community.

I consider myself knowledgeable about good search techniques on the 